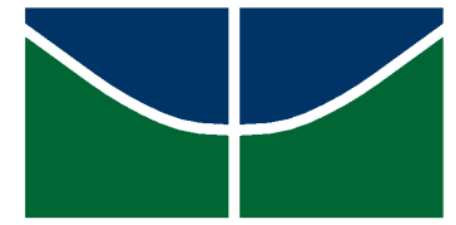

Universidade de Brasília

Instituto de Química-IQ

Programa de Pós-Graduação em Química

\title{
Síntese, Caracterização e Estudo Fotofísico de Chalconas Fluorescentes
}

\author{
Lennine Rodrigues de Melo
}

Dissertação de Mestrado

Orientador: Prof. Dr. Wender Alves da Silva

Coorientador: Prof. Dr. Brenno Amaro da Silveira Neto

Brasília-DF

2015 
EXISTEM MOMENTOS NA VIDA ONDE A QUESTÃo DE SABER SE PODE PENSAR DIFERENTEMENTE do QUE SE PENSA, E PERCEBER difERENTEMENTE do QUE SE VÊ, É INDISPENSÁVEl PARA CONTINUAR A OLHAR OU A REFLETIR. MichaEl Foucault 


\section{COMUNICADO}

Comunicamos a aprovação da Defesa de Dissertação de Mestrado

do (a) aluno (a) Lennine Rodrigues de Melo, matrícula no 13/0169196, intitulada "Síntese, Caracterização e Estudo Fotofísico de Chalconas Fluorescentes", apresentada no (a) Auditório Azul do Instituto de Química (IQ) da Universidade de Brasília (UnB) em 17 de julho de 2015.

Prof. Dr. Wender Alves da Silva

Presidente de Banca (IQ/UnB)

Profa Dra Maria Márcia Murta Membro Titular (IQ/UnB)

Prof. Dr. Angelo Henrique de Lira Machado Membro Titular (IQ/UnB)

Prof. Dr. Marcelo Oliveira Rodrigues Membro Suplente (IO/UnB)

Em 17 de julho de 2015.

$\triangle$ Caixa Postal 4478 - CEP: 70904-970 - Brasília - DF - BRASIL 


\section{Agradecimentos}

Aos meus pais: Creusa e Vicente pelo apoio irrestrito, companheirismo, amizade e amor incondicional. Vocês são meus maiores exemplos de garra, perseverança, luta e dedicação. Muitíssimo obrigada por me apoiarem e se fazerem intensamente presentes em meu viver.

Ao meu orientador Prof. Wender pela orientação atenta e disponibilidade diária. Obrigada por ter me aceitado como aluna (desde a iniciação científica), acreditar no meu potencial, motivar e acompanhar meu crescimento profissional e pessoal desde então.

Ao meu coorientador Prof. Brenno pelas discussões, colaborações e divergências que muito tem sido válidas para meu amadurecimento no meio acadêmico.

Ao grupo LaPSCA todo. Em especial aos meninos Gabriel, Lucas e Mathur que muito me auxiliaram na execução do trabalho de bancada.

Aos colegas de laboratório: Kadu, Lucília, Gisele, Jean, Thaíssa, pela ajuda e bons momentos. Angélica, que além do laboratório, convivemos no RMN, por todo apoio, ajuda e paciência.

A amizade da Ana Paula, Fernanda, Gisele Medeiros, Haline ("Rá!"), Thyago, Betinho, Alberto, Marcos que sempre me apoiaram com sorrisos, bate papos e zoações para aliviar a tensão do trabalho. As amigas Dayla, Daiane e Angélica pelo apoio, troca de ideias e companheirismo.

Aos professores que muito colaboraram para minha formação: Wender, Ângelo (criatura!), Jez, Patrícia Lootens, Ricardo Gauche. Ao Marcelo O. pela disponibilidade e colaboração, a Ingrid pela atenção e conversas.

Ao Prof. Dr. Gustavo Trossini - USP, pelos estudos de docagem molecular e in vitro das estruturas sintetizadas. A Prof ${ }^{a}$. Dr ${ }^{a}$. Claudia Gatto IQ/UnB pelas resoluções estruturais por Raios-X. Ao Thiago O. Lopes (UnBDoutorando) por meio da parceria com Prof. Dr. Heibbe C. B. Oliveira - IQ/UnB pelos estudos DFT. Ao Prof. Dr. Jez Willian pela utilização do espectrofotômetro e espectrofluorímetro.

A CAPES pelo apoio financeiro. 


\section{Resumo}

A busca por compostos que apresentem atividade luminescente (fluorescência) é de extrema importância em razão da alta sensibilidade de detecção desses em técnicas analíticas. Porém, a técnica de espectroscopia de fluorescência molecular não é muito utilizada em decorrência do número limitado de sistemas químicos que atuem com atividade luminescente apreciável. Nessa perspectiva foram sintetizadas e avaliadas onze estruturas de chalconas, partindo-se do 4(dimetilamino)benzaldeído e do 3,4,5-trimetoxibenzaldeído, já amplamente discutidos na literatura por ser um cromóforo e pela atividade biológica, respectivamente. Os compostos foram devidamente caracterizados e tiveram suas estruturas determinadas por difração de raios-X, quando possível. Suas propriedades fotofísicas e comportamentos solvatocrômicos foram investigados. Observado o amplo espectro de atuação da classe de compostos avaliada, estudos de docagem molecular e testes in vitro foram realizados para a doença de Chagas, reconhecida pela OMS como negligenciada. Visando uma importante aplicação tecnológica, foram produzidas microfibras do acervo sintetizado a partir do polímero polivinilpirrolidona e as caracterizações se deram por MEV. 


\begin{abstract}
The search for compounds having luminescent activity (fluorescence) have extreme importance because high sensitivity detection of these in analytical techniques. However, the technique of molecular fluorescence spectroscopy is not widely used due to the limited number of chemical systems which operate with considerable luminescent activity. In this perspective were synthesized and evaluated eleven chalcones structures, starting from the 4(dimethylamino)benzaldehyde and 3,4,5-trimethoxybenzaldehyde, as well discussed in the literature to be a chromophore and for the biological activity, respectively. The compounds were characterized and have their structures determined by X-ray diffraction, when possible. Their photophysical properties and solvatochromic behaviors were investigated. Noted the broad spectrum of compounds class performance were also evaluated molecular docking studies and in vitro tests were conducted to Chagas disease, by WHO recognized as neglected. Searching for better possibility in technological application were produced microfibers with the polyvinylpyrrolidone polymer and these were characterized for SEM analysis.
\end{abstract}




\section{Lista de Acrônimos}

DTEP - (E)-1-(2,5-dimetiltiofen-3-il)-3-(9-etil-9H-carbazol-3-il)prop-2-en-1-ona) $\boldsymbol{E}_{T}^{N}$ - Coeficiente de polaridade de Reichardt.

ICT - Transferência interna de carga, Internal Charge Trasnfer

OMS - Organização Mundial da Saúde.

RMN - Ressonância magnética nuclear

$\mathbf{S}_{0}$ - Estado singleto fundamental.

$\mathbf{S}_{1}$ - Estado singleto de primeira excitação

UV-Vis - Faixa de radiação que abrange o ultravioleta próximo e o visível.

WHO - Organização Mundial da Saúde, World Healthy Organization.
$\lambda$ - Comprimento de onda
$\Phi$ - Rendimento quântico
$\delta$ - Deslocamento químico 


\section{Índice}

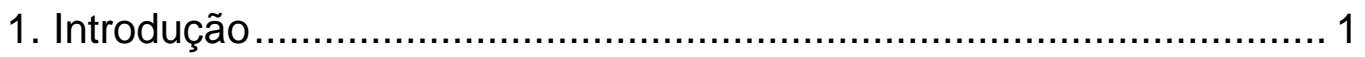

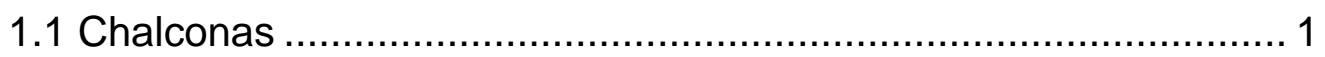

1.2 Luminescência e Aplicações Tecnológicas ................................... 6

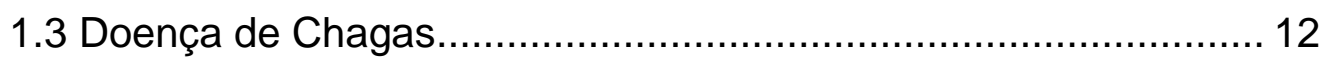

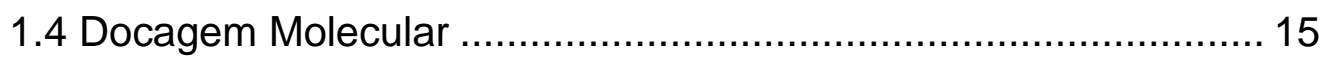

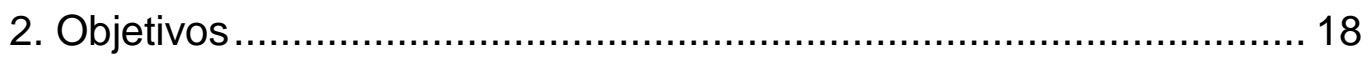

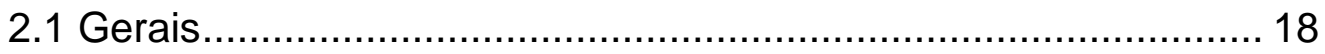

2.2 Objetivos Específicos:......................................................... 18

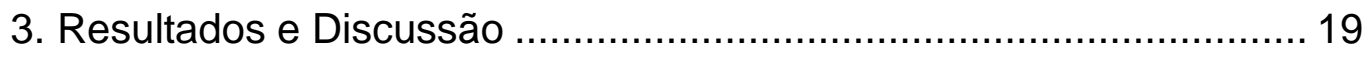

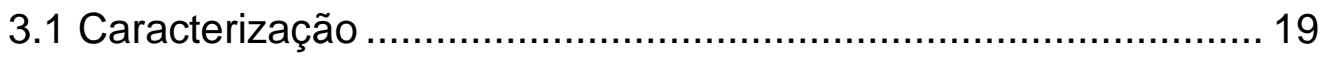

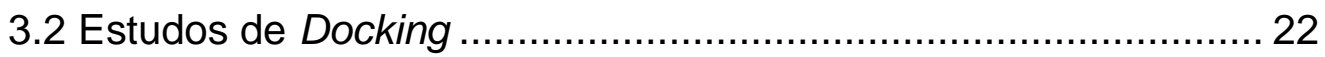

3.2.1 Ensaios de Inibição com a Cruzaína de T. cruzi.................... 27

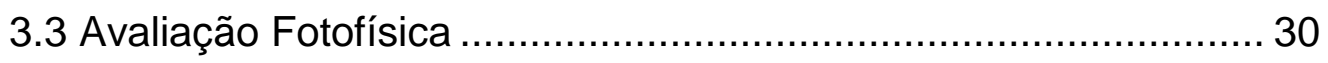

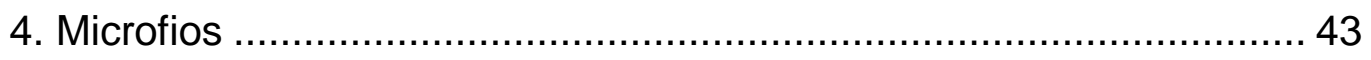

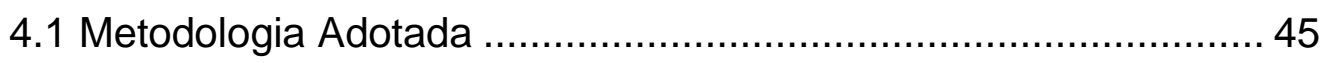

4.2 Resultados Obtidos ............................................................... 46

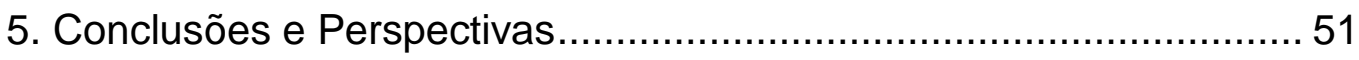

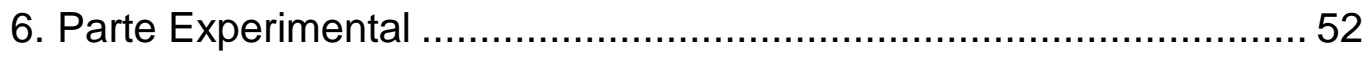

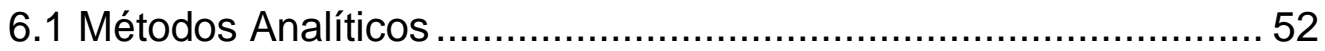

6.1.1 Ressonância Magnética Nuclear ........................................ 52

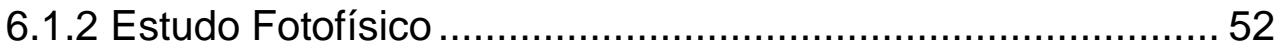

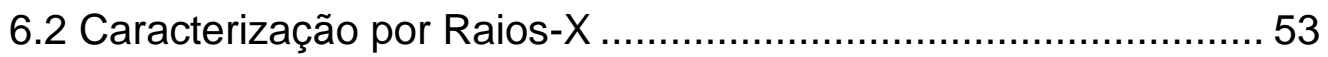

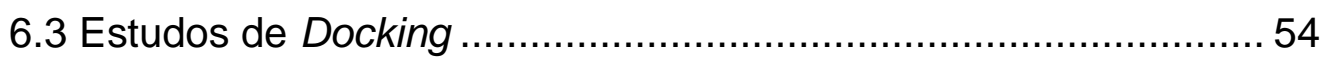

6.3.1 Ensaios de Inibição com a Cruzaína de T. cruzi.................... 54 
6.4 Síntese das Chalconas .................................................. 55

6.4.1 Procedimento Geral .................................................. 55

6.4 Dados Espectroscópicos...................................................... 56

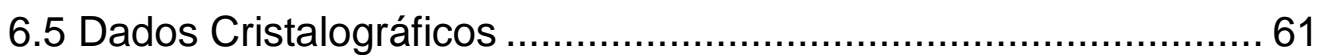

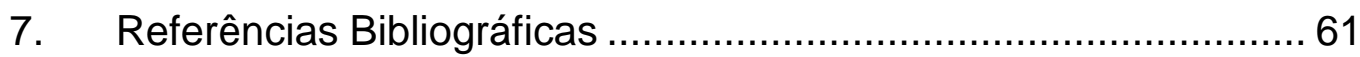

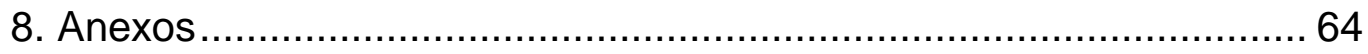

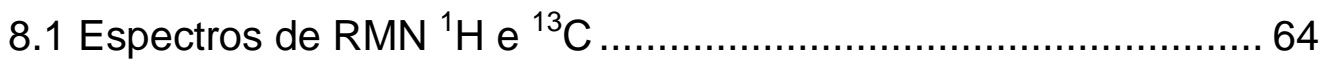

8.2 Absorção e Emissão ...................................................... 80

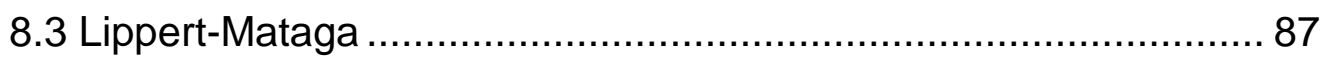




\section{Índice de Figuras}

Figura 1. Exemplo de rota biossintética de chalconas (adaptada da referência 4).

Figura 2. Mecanismo da condensação aldólica de Claisen-Schmidt, onde HB é um ácido e $\mathrm{B}$ a base conjugada desse.

Figura 3. Metochalcona e solfacona: fármacos derivados de chalconas disponíveis no mercado.

Figura 4. Chalconas 1 atividade antimicrobial (E. coli) e 4-Dimetilamino chalcona - DMA anti-inflamatório relevantes. 4

Figura 5. Chalconas com $\mathrm{IC}_{50}$ representativos contra T. cruzi in vivo. ${ }^{10}$ 5

Figura 6. (A) Fluorescência de (E)-1-(4-(dimetilamino)fenil)-3-(1H-indol-5il)prop-2-en-1ona em uma seção de tecido cerebral de um rato (Im 6 de espessura) Tg-C57 (APP / PS1) com um conjunto de filtros para GFP. (B) com um conjunto de filtros para DAPI............................................................ 5

Figura 7. Diagrama de Jablonski, adaptado da referência 12......................... 6

Figura 8. Estruturas fluorescentes já descritas na literatura, quinina, fluresceína, rodamina B e laranja de acridina. .............................................. 7

Figura 9. Arquitetura molecular push-pull.................................................. 8

Figura 10. Estrutura DMA e 4' Nitro DMA, retirada do estudo de Danko e

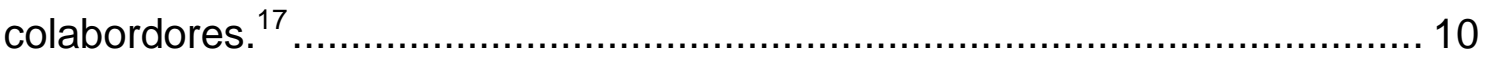

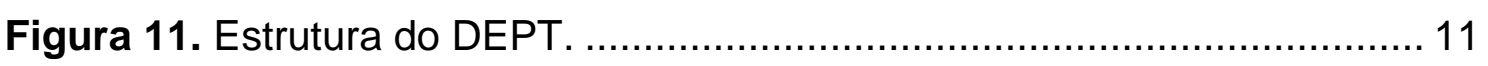

Figura 12. Lippert Mataga adaptado da referência 20................................ 11

Figura 13. Triatoma infestans, vulgo barbeiro. ........................................... 13

Figura 14. Esquemas tridimensionais das formas (direita para esquerda): tripomastigota, epimastigota e amastigota do $T$. cruzi, apresentando as

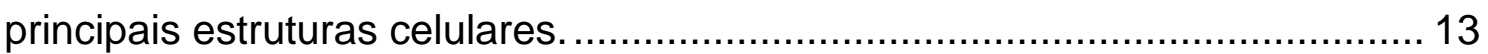

Figura 15. Evolução do coração acometido pela doença de Chagas. ............ 14

Figura 16. Medicamentos quimioterápicos disponíveis no mercado para tratamento da doença de Chagas. ........................................................... 15

Figura 17. Melhor orientação calculada no sítio ativo da cruzaína para a 3bromopropiofenona-tio-semicarbazona. A superfície ativa da cisteíno protease 
é apresentada em pontos cinza. Os resíduos Cys25 e His159 estão na coloração verde. 16

Figura 18. Espectro e expansão da região da região aromática do composto 9 obtido através da análise de ${ }^{1} \mathrm{H}$ RMN $\left(\mathrm{CDCl}_{3}, 300 \mathrm{MHz}\right)$.

Figura 19. Estruturas resolvidas por difração de raio- $X$ das estruturas $9,11,12$, $13,14,15,16,17,18$ e 19.

Figura 20. Estrutura cristalizada da cruzaína contendo seus respectivos bolsos de interação. 22

Figura 21. Pose melhor ranqueada no estudo docking para o composto 9 ..... 23

Figura 22. Pose melhor ranqueada no estudo docking para o composto $10 \ldots 23$

Figura 23. Pose melhor ranqueada no estudo docking para o composto 11... 24

Figura 24. Pose melhor ranqueada no estudo docking para o composto 12... 24

Figura 25. Pose melhor ranqueada no estudo docking para o composto 13... 24

Figura 26. Pose melhor ranqueada no estudo docking para o composto $14 \ldots 25$

Figura 27. Pose melhor ranqueada no estudo docking para o composto 15... 25

Figura 28. Pose melhor ranqueada no estudo docking para o composto 16... 25

Figura 29. Pose melhor ranqueada no estudo docking para o composto $17 . . .26$

Figura 30. Pose melhor ranqueada no estudo docking para o composto $18 \ldots 26$

Figura 31. Pose melhor ranqueada no estudo docking para o composto $19 \ldots 26$

Figura 32. Gráfico da \% de inibição da cruzaína para as estruturas testadas; a estrutura 11 não foi solúvel. 29

Figura 33. Tiosemicarbazonas desenvolvidas no trabalho de Blau e colaboradores $^{32}$ e seus respectivos valores de inibição à cruzaina em $10 \mu \mathrm{M} . .29$ Figura 34. A cor verde e a laranja emitida pelas estruturas 14 e 18 pode ser caracterizada a partir das seguintes coordenadas no diagrama de cromaticidade CIE 1931: (x: 0,287; y: 0,617) e (x: 0,508; y: 0,460), respectivamente. 30

Figura 35. Gráficos de absorção (esquerda) e emissão (direita) para a chalcona 9.

Figura 36. BNP e BTP, estruturas investigada no trabalho de Pannipara e colaboradores. 32

Figura 37. Ângulos torcionais para a chalcona com grupo N,N-dimetilamino, segundo Komarova e colaboradores. ${ }^{37}$ 38 
Figura 38. Configuração típica de electrospinning vertical usado para a produção de microfios. Imagem adaptada da referência 51.

Figura 39. MEV de microfios produzidos com ferroceno/PVP, com $25 \%$ e $30 \%$, respectivamente d) e e). Voltagem de $10 \mathrm{kV}$ e distância de $15 \mathrm{~cm} .{ }^{54}$ 45

Figura 40. Sistema de electrospinning completo (A), bomba ide injeção usada para controlar o fluxo de vazão da solução do polímero (B) e fonte de alta tensão (C) 45

Figura 41. Sistemas construídos em arame para depósito dos microfios nas placas de microscópio. 46

Figura 42. Imagem de MEV para a chalcona 14. 47

Figura 43. MEV com escala de $50 \mu \mathrm{m}$ da chalcona 16 e gráfico de distribuição percentual do material obtido. 47

Figura 44. MEV com escala de $50 \mu \mathrm{m}$ da chalcona 19 e gráfico de distribuição percentual do material obtido.

Figura 45. Imagens das placas de microscópio com o material PVP/chalcona irradiadas a $365 \mathrm{~nm}$. A indicação foi realizada com o mesmo número designado as chalconas sintetizadas.

Figura 46. Espectro de emissão do material sólido PVP/chalcona. As etiquetas MAT são designações referentes aos materiais PVP/chalcona, os números do acervo foi mantido nas designações, visando compreensão didática. 49 


\section{Índice de Esquemas}

Esquema 1. Esquema reacional para síntese de chalconas............................ 3 Esquema 2. Mecanismo proposto de interação covalente reversível entre chalcona e cruzaína, de acordo com estudos teóricos e resultados

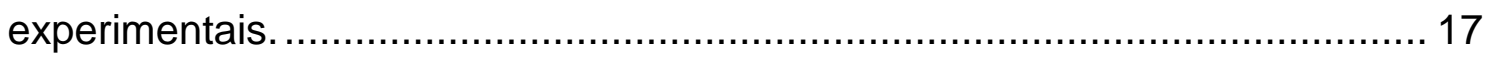

Esquema 3. Síntese das chalconas fluorescentes planejadas e respectivos

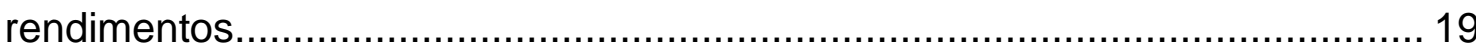


Tabela 1. Resultados dos ensaios de inibição da cruzaína na concentração de $100 \mu \mathrm{M}$.

Tabela 2. Dados resultantes do estudo fotofísico das onze chalconas em concentração $10 \mu \mathrm{M}$.

Tabela 3. Valores de $\boldsymbol{E}_{T}^{N}$ dos solventes utilizados no estudo.

Tabela 4. Dados extraídos dos gráficos de Lippert- Mataga: equação da reta e fator de correlação $\left(R^{2}\right)$.

Tabela 5. Dados de rendimento quântico obtidos pela metodologia do isosbéstico.

Tabela 6. Dados de rendimento quântico para as chalconas, comparativo com sulfato de quinina e com excitação em $366 \mathrm{~nm}$, acompanhadas de erro.

Tabela 7. Comprimentos de onda máximos obtidos com irradiação em $365 \mathrm{~nm}$ para os materiais PVP/chalcona, designados como MAT 


\section{Introdução}

\subsection{Chalconas}

As chalconas (1,3-diaril-2-propen-1-ones) pertencem a uma classe de compostos da família dos flavonoides. Sendo precursoras das auronas e das flavonas, são metabólitos secundários comumente extraídos como polifenóis de vegetais e frutas. A ocorrência natural das chalconas ocorre na forma de pigmentos de pétalas, sendo também encontradas no cerne, folhas, frutos e raízes. ${ }^{1}$ Tais estruturas tem um apelo medicinal muito grande, sendo justificado pelo estudo delas como anticancerígenas, antimicrobiais, anti-inflamatórias, antiprotozoária, entre outros. ${ }^{2,3}$

Biologicamente elas são obtidas a partir da fenilanina (principal rota), de acordo com a biossíntese descrita por Dao e colaboradores. ${ }^{4}$ De forma simplificada, na rota biossintética são necessárias no mínimo 7 etapas até a obtenção da trihidroxichalcona. Inicialmente, tem-se três enzimas para a obtenção do intermediário $p$-Coumaroil-CoA. Este intermediário juntamente com três equivalentes do Malonil-CoA forma o núcleo de interesse.

\footnotetext{
${ }^{1} \mathrm{Ni}$, L.; Meng, C.Q.; Sikorski, J. A.; Exp. Opn. 2004, 14, 1669.

${ }^{2}$ Alvim, H. G. O.; Fagg, E. L.; Oliveira, A. L.; Oliveira, H. C. B.; Freitas, S. M., Xavier, M. A. E.; Soares, T. A.; Gomes, A. F.; Gozzo, F. C.; Silva, W. A.; Neto, B.A.D.; Org. Biomol. Chem. 2013, 11, 4764.

${ }^{3}$ a) Aksöz, B. E.; Ertan, R.; J. Pharm. Sci. 2011, 36, 223. b) Liu, M.; Wilairat, P.; Croft, S. L.; Tan, A. L.; Go, M.; Bio. Med. Chem. 2003, 11, 2729. c) Mahapatra, D. K.; Bharti, S. K.; Asati, V.; Eur. J. Med. Chem. 2015, 98, 69. d) Mahapatra, D. K.; Bharti, S. K.; Asati, V.; Eur. J. Med. Chem. 2015, 101, 496.

${ }^{4}$ Dao, T. T. H.; Linthorst, H. J. M.; Verpoorte, R.; Phytochem. Rev. 2011, $10,397$.
} 


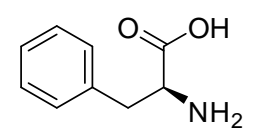

fenilalanina

$\int$ Fenilalanina Amônia-liase<smiles>O=C(O)/C=C/c1ccccc1</smiles>

$\int$ Cinamato-4Hidroxilase<smiles>O=C(O)/C=C/c1ccc(O)cc1</smiles>

Hidroxicinamoil CoA Ligase

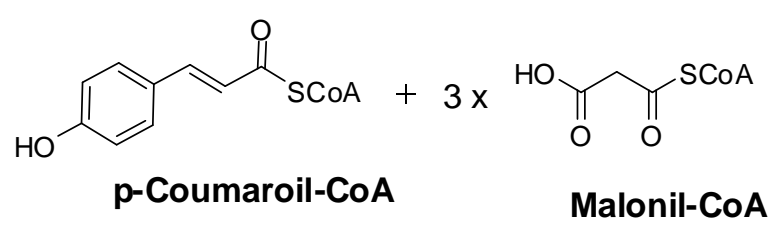

Chalcona Sintase/Chalcona Redutase<smiles>O=C(/C=C/c1ccc(O)cc1)c1ccc(O)cc1O</smiles>

trihidroxichalcona

Figura 1. Exemplo de rota biossintética de chalconas (adaptada da referência 4).

Em aspectos sintéticos, a obtenção de tais compostos se mostra economicamente viável, uma vez que não são necessárias condições experimentais drásticas (elevadas temperaturas, excesso de reagentes e longos períodos reacionais), tampouco utilização de catalisadores caros. A reação ocorre por meio da condensação de Claisen Schmidt. ${ }^{5}$ Experimentalmente, consiste na reação entre acetofenonas e arilaldeídos (substituídos ou não). Em geral, utiliza-se como meio básico uma solução alcoólica de hidróxido de sódio, temperatura ambiente e períodos reacionais de 12 a $24 h$.

${ }^{5}$ Lawrence, N. J.; Rennison, D.; McGown, A. T.; Ducki, S.; Gul, L. A.; Hadfield, J. A.; Khan, K.; J. Comb. Chem. 2001, 3, 421. 


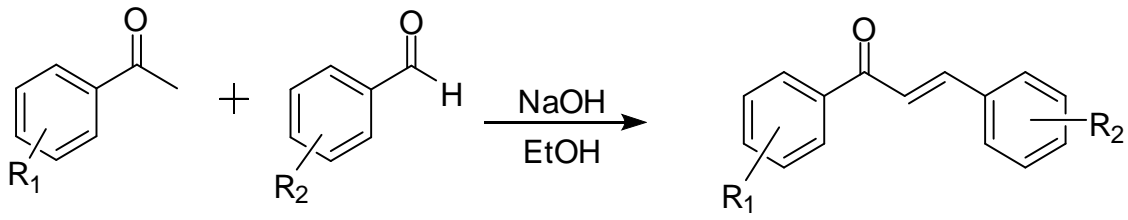

Esquema 1. Esquema reacional para síntese de chalconas.

O mecanismo para a condensação aldólica de Claisen-Schmidt em meio básico (representado por B) é amplamente conhecido, como descrito na Figura 2. Inicialmente, tem-se o ataque da base $(B)$ a cetona $(\mathbf{A})$ formando o enolato (C). Este ataca o aldeído ao ter a carbonila regenerada, formando o composto D que está em equilíbrio com sua forma aldólica (E). A base presente no meio retira o hidrogênio ácido em $\mathbf{F}$, formando a espécie indicada em $\mathbf{G}$ que por mecanismo $E_{1} C B$ forma o composto $\alpha, \beta$ insaturado.

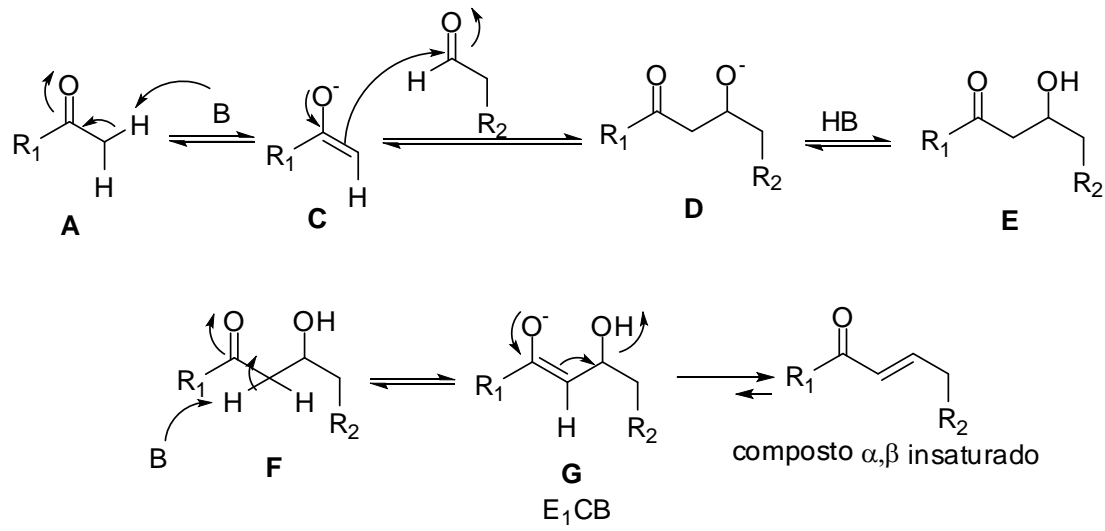

Figura 2. Mecanismo da condensação aldólica de Claisen-Schmidt, onde HB é um ácido e B a base conjugada desse.

Chalconas possuem sua química bastante fundamentada, havendo uma vasta gama de derivados estudados e que inclusive apresentam atividades biológicas e medicinais. Como exemplos comerciais pode-se citar a metochalcona e a solfacona, Figura 3. A primeira possui ação colerética (simula a produção de bile pelo fígado) e a outra ação anti-úlcera. ${ }^{1}$
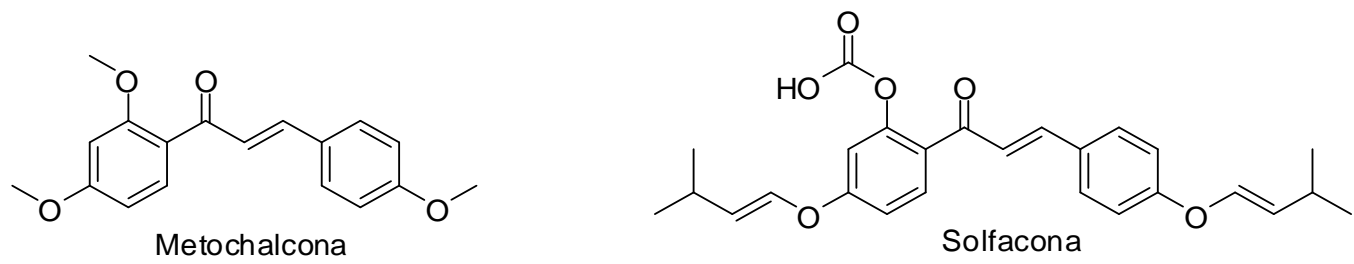

Figura 3. Metochalcona e solfacona: fármacos derivados de chalconas disponíveis no mercado. 
Como exemplo de atividade antimicrobial e anti-inflamatória podemos citar o trabalho de Kumar e colaboradores, ${ }^{6}$ no qual dez estruturas foram avaliadas. No quesito antimicrobial, quatro foram os micro-organismos testados, a saber: S. aureus, B. subtilis, E. coli e P. putida, tendo resultado apreciável 1 (Figura 4) frente a E. coli. Já em testes com ação anti-inflamatória 4-dimetilamino chalcona - DMA (Figura 4) foi a única que apresentou ação prolongada inibindo edemas, sendo esta uma chalcona bastante promissora. ${ }^{7}$
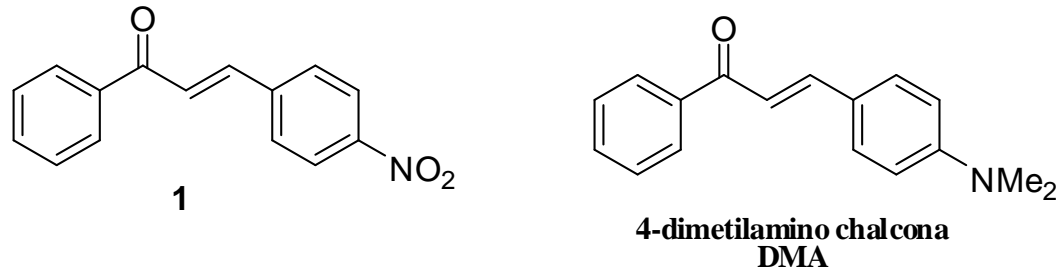

Figura 4. Chalconasb 1 atividade antimicrobial (E. coli) e 4-dimetilamino chalcona - DMA antiinflamatório relevantes.

Os trabalhos de Lawrence e colaboradores ${ }^{7,8}$ demonstraram que as chalconas derivadas do 3-hidroxi-4-metoxibenzaldeído e 3,4,5trimetoxiacetofenona apresentaram alta citoxicidade na marcação de células cancerígenas. Corroborando com a substituição 3,4,5-trimetoxi na estrutura da chalcona, fica indicado que as mesmas apresentam efeitos anti-inflamatórios, justificado por serem inibidoras do óxido nítrico segundo o trabalho desenvolvido por Ni e colaboradores. ${ }^{1}$

Para a atividade antiprotozoária o trabalho apresentado por Borchhardt e colaboradores $^{9}$ indica sete chalconas com atividade significativa in vitro anti $T$. cruzi (protozoário responsável pela doença de Chagas). As estruturas que apresentaram $\quad \mathrm{IC}_{50}$ significativos (valores entre 20 e $25 \mu \mathrm{MM}$ ) estão representadas na Figura 5.

\footnotetext{
${ }^{6}$ Kumar, N.; Jain, J. S.; Sinha, R.; Garg, V. K.; Bansal, S. K.; Der Pharm. Lett. 2009, 1, 169.

${ }^{7}$ Lawrence, N. J.; Patterson, R. P.; Ooi L.; Cookc D.; Duckic, S.; Bioorg. Med. Chem. Lett. 2006, 16,5844

${ }^{8}$ Lawrence, N. J.; Ducki, S.; Rennison, D.; Woo, M.; Kendall, A.; Chabert, J. F. D.; McGown, A. T.; Bioorg. Med. Chem. 2009, 17, 7698.

${ }^{9}$ Borchhardt, D. M.; Mascarello A.; Chiaradia, L. D.; Nunes, R. J.; Oliva,G.; Yunes, R. A.; Andricopulo, A.D.; J. Braz. Chem. Soc. 2010, 21, 142.
} 
<smiles>O=C(/C=C/c1ccc2c(c1)OCO2)c1ccc(Br)cc1</smiles><smiles>O=C(/C=C/c1c(Cl)cccc1Cl)c1ccc2c(c1)OCO2</smiles>

4<smiles>O=C(/C=C/c1cccc2ccccc12)c1ccc2c(c1)OCO2</smiles>

6<smiles>COc1ccc(/C=C/C(=O)c2c(OC)cc(OC)c(Br)c2O)cc1</smiles>

3<smiles>COc1cc(OC)c(OC)cc1/C=C/C(=O)c1ccc2c(c1)OCO2</smiles><smiles>O=C(/C=C/c1ccc(O)o1)c1ccc2c(c1)OCO2</smiles>

7<smiles>O=C(/C=C/c1cccs1)c1ccc2c(c1)OCO2</smiles>

Figura 5. Chalconas com $\mathrm{IC}_{50}$ representativos contra T. cruzi in vivo. ${ }^{10}$

O trabalho de Cui e colaboradores ${ }^{10}$ tem apontado os grupos substituintes no benzaldeído $N$-metilamino e $N, N$-dimetilamino como determinantes para que a afinidade com agregados $A \beta$ (placas protéicas responsáveis pelo acometimento do mal de Alzheimer) seja efetiva e, portanto, chalconas e derivados de indol ${ }^{11}$ que contenham esses grupos são formas não invasivas de detecção da doença, servindo como marcadores (Figura 6).
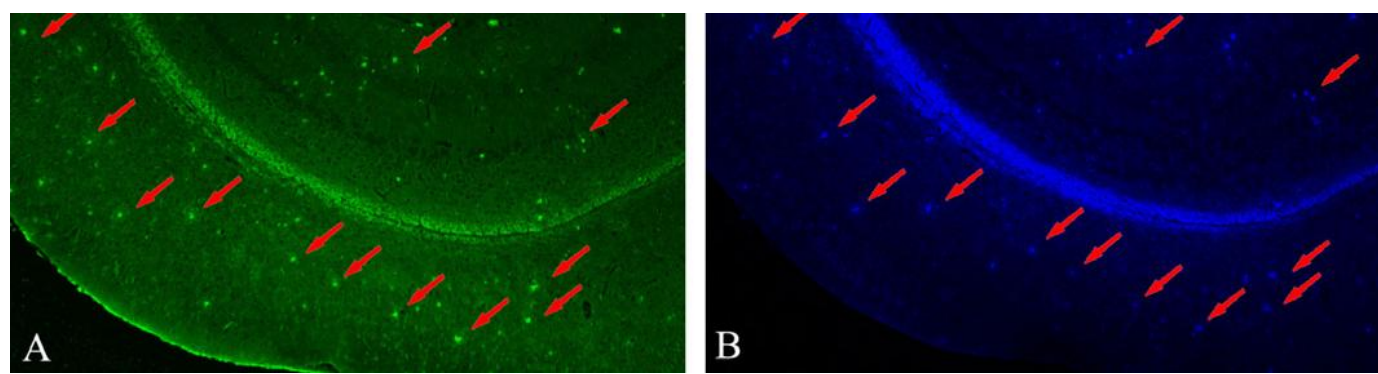

Figura 6. (A) Fluorescência de (E)-1-(4-(dimetilamino)fenil)-3-(1H-indol-5-il)prop-2-en-1ona em uma seção de tecido cerebral de um rato (Im 6 de espessura) Tg-C57 (APP / PS1) com um conjunto de filtros para GFP. (B) com um conjunto de filtros para DAPI.

${ }^{10}$ Cui, M.; Ono, M.; Kimura, H.; Liu, B.L.; Saji, H.; Bioorg. Med. Chem. Lett. 2011, 21, 980.

${ }^{11}$ Qu, W.; Choi, S.-R.; Hou, C.; Zhuang, Z.; Oya, S.; Zhang, W.; Kung, M.-P.; Manchandra, R.; Skovronsky, D. M.; Kung, H. F.; Bioorg.. Med. Chem. Lett. 2008, 18, 4823. 


\subsection{Luminescência e Aplicações Tecnológicas}

Fenômenos luminescentes são compreendidos como a emissão de luz por uma substância e ocorrem a partir de estados eletronicamente excitados das moléculas. Para a obtenção de um estado excitado é necessário que uma fonte forneça tal energia a substância, dependendo desta temos designações para os consequentes fenômenos luminescentes. Quando a excitação é fornecida ao sistema por luz, temos a fotoluminescência, quando por reação química, quimioluminescência e bioluminescência (caso especial, ocorrendo em seres vivos, como, por exemplo: vagalume).

Alexander Jablonski, considerado o pai da espectroscopia de fluorescência devido as suas colaborações, desenvolveu uma teoria fundamental para a compreensão da relaxação molecular e seus processos. Como resultado das investigações que possibilitaram o desenvolvimento teórico, temos o diagrama de Jablonski simplificado, ${ }^{12}$ Figura 7.

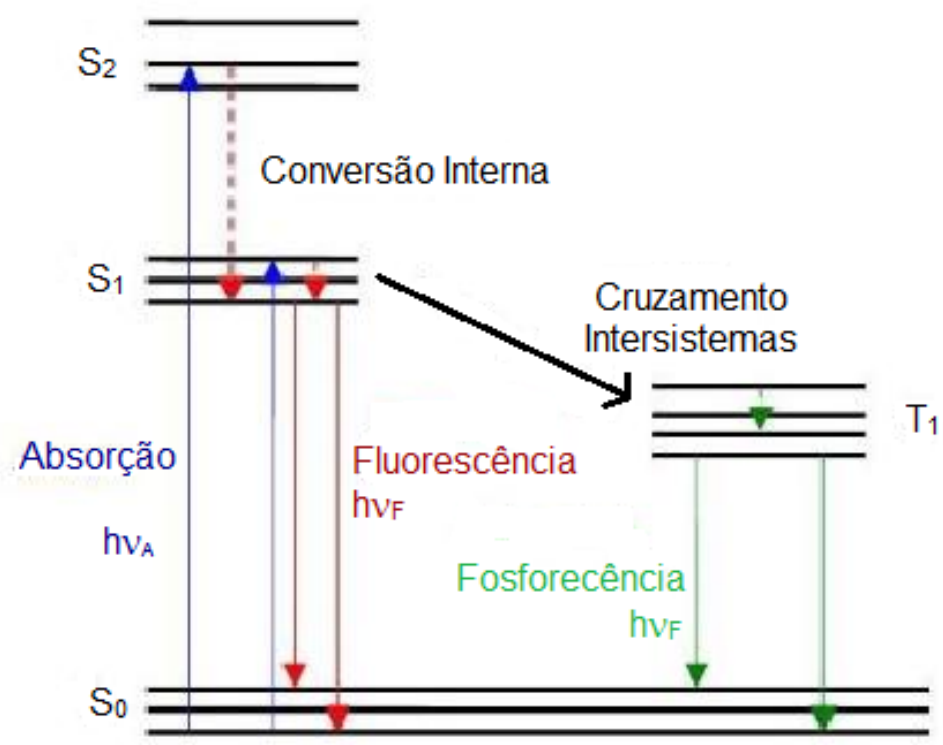

Figura 7. Diagrama de Jablonski, adaptado da referência 12.

$S_{0}, S_{1}$ e $S_{2}$ são estados singleto fundamental e primeiro e segundo estados eletrônicos excitados, respectivamente. $\mathrm{T}_{1}$ é o primeiro estado tripleto. O diagrama acima representa também as formas de relaxação radiativa, fluorescência e fosforescência, nos quais as energias absorvidas são

\footnotetext{
${ }^{12}$ Lakowicz, J.R.; Principles of Fluorescence Spectroscopy, 3를 ed.; Springer: Nova York, USA,
} 2006. 
dissipadas como energia luminosa, mas com uma energia menor que a incidente, portanto maiores comprimentos de onda são atingidos. Os mecanismos não radiativos representados são conversão interna e cruzamento intersistemas, valendo ressaltar que são mecanismos físicos. Há também nessa última categoria o mecanismo não radiativo químico no qual a energia incidente se torna energia eletromotriz para uma reação química.

Vale salientar que a relaxação não radiativa é concomitante e concorrente à emissão luminescente. A emissão luminescente pode ser caracterizada por dois fenômenos, a fosforescência e a fluorescência.

A fosforescência se caracteriza no diagrama de Jablonski como a emissão do estado tripleto para o estado singleto fundamental $\left(\mathrm{S}_{0}\right)$, sendo essa transição proibida, tornando o fenômeno mais longo quanto à duração $\left(10^{-3}\right.$ a 1 s). No estado excitado há a transição do spin de $S_{1}$ para o estado tripleto $\left(T_{1}\right)$ por conversão intersistemas. A fluorescência, por sua vez, envolve a transição do estado singleto excitado $\left(S_{1}\right)$ para o estado singleto fundamental $\left(S_{0}\right)$ e ocorre na escala de $10^{-9}$ a $10^{-6} \mathrm{~s}$.

$\mathrm{Na}$ literatura, encontram-se compostos que apresentam propriedades fluorescentes. Na Figura 8, tem-se alguns dos núcleos mais conhecidos que apresentam esta propriedade, dentre eles destaca-se a quinina, fluoresceína, rodamina e a laranja de acridina.
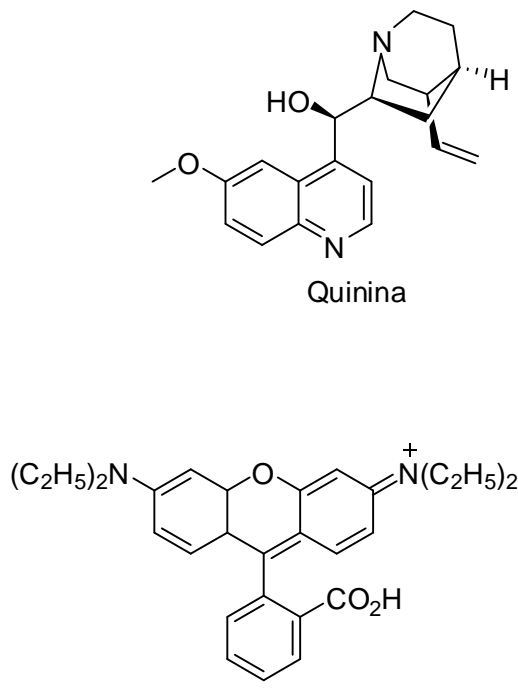

Rodamina B

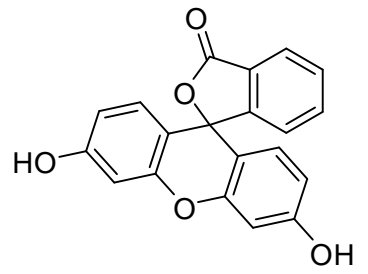

Fluoresceína

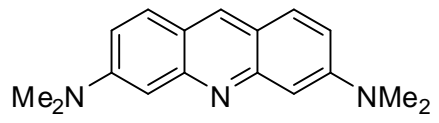

Laranja de acridina

Figura 8. Estruturas fluorescentes já descritas na literatura, quinina, fluresceína, rodamina B e laranja de acridina. 
Contudo, para que uma molécula orgânica possua atividade fluorescente, ou seja, dissipe a energia absorvida em forma de luz, é necessário que esta apresente certos requisitos, tais como: (a) rigidez estrutural, (b) planaridade, (c) ligações $\pi$-conjugadas (geralmente), (d) grupos funcionais aromáticos (geralmente), (e) anéis condensados (geralmente). ${ }^{12}$.

O interesse no núcleo chalcona deve-se ao fato deste poder apresentar todas as características supracitadas e possuir uma arquitetura molecular que favoreça a sua atividade fluorescente. Esta classe de interesse apresenta estruturas do tipo doador-aceptor-doador (D-A-D) ou push pull ${ }^{2}$ (Figura 9) que favorecem a atividade fluorescente devido a uma melhor estabilização no estado excitado.

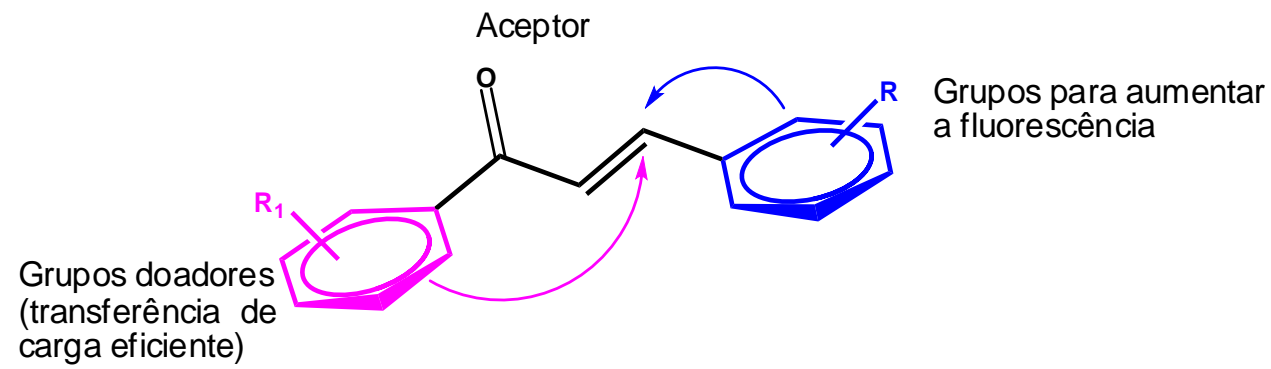

Figura 9. Arquitetura molecular push-pull.

A partir da escolha de grupos com caráter doador nos anéis aromáticos da estrutura torna-se plausível a ocorrência de transferência interna de carga, TIC ou ICT- Internal Transfer Charge, uma vez que o fluxo eletrônico é favorecido. ${ }^{13}$

O sistema de chalconas consiste em uma ponte ceto-vinil entre os grupos aromáticos, caracterizando um sistema $\pi$-conjugado. Para que tais estruturas possam vir a suprir a busca por novas tecnologias que exploram a capacidade de fótons transmitirem informações e energia, há de se compreender e quantificar o fenômeno da transferência de carga.

Os parâmetros básicos dentro do estudo fotofísico são deslocamento de Stokes, rendimento quântico e Lippert-Mataga. Fazem-se necessários para avaliação da transferência interna de carga e comportamento da molécula com

\footnotetext{
${ }^{13}$ Lee, S. C.; Kang, N. Y.; Park, S. J.; Yun, S. W.; Chandran, Y.; Chang, Y. T.; Chem. Commun.
} 2012, 48, 6681. 
relação aos solventes, permitindo a compreensão acerca do fenômeno da fluorescência e avaliação das potencialidades de aplicação da estrutura.

De modo geral, a energia de emissão é relativamente menor que a energia de absorção, ou seja, com maiores comprimentos de onda. 0 deslocamento de Stokes se dá pela diferença desses valores, em comprimento de onda. Esse parâmetro nos fornece informações significativas com relação ao estado de excitação. Quanto maior o valor deste fica indicado que o estado excitado $\left(S_{1}\right)$ é melhor estabilizado, em consequência dessa estabilização maiores comprimentos de onda são atingidos. ${ }^{14}$

O rendimento quântico é definido como a razão entre os fótons emitidos e os absorvidos. Esse parâmetro mantém estreita relação com o caminho de relaxação, já que a perda de energia no fenômeno fotoluminescente pode ocorrer por mecanismos $n$, como já mencionado anteriormente.

Segundo Skoog e colaboradores, ${ }^{15}$ o rendimento quântico de fluorescência molecular é simplesmente a razão entre o número de moléculas que fluorescem e o número total de moléculas excitadas, ou a razão entre os fótons emitidos e os fótons absorvidos.

A equação: $\Phi_{F}=\frac{K_{F}}{K_{n r}+K_{F}}$; é descrita como o rendimento quântico da fluorescência. $K_{F}$ é a constante de velocidade de primeira ordem para a relaxação por fluorescência e $\mathrm{K}_{\mathrm{nr}}$ é para a relaxação não radiativa.

As equações de Lippert- Mataga permitem o entendimento do efeito dos solventes, levando em consideração o efeito do momento de dipolo, de constante dielétrica, das interações entre o fluoróforo e o solvente no estado fundamental e excitado, ou seja, a diferença entre $S_{1}$ e $S_{0}$ (fluorescência). Em termos práticos, teremos como parâmetro a sensibilidade do solvente para um fluoróforo com a obtenção de uma curva. Os fluoróforos mais sensíveis são os que têm uma grande mudança no momento dipolo no estado excitado, ou seja, aqueles que apresentarem maior inclinação da reta. ${ }^{12,16}$

A fim de viabilizar novas estruturas para aplicação tecnológica, o design adotado para a síntese de chalconas já parte de cromóforos conhecidos, sendo

${ }^{14}$ Reichardt, C.; Solvents and Solvent effects in Organic Chemistry. $3^{\text {a }}$ ed.; Wylei- VHC: Alemanha, Weinheim, 2004.

${ }^{15}$ Skoog, D. A.; West, D. M.; Hooler, F. J.; Stanley, R. C.; Fundamentos da Química Analítica, Tradução da 8ª ed.; Ed. Thomson: São Paulo, SP, 2008.

${ }^{16}$ Reichardt, C.; Chem. Rev. 1994, 94, 2319. 
um deles o grupo $\mathrm{N}, \mathrm{N}$-dimetilaminofenil, abordado no trabalho de Danko e colaboradores. ${ }^{17}$ Este trabalho apresenta resultados interessantes acerca de duas chalconas (Figura 10).<smiles>CN(C)c1ccc(/C=C/C(=O)c2ccccc2)cc1</smiles><smiles>CON(C)c1ccc(/C=C/C(=O)c2ccc([N+](=O)[O-])cc2)cc1</smiles>

Figura 10. Estrutura DMA e 4' Nitro DMA, retirada do estudo de Danko e colabordores. ${ }^{17}$

A estrutura do DMA apresenta maiores valores de deslocamento de Stokes em solventes polares e rendimento quântico melhor que 4'-Nitro 4dimetilamino chalcona - 4'- $\mathrm{NO}_{2}$ DMA. A presença de grupo nitro nessa estrutura implica em menor efeito do fenômeno de transferência interna de carga, devido ao grupo nitro ser retirador de elétrons, ocasionando menores valores de deslocamento e rendimento. Em contrapartida, as duas apresentam aumento de rendimento quântico quando associadas à rede polimérica (PVC), viabilizando aplicações tecnológicas do material obtido.

O grupo $N, N$-dimetilaminofenil tem justificativa de seu grande interesse de estudo por: apresentar uma relativa simplificação estrutural, ser comercialmente disponível e poder ser associado a diferentes grupos funcionais e apresentar um comportamento peculiar em solventes polares. No estado fundamental, a molécula é planar que significa máxima conjugação entre o grupo dimetilamino e o anel aromático. Pelo princípio de FranckCondon o estado localmente excitado (LE) é planar, porém o relaxamento do solvente gera uma rotação do grupo, até que se perca o alinhamento necessário para a conjugação. Como resultado, a transferência de carga na estrutura torcida (TICT_Twisted Intramolecular Charge Transfer) é estabilizada em solventes polares. ${ }^{18}$

Quando essa estrutura está associada a um esqueleto fenil, $\alpha-\beta-$ insaturado o momento dipolo associado é muito alto, enfatizando o efeito doador-aceptor, se comportando como os estilbenos. ${ }^{18}$

\footnotetext{
${ }_{17}^{17}$ Danko, M.; Andics, A.; Kosa, C.; Hrdlovic, P.; Vegh, D.; Dyes Pig. 2012, 92, 1257.

18 Valeur, B.; Molecular Fluorescence: Principles and Applications, Wiley-VCH: Alemanha, Weinheim, 2002.
} 
Outro exemplo de aplicação tecnológica para sistemas de chalconas consiste no trabalho apresentado por Marwani e colaboradores ${ }^{19}$ que faz um levantamento de propriedades fotofísicas e de estabilidade do composto DTEP: (E)-1-(2,5-dimetiltiofen-3-il)-3-(9-etil-9H-carbazol-3-il)prop-2-en-1-ona) (Figura 11), obtendo dados como absorção atômica, absortividade molar, força de oscilação, momento de dipolo e rendimento quântico de fluorescência.

A estrutura tem potencial aplicação em determinação de concentração micelar em surfactantes, já que apresentou um desvio de Stokes apreciável (4268 a $6752 \mathrm{~cm}^{-1}$, a depender do solvente), além de estabilidade.

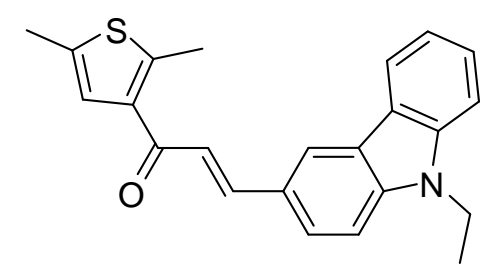

Figura 11. Estrutura do DTEP.

O trabalho de El- Daly e colaboradores ${ }^{20}$ apresenta o uso do parâmetro de Lippert-Mataga para uma chalcona, Figura 12. A escala de Reichardt, ${ }^{16}$ conhecida como $E_{T}^{N}$, são parâmetros de polaridade específicos para cada solvente.

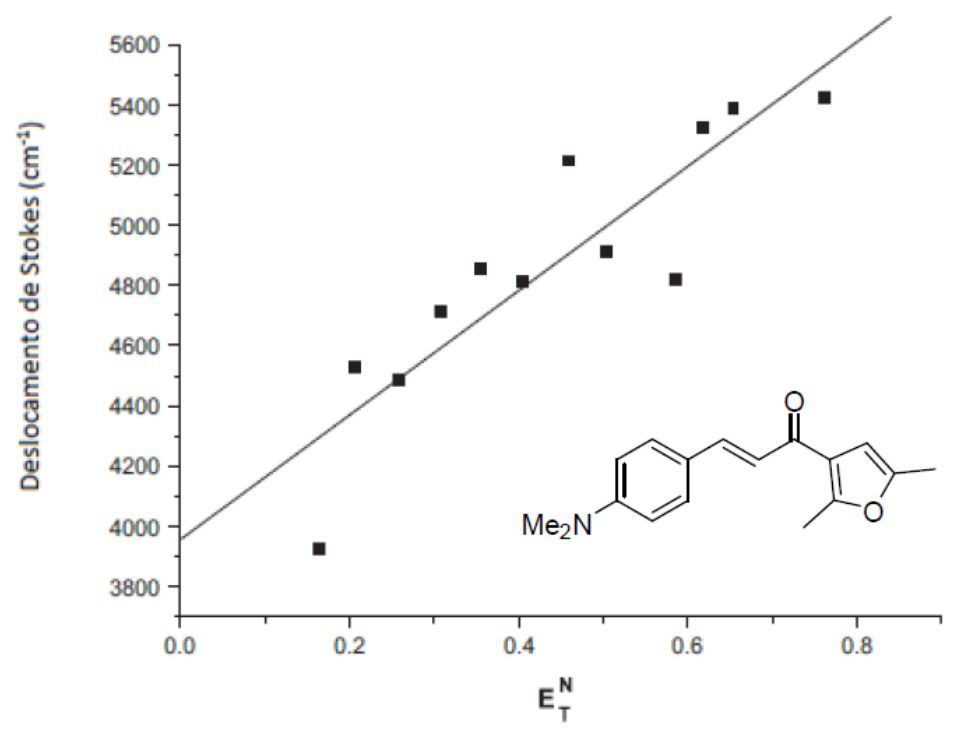

Figura 12. Lippert Mataga adaptado da referência 20. ${ }^{20}$

\footnotetext{
${ }^{19}$ Marwani, H.M.; Asiri, A. M.; Khan, S.A.; J. Lumi. 2013, 136, 296.

${ }^{20}$ El-Daly, S.A.; Asiri, A. M.; Alamry, K.; Khan, S. A.; J. Lumi. 2013, 137, 6.
} 
A curva de Lippert-Mataga para a estrutura de chalcona apresentada permite concluir que o comportamento de emissão da estrutura tem caráter de ICT pronunciado.

Neste trabalho, a investigação se dará no uso do grupo 4(dimetilamino)benzaldeído como precursor sintético, devido a seu preço de mercado não ser tão elevado, pela aplicação biológica ${ }^{6,9}$ e potenciais aplicações tecnológicas enfocando este ramo como marcador tumoral ${ }^{10,11} \mathrm{e}$ também associados a redes poliméricas. ${ }^{17}$ De forma a se compreender melhor o efeito do substituintes no processo de transferência interna carga novos derivados foram obtidos com acetofenonas substituídas tanto com grupos retiradores e doadores de elétrons.

\subsection{Doença de Chagas}

Dentro do amplo espectro de doenças negligenciadas a Organização Mundial de Saúde $(\mathrm{OMS})^{21}$ classifica e destaca a doença de Chagas. Doenças negligenciadas são assim classificadas porque prevalecem em situações de pobreza e más condições de sobrevivência e perpetuam essa desigualdade, sendo empecilhos para o desenvolvimento das nações acometidas por elas. Para agravar a situação os investimentos em políticas de desenvolvimento nem sempre são prioritárias na política nacional. Embora haja o investimento em pesquisa, os conhecimentos não são convertidos em produtos para o mercado, principalmente devido à falta de interesse da indústria farmacêutica, uma vez que a doença atinge um contingente populacional alto que disponibiliza de baixíssimos recursos aquisitivos.

A cada ano milhões de pessoas morrem no mundo em consequência da doença, sendo que a região mais afetada no globo terrestre é a América Latina; mais especificamente o Brasil. Desta forma, é necessário o desenvolvimento de medicamentos mais seletivos e mais potentes, além de economicamente viáveis, para o combate da doença de Chagas.

A enfermidade de Chagas é classificada como parasitária, sendo o vetor transmissor o inseto hematófago o qual é vulgarmente conhecido como barbeiro, Figura 13. O barbeiro pertence à espécie triatomíneo, onde o

\footnotetext{
${ }^{21}$ Nowakowska, Z.; Eur. J. Med. Chem., 2007, 42, 125.
} 
Triatoma infestans é o principal agente transmissor do protozoário - o Trypanosoma cruzi. Vale ressaltar que transfusão de sangue e a transmissão congênita, ou direta, são outras formas possíveis de contaminação. ${ }^{22}$

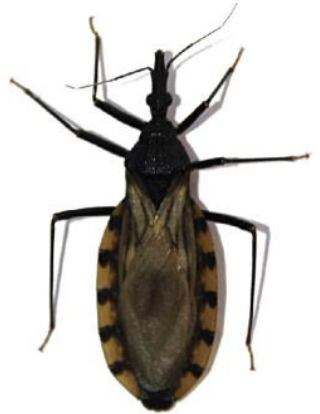

Figura 13. Triatoma infestans, vulgo barbeiro. ${ }^{23}$

O Trypanosoma cruzi apresenta em seu ciclo três formas evolutivas: tripomastigota, epimastigota e amastigota, apresentados na Figura 14. O que as diferencia são: o flagelo e a posição entre cinetoplasto e núcleo celular. A forma tripomastigota apresenta o cinetoplasto na parte posterior do flagelado $\mathrm{e}$ flagelo aparente. No epimastigota, o cinetoplasto e a bolsa flagelar estão em posição anterior ao núcleo. Amastigota apresenta-se com morfologia arredondada, sem flagelo (externo).

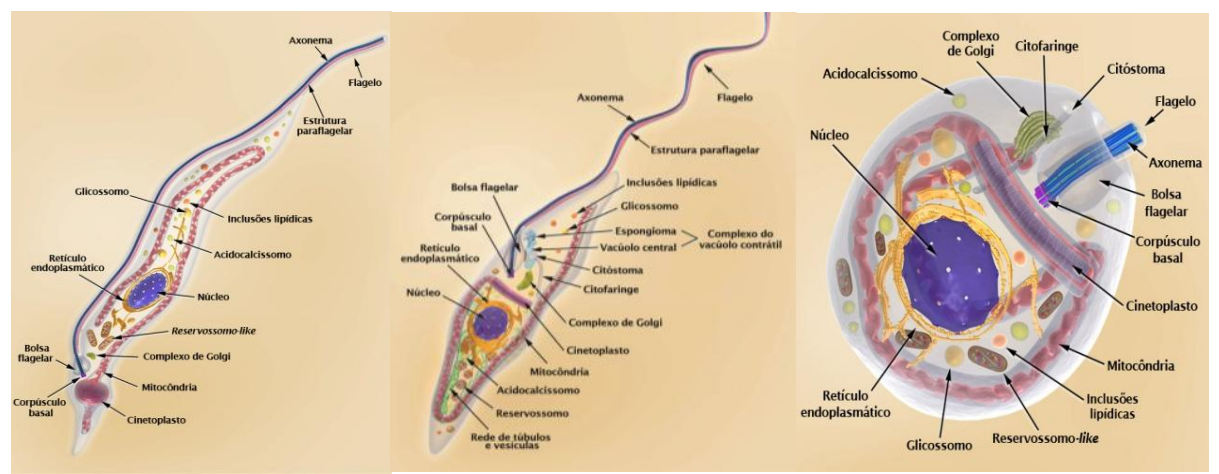

Figura 14. Esquemas tridimensionais das formas (direita para esquerda): tripomastigota, epimastigota e amastigota do T. cruzi, apresentando as principais estruturas celulares ${ }^{24}$.

No inseto o protozoário assume as formas de epimastigotas (ao longo de todo o tubo digestivo) e tripomastigotas metacíclicos (quando atingem o reto).

22 Júnior, E. N. S., Jardim, G. A. M., Barreto, R. F. S. M., Castro, S. L., J. Braz. Chem. Soc., 2014, 25, 1780.

${ }^{23}$ Noireau, F.; Diosque, P.; Jansen, A. M.; Vet. Res. 2009, 40, 26.

${ }^{24} \mathrm{http}: / /$ labspace.open.ac.uk/course/view.php?id=7590, acessado em: 1/9/14. 
Essa última forma contamina um humano quando o vetor hematófago expele suas fezes ou urina após o ato de sucção de sangue, ocorrendo então a penetração da forma tripomastigota nas células humanas. ${ }^{25}$

O ciclo evolutivo em seres vertebrados tem sequência com a coexistência tripomastigota/amastigota. A última forma realiza a divisão binária, intracelularmente. Essa forma é convertida na primeira para a contaminação de mais células. Células contaminadas eclodem pelo excesso de parasitos e os tripomastigotas continuam o processo de contaminação ou caem na corrente sanguínea, acometendo tecidos musculares. ${ }^{25}$

O preocupante nos quadros avançados da doença de Chagas são as complicações decorrentes da destruição neuronal do trato gastrointestinal que leva a dilatação do esôfago e cólon, causando a desnutrição e constipação intratável, sem mencionar a destruição dos tecidos musculares lisos, com ênfase para o coração, Figura 15.

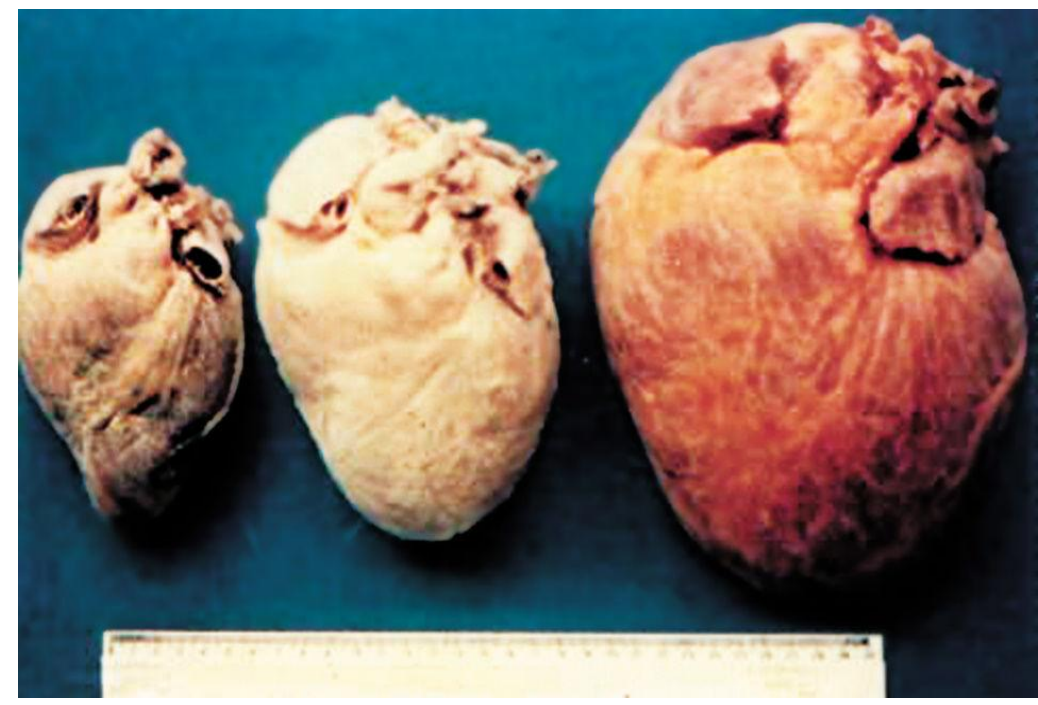

Figura 15. Evolução do coração acometido pela doença de Chagas. ${ }^{26}$

Problemas cardíacos são as principais causas de morte dos portadores crônicos da doença de Chagas e se manifesta após anos da infecção inicial. A cardiomiopatia chagásica crônica (CCC) pode gerar, a depender do grau,

${ }^{25}$ DIAS, J.C.P. e COURA, J.R., org. Clínica e terapêutica da doença de Chagas: uma abordagem prática para o clínico geral [online]. Rio de Janeiro. Ed.FIOCRUZ. 1997.

${ }^{26} \mathrm{http}: / / w w w$.jornalufgonline.ufg.br/pages/44396-laboratorio-de-pesquisa-da-doenca-de-chagasda-ufg-e-referencia-internacional, acessado em Novembro 2014. 
arritmia ventricular, distúrbios de condução e dilatação de câmaras cardíacas, além de insuficiência cardíaca congestiva, sendo a evolução desta última fatal.

Os fármacos atualmente utilizados para o tratamento da doença são nifurtimox e benzonidazol (Figura 16). Estes dois compostos ativos atuam na redução dos parasitos, mas causam inúmeros efeitos adversos, tais como: náuseas, insônia, depressão, anorexia, convulsões, cefaleia, e intolerância hepática entre outros. ${ }^{25}$<smiles>O=C(Cn1cccc1[N+](=O)[O-])NCc1ccccc1</smiles>

Benzonidazol<smiles>CC1CS(=O)(=O)CCN1/N=C/c1ccc([N+](=O)[O-])o1</smiles>

Nifurtimox

Figura 16. Medicamentos quimioterápicos disponíveis no mercado para tratamento da doença de Chagas.

Neste contexto, novos compostos têm sido investigados para contornar a problemática envolta dos derivados usados no tratamento desta doença. Sendo as estruturas da classe das chalconas uma ótima alternativa a estes compostos. Estas tem sido investigadas por conta de suas propriedades medicinais, já havendo relatos de potenciais quimioterápicos com êxito em testes in vitro para o combate ao protozoário. $^{9}$

Há relatos de chalconas que apresentam atividade anti-inflamatória, ${ }^{1,6} 0$ que corrobora a investigação dessa classe de compostos para a atuação como quimioterápicos aos quadros inflamatórios que se seguem da contaminação da doença de Chagas.

\subsection{Docagem Molecular}

Os estudos de docagem molecular (docking) são ferramentas muito eficazes na predição de possíveis fármacos. Através de cálculos teóricos são identificados os requisitos estruturais, em nível molecular, para a atividade de inibição do alvo a ser estudado, auxiliando, assim, o entendimento da forma de interação com proteínas e resíduos de aminoácidos, por exemplo. 
Estudos selecionaram a cruzaína, uma cisteíno-protease, como alvo para o desenvolvimento de novos agentes antitripanossoma. ${ }^{27} \mathrm{~A}$ cruzaína é responsável por muitos processos vitais do parasita, como: replicação, metabolismo e tem papel determinante na infecção dos macrófagos (células hospedeiras). Algumas chalconas já vêm sendo reportadas como inibidoras da cruzaína. 28,29

Tanto o trabalho de Trossini e colaboradores ${ }^{29}$ quanto o de Du e colaboradores, ${ }^{30}$ sugerem que o mecanismo de ação das semicarbazonas na inibição da cruzaína se dá pelo ataque nucleofílico do resíduo Cys25 no sítio carbonílico da tiosemicarbazona e compostos análogos a este, Figura 17.

O trabalho original de Du e colaboradores ${ }^{30}$ apresenta a Figura 17 como a melhor orientação calculada para a estrutura 3-bromopropiofenona-tiosemicarbazona no bolso $\mathrm{S} 2$, sítio ativo da cisteíno protease que contém 0 resíduo Cys25.

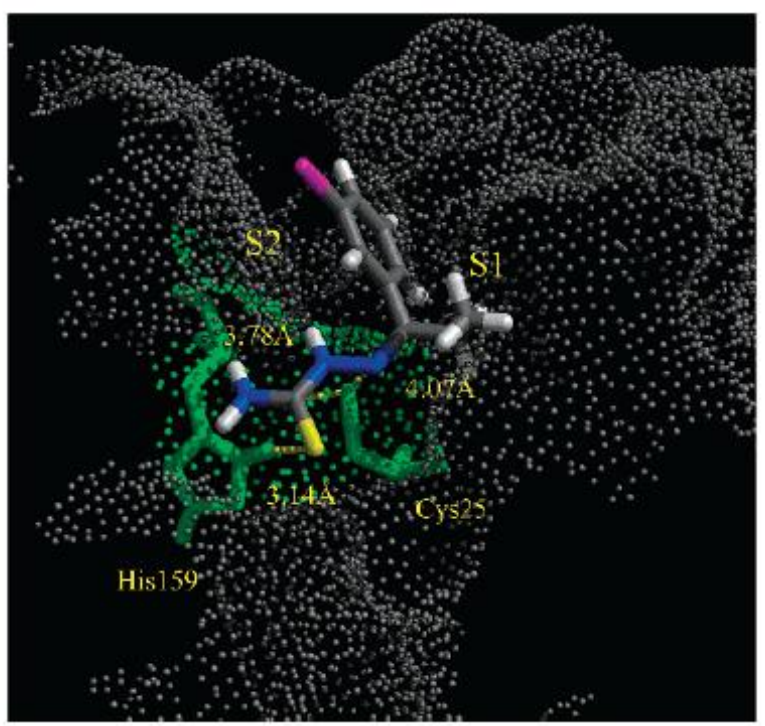

Figura 17. Melhor orientação calculada no sítio ativo da cruzaína para a 3-bromopropiofenonatio-semicarbazona. A superfície ativa da cisteíno protease é apresentada em pontos cinza. Os resíduos Cys25 e His159 estão na coloração verde.

De acordo com Trossini e colaboradores, ${ }^{29}$ de forma análoga, as chalconas apresentam o mesmo mecanismo de ação que as hidrazinas. Vale

${ }^{27}$ Sajid, M.; McKerrow, J. H.; Mol. Biochem. Parasitol. 2002, 159, 1221.

${ }^{28}$ Fayed, T. A.; Shaaban, M. H.; El-Nahass, M. N.; Hassan, F. M.; Micro. Meso. Mat. 2014, 198, 144.

${ }^{29}$ Trossini, G. H. G.; Vital, D. G.; Arribas, M.; Lett. Drug Design Disc. 2014, 11, 249.

${ }^{30}$ Du, X.; Guo, C.; Hansell, E.; Doyle, P.S.; Caffrey, C.R.; Holler, T.P.; McKerrow, J.H.; Cohen, F.E.; J. Med. Chem. 2002, 45, 2695. 
ressaltar que o ataque nucleofílico do resíduo da cisteína pode ocorrer tanto por adição 1,2 ou 1,4. Esquema 2:
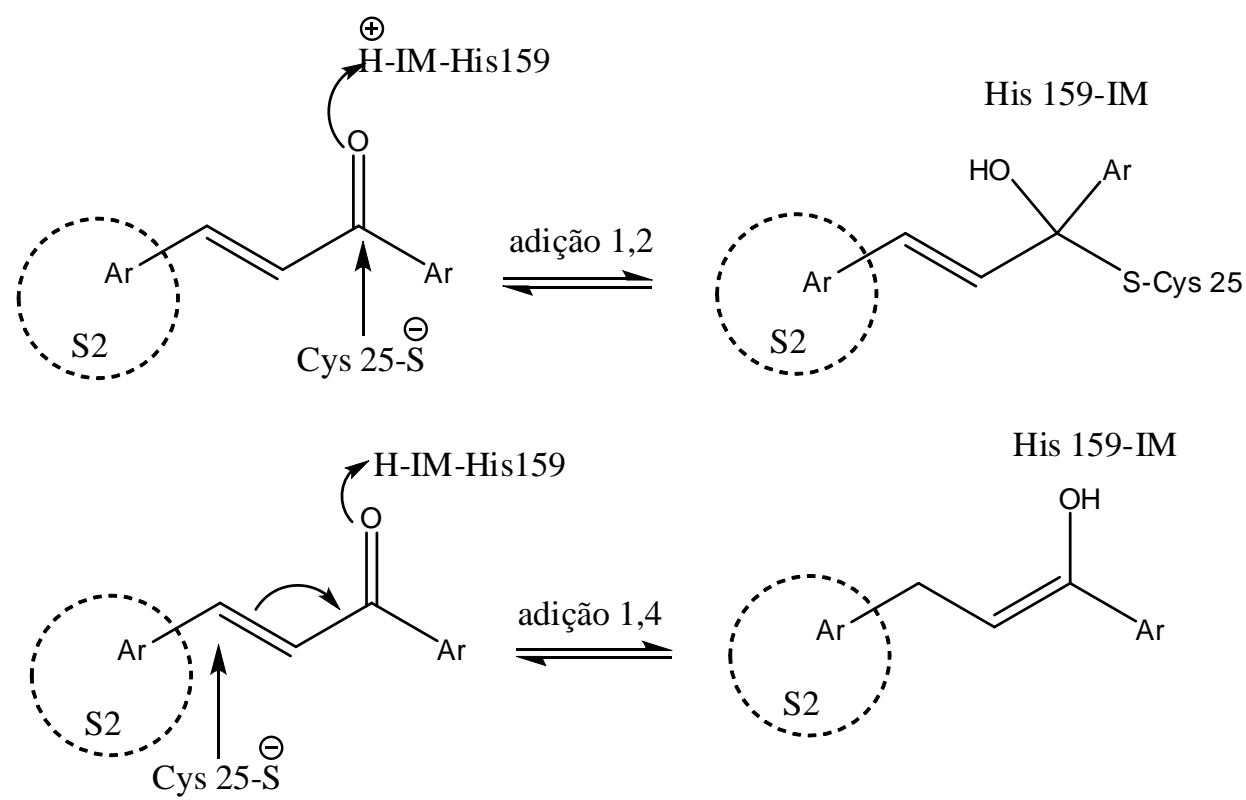

Esquema 2. Mecanismo proposto de interação covalente reversível entre chalcona e cruzaína, de acordo com estudos teóricos e resultados experimentais.

Embora as pesquisas no desenvolvimento de potenciais quimioterápicos antichagássicos serem contínuas, até o presente momento não há um tratamento efetivo para as outras fases da doença, como por exemplo, para os casos crônicos, sendo estes os maiores responsáveis pelo alto percentual de mortalidade nos indivíduos chagássicos.

Devido à importância do desenvolvimento de novos medicamentos que atendam o tratamento da doença de Chagas, as chalconas justificam o grande interesse de estudo por possuírem grande espectro de atuação biológica. 


\section{Objetivos}

\subsection{Gerais}

Esse trabalho tem como objetivos a síntese e a avaliação das propriedades fotofísicas de chalconas derivadas do $\mathrm{N}, \mathrm{N}$ dimetilaminobenzaldeído e 3,4,5-trimetoxibenzaldeído. A presença do grupo $\mathrm{N}, \mathrm{N}$-dimetilamino contribui positivamente para as propriedades de fluorescência de derivados de chalconas e 3,4,5-trimetoxi apresentam grande apelo biológico.

Desta forma, espera-se que a arquitetura molecular planejada para os derivados do 4-(dimetilamino)benzaldeído apresentem boas propriedades de emissão de luz e boa estabilidade no estado excitado.

\subsection{Objetivos Específicos:}

Dentre os objetivos específicos do trabalho encontram-se:

- Síntese e caracterização estrutural de chalconas derivadas do 4(dimetilamino)benzaldeído e outros aldeídos;

- Avaliação de parâmetros fotofísicos das estruturas sintetizadas;

- Avaliação de atividade antitripanossoma das moléculas;

- Produção de nanofibras a partir do material PVP-chalcona com potencial aplicação tecnológica. 


\section{Resultados e Discussão}

A síntese das chalconas foi realizada através da reação de condensação aldólica do tipo Claisen Schmidt $^{5}$ sendo utilizados aldeídos e cetonas aromáticos. No total foram sintetizados 11 derivados de chalcona com rendimentos entre 50 a $90 \%$.

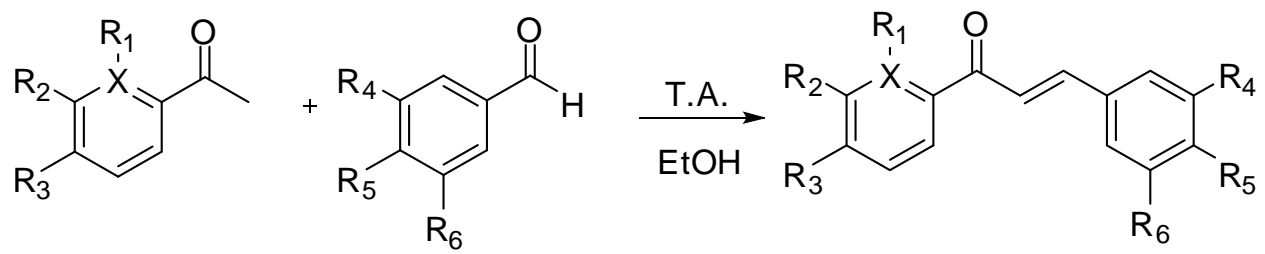

$$
\begin{aligned}
& \text { 9- } R_{1}, R_{2}, R_{3}, R_{4}, R_{6}=H, R_{5}=N M e_{2}, X=C \\
& \text { 10- } R_{1}, R_{2}, R_{4}, R_{6}=H, R_{3}=P h, R_{5}=N M e_{2}, X=C \\
& \text { 11- } R_{1}, R_{2}, R_{4}, R_{6}=H, R_{3}=N O_{2}, R_{5}=N M e_{2}, X=C \\
& \text { 12- } R_{1}=O H, R_{2}, R_{3}, R_{4}, R_{6}=H, R_{5}=N e_{2}, X=C \\
& \text { 13- } R_{1}, R_{3}, R_{4}, R_{6}=H, R_{2}=O H, R_{5}=N M e_{2}, X=C \\
& \text { 14- } R_{1}, R_{3}, R_{4}, R_{6}=H, R_{2}=N_{2}, R_{5}=N M e_{2}, X=C \\
& \text { 15- } R_{1}, R_{2}, R_{4}, R_{6}=H, R_{3}=C l, R_{5}=N_{2}, X=C \\
& \text { 16- } R_{1}, R_{2}, R_{4}, R_{6}=H, R_{3}=O M e, R_{5}=N M e_{2}, X=C \\
& \text { 17- } R_{1}=O H, R_{2}, R_{3}=H, R_{4}, R_{5}, R_{6}=O M e, X=C \\
& \text { 18- } R_{1}, R_{2}, R_{3}, R_{4}, R_{6}=H, R_{5}=N M e_{2}, X=N \\
& \text { 19- } R_{1}=N H_{2}, R_{2}, R_{3}=H, R_{4}, R_{5}, R_{6}=O M e, X=C
\end{aligned}
$$

Esquema 3. Síntese das chalconas fluorescentes planejadas e respectivos rendimentos.

\subsection{Caracterização}

Para a caracterização dos derivados foi utilizada análise de ressonância magnética nuclear de hidrogênio e carbono $\left({ }^{1} \mathrm{H} \mathrm{e}{ }^{13} \mathrm{C} \mathrm{RMN}\right)$. Na Figura 18, temse o espectro de ${ }^{1} \mathrm{H}$ RMN da estrutura 9 , sendo expandida a região aromática de 8,11 a 7,60 ppm. 


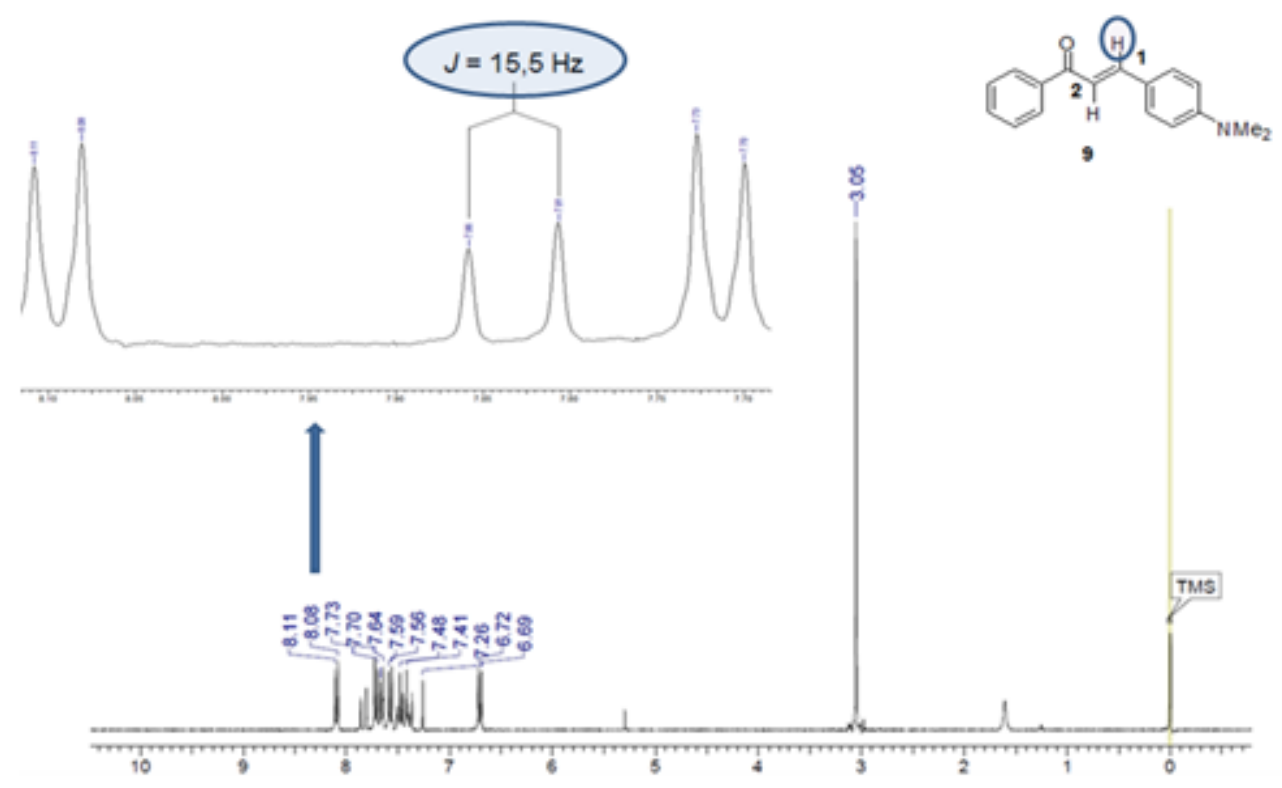

Figura 18. Espectro e expansão da região da região aromática do composto 9 obtido através da análise de ${ }^{\mathrm{H} \mathrm{RMN}}\left(\mathrm{CDCl}_{3}, 300 \mathrm{MHz}\right)$.

A análise do ${ }^{1} \mathrm{H}$ RMN indicou, para as estruturas sintetizadas, a presença de dois dupletos na região de 7,0 a 8,0 ppm, garantindo a existência de hidrogênio mais desblindado, indicado para o carbono 1 da Figura 18, pertencente à dupla ligação, este hidrogênio (1) é atribuído como mais desblindado por possuir uma carga parcial positiva devido a ressonância existente entre C3-C2-C1. O hidrogênio, indicado em 2, encontra-se na região de 6,5 ppm, mais blindado devido à vizinhança da carbonila (cone anisotrópico). Ainda analisando os dois dupletos, a constante de acoplamento (J) no valor de $15,5 \mathrm{~Hz}$ caracteriza acoplamento trans.

Para corroborar as caracterizações dos derivados, foram realizadas análises de raios- $X$ de monocristal para os cristais obtidos por recristalização com evaporação direta (frasco aberto) à temperatura ambiente. Somente a estrutura 10 não foi analisada, porque não se obteve monocristal. Todas essas análises foram realizadas pela Prof ${ }^{a} \mathrm{Dr}^{\mathrm{a}}$ Claudia Cristina Gatto, IQ-UnB.

As chalconas elucidadas estão apresentadas pelas estruturas ORTEPS na Figura 19. 


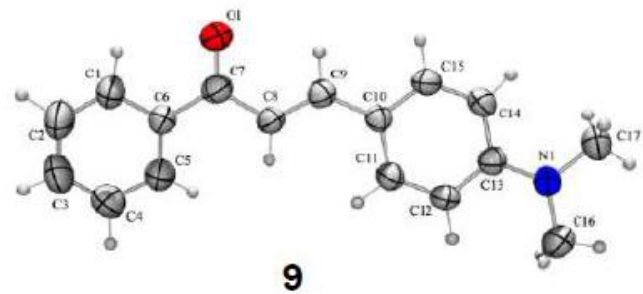

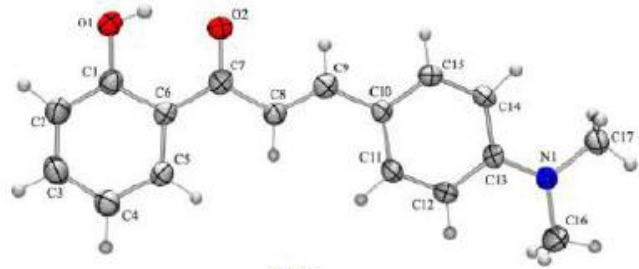

12

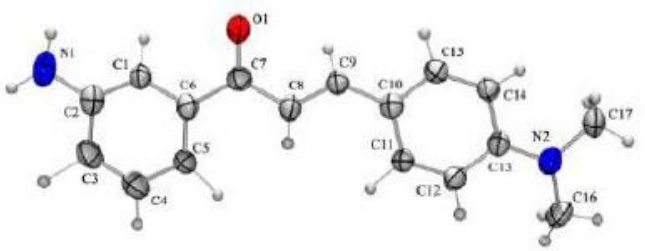

14

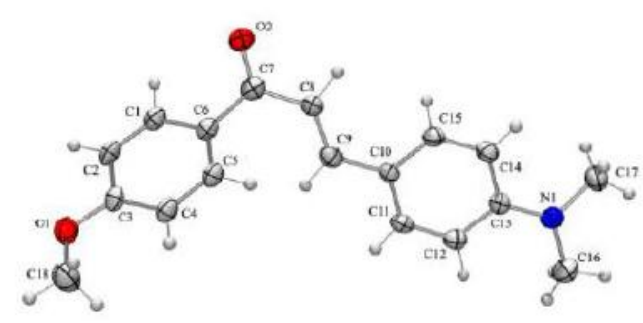

16

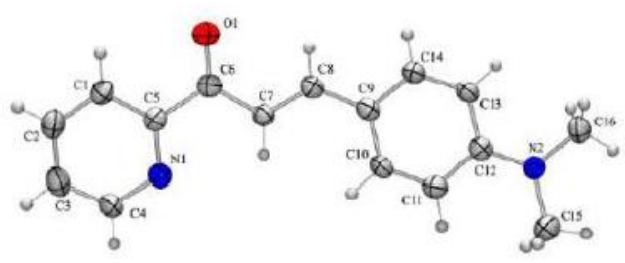

18
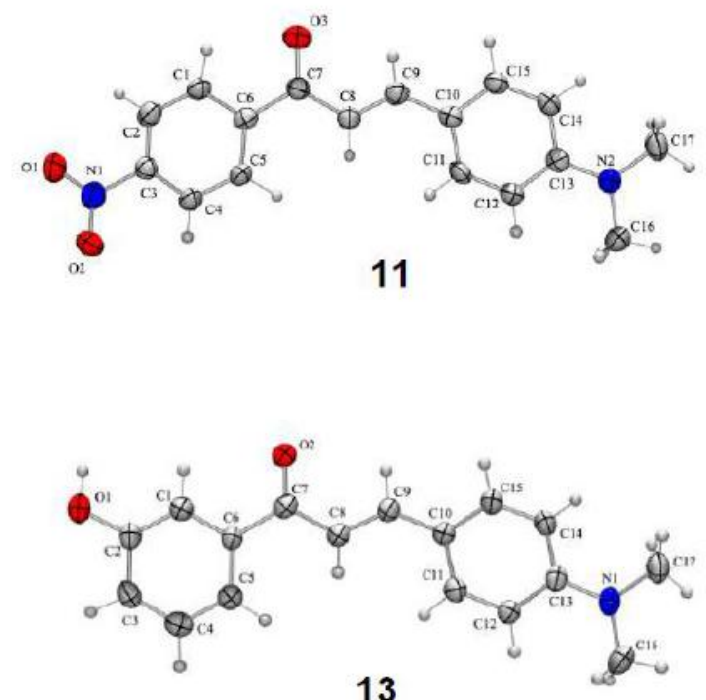

13

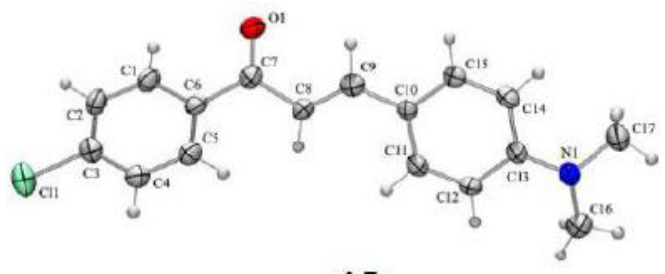

15

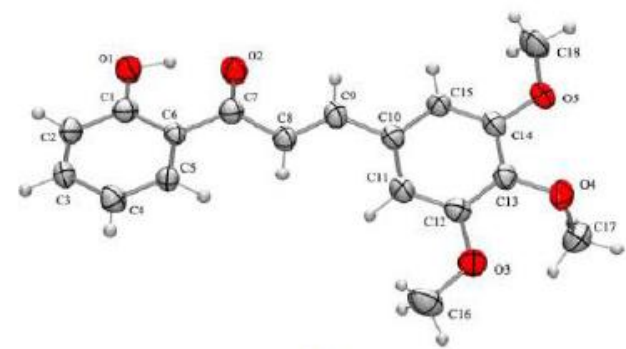

17

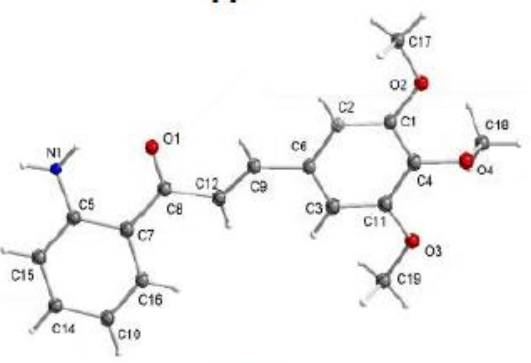

19

Figura 19. Estruturas resolvidas por difração de raio- $X$ das estruturas $9,11,12,13,14,15,16$, 17,18 e 19. 


\subsection{Estudos de Docking}

Os estudos de docking foram realizados em parceria com o Prof. Dr. Gustavo Henrique Goulart Trossini-USP.

Os estudos de docking foram realizados para todos os derivados de modo a avaliar a possibilidade da interação entre os ligantes e o sítio ativo da cruzaína, visando o mecanismo de ação proposto.

Com base em dados da literatura sugere-se a ocorrência do ataque nucleofílico do resíduo de Cys25 presente no sítio catalítico da enzima cruzaína à carbonila presente nesses compostos. ${ }^{29} \mathrm{~A}$ análise dos resultados foi baseada na interação dos ligantes e as propriedades químicas do sítio ativo da enzima previamente reportadas, tais como afinidade por grupos hidrofóbicos e aromáticos no bolso S2, e por grupos que proporcionem ligações de hidrogênio no bolso S1 e S1'.31

$\mathrm{Na}$ Figura 20 apresenta-se a estrutura da cruzaína em forma de superfície gerada no programa Pymol Viewer 1.5, e seus respectivos bolsos de interação, sendo estes S1 e S1'; S2 e S2' e S3.

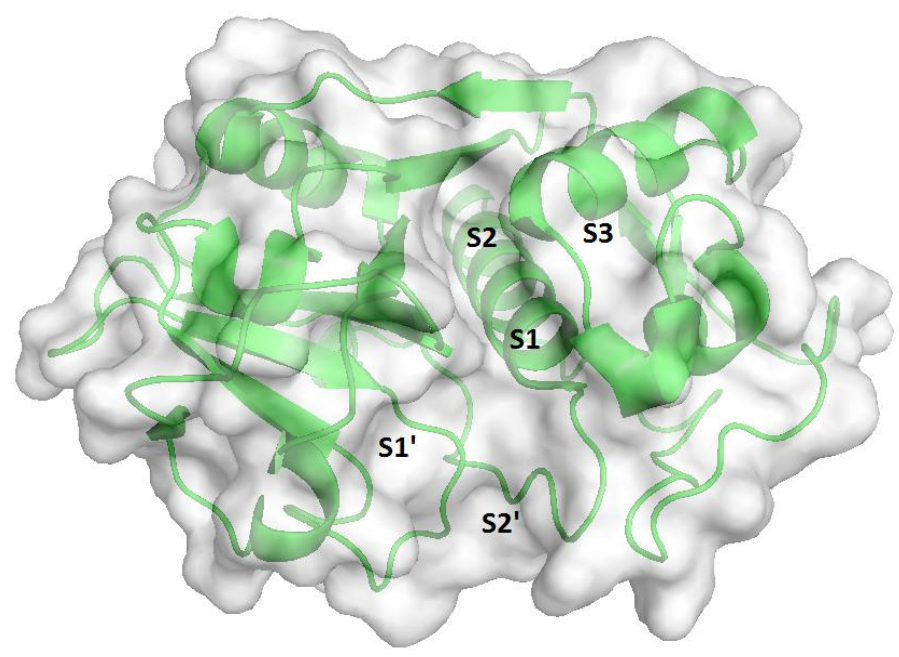

Figura 20. Estrutura cristalizada da cruzaína contendo seus respectivos bolsos de interação.

As análises foram realizadas avaliando a complementaridade estrutural das poses melhor ranqueadas pelo estudo de docking, que sugere interação

${ }^{31}$ Leach, A. R.; Shoichet, B. K.; Peishoff, C. E.; J. Med. Chem. 2006, 49, 5851. 
entre grupos aromáticos e o bolso S2 da cruzaína, corroborando com a literatura. ${ }^{30}$ Observou-se, para todas as estruturas docadas, com exceção da estrutura 15, uma pose favorável ao ataque da Cys 25 da cruzaína, mecanismo de inibição proposto para essa classe química. Das Figura 21 a Figura 31 pode-se visualizar a melhor pose de raqueamento para os derivados sintetizados.

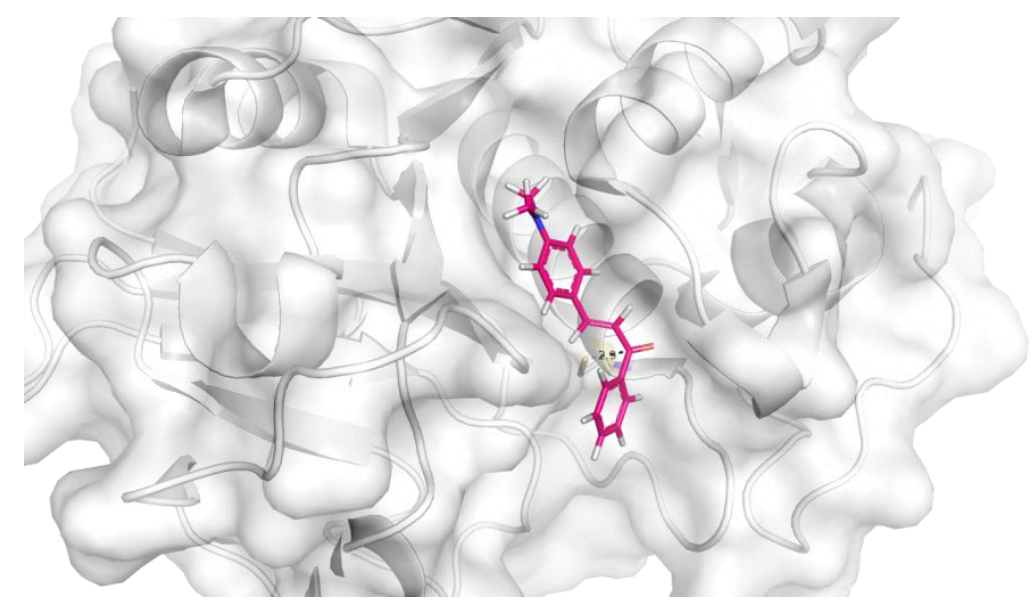

Figura 21. Pose melhor ranqueada no estudo docking para o composto 9.

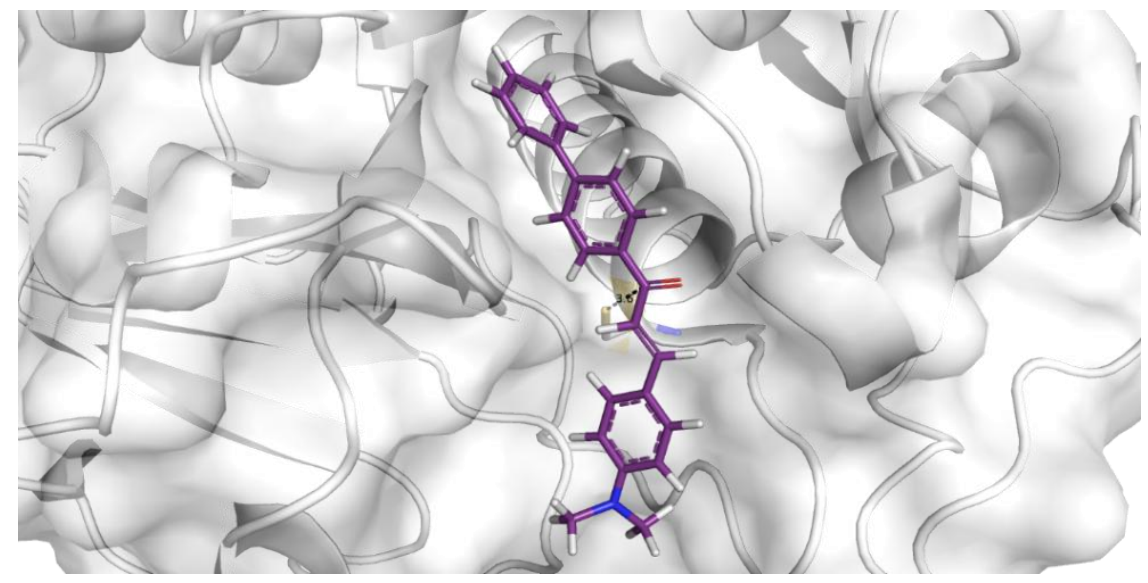

Figura 22. Pose melhor ranqueada no estudo docking para o composto 10. 


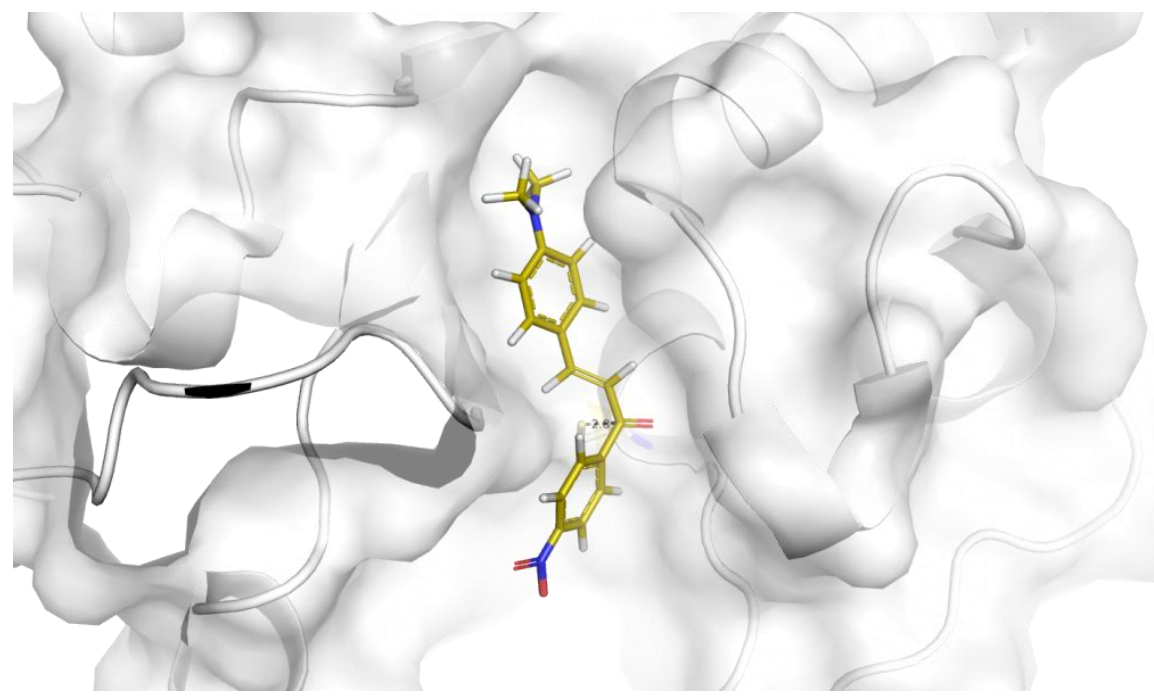

Figura 23. Pose melhor ranqueada no estudo docking para o composto 11.

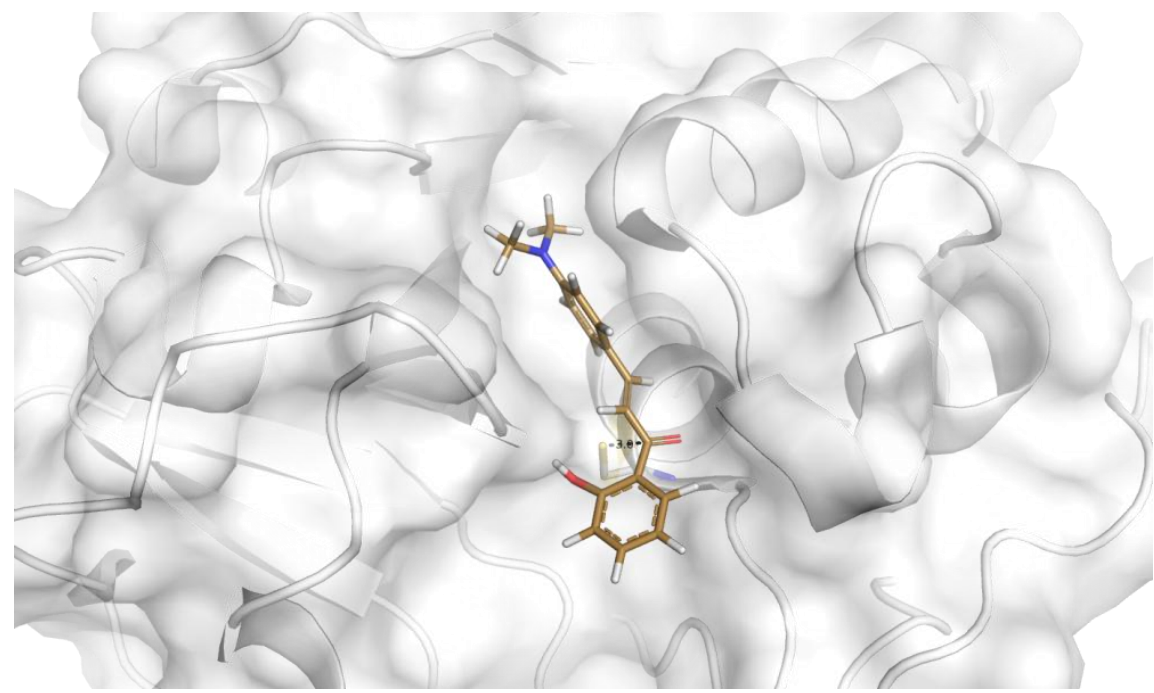

Figura 24. Pose melhor ranqueada no estudo docking para o composto 12.

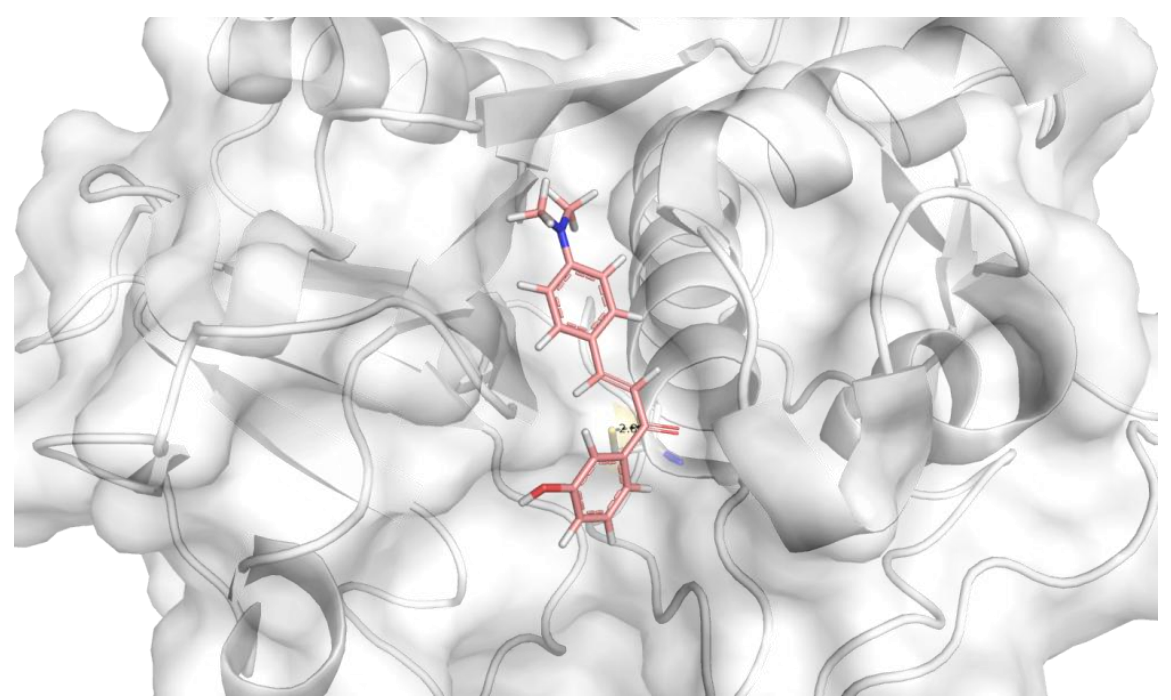

Figura 25. Pose melhor ranqueada no estudo docking para o composto 13. 


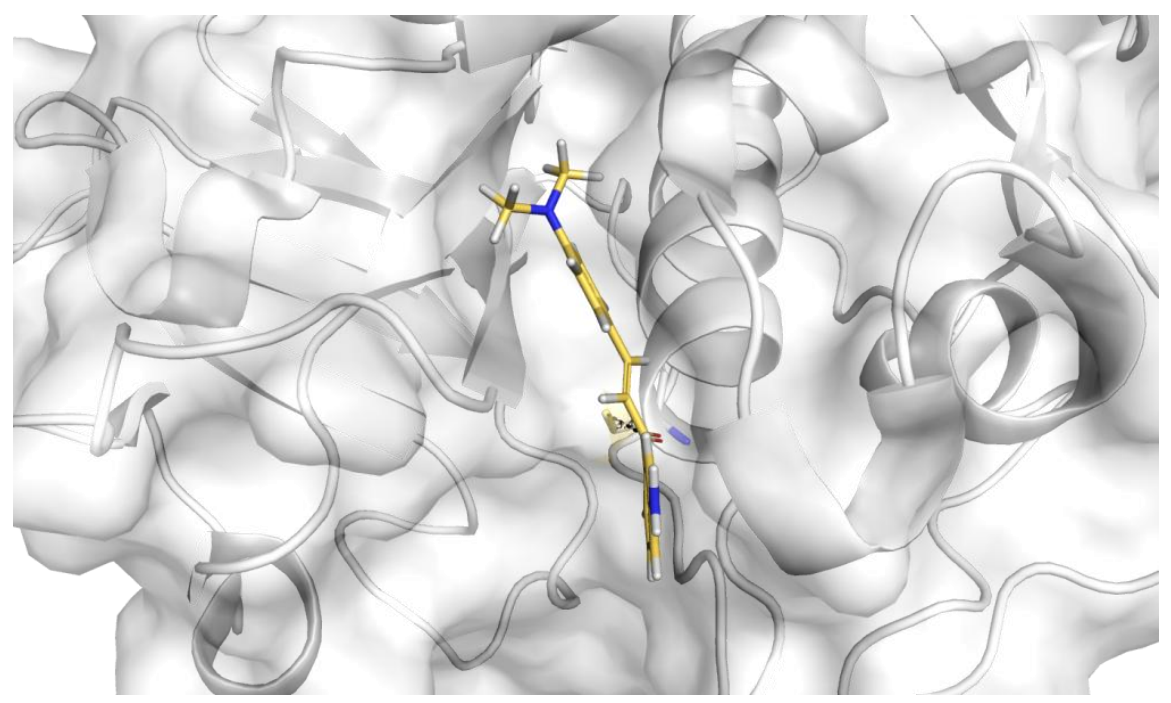

Figura 26. Pose melhor ranqueada no estudo docking para o composto 14.

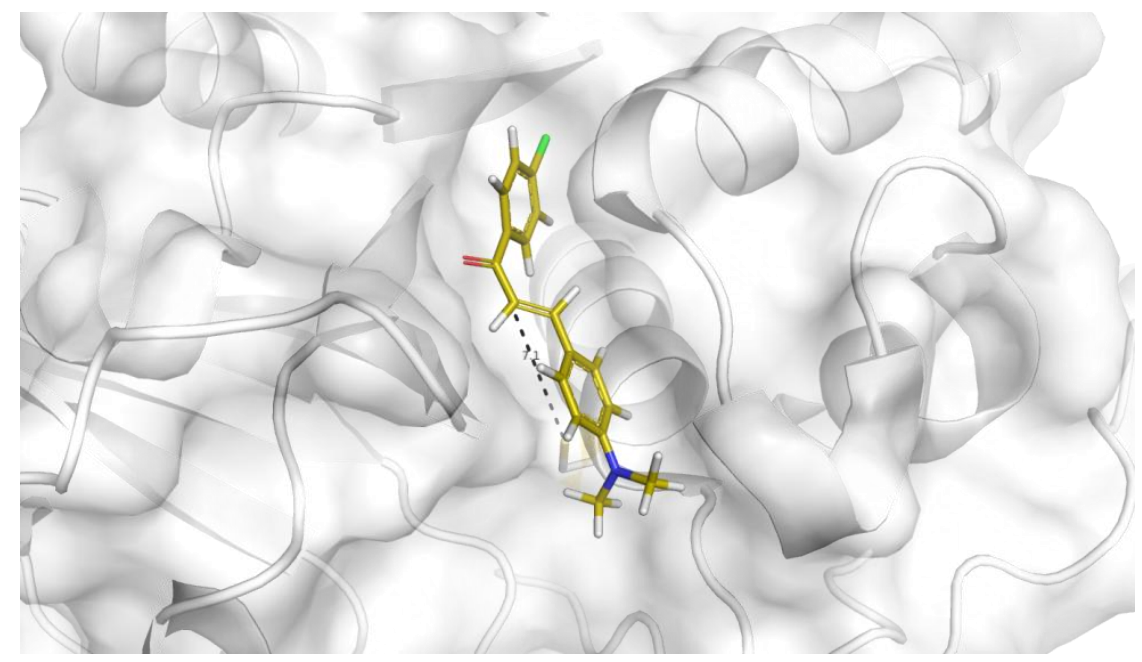

Figura 27. Pose melhor ranqueada no estudo docking para o composto 15.

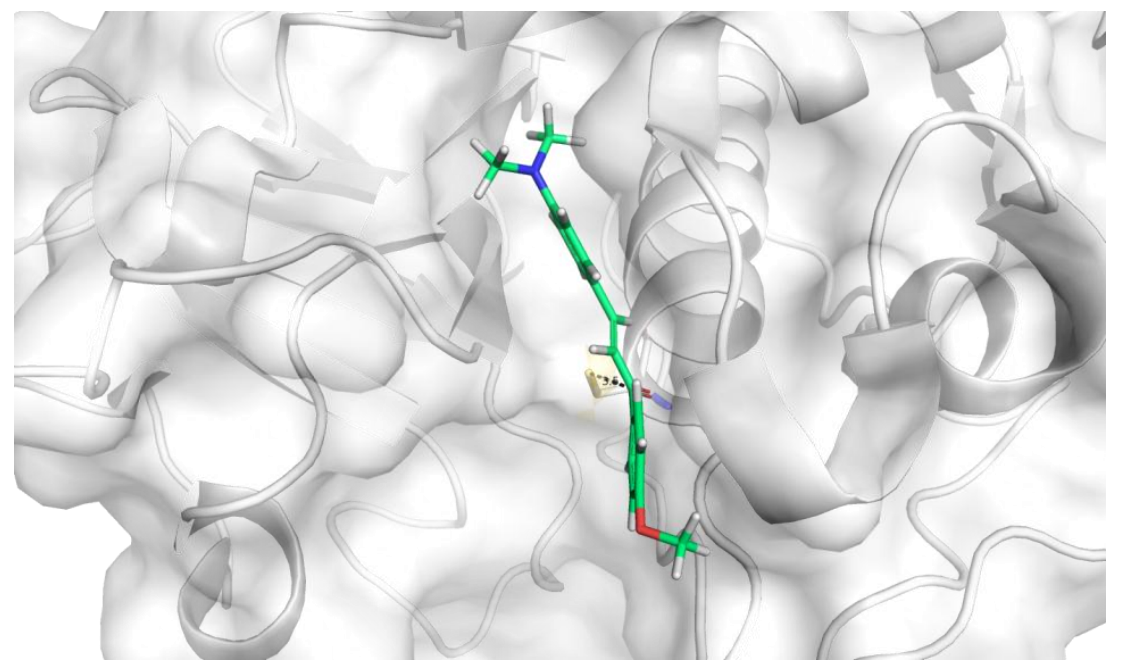

Figura 28. Pose melhor ranqueada no estudo docking para o composto 16. 


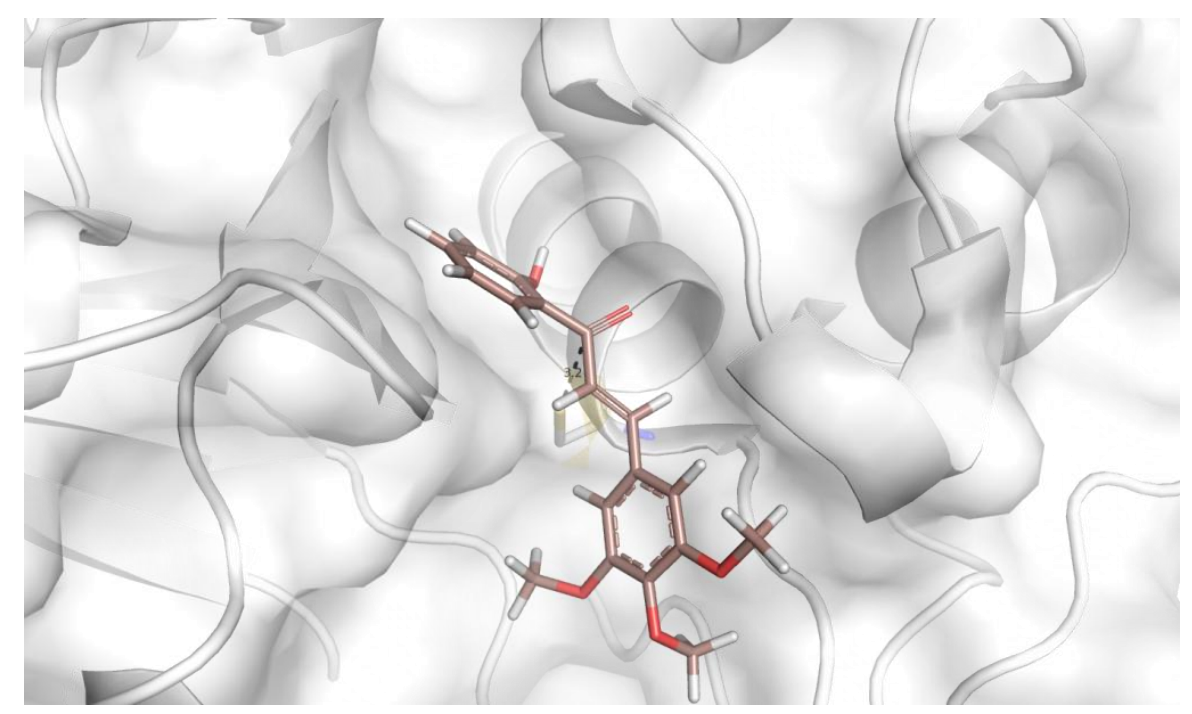

Figura 29. Pose melhor ranqueada no estudo docking para o composto 17.

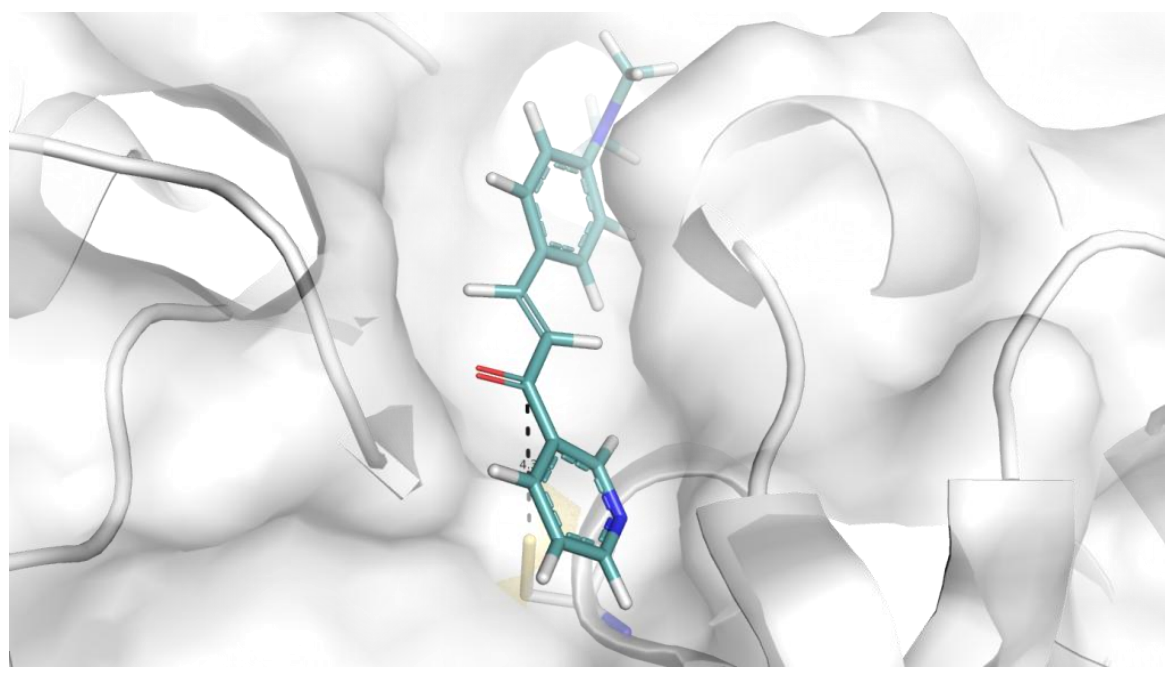

Figura 30. Pose melhor ranqueada no estudo docking para o composto 18.

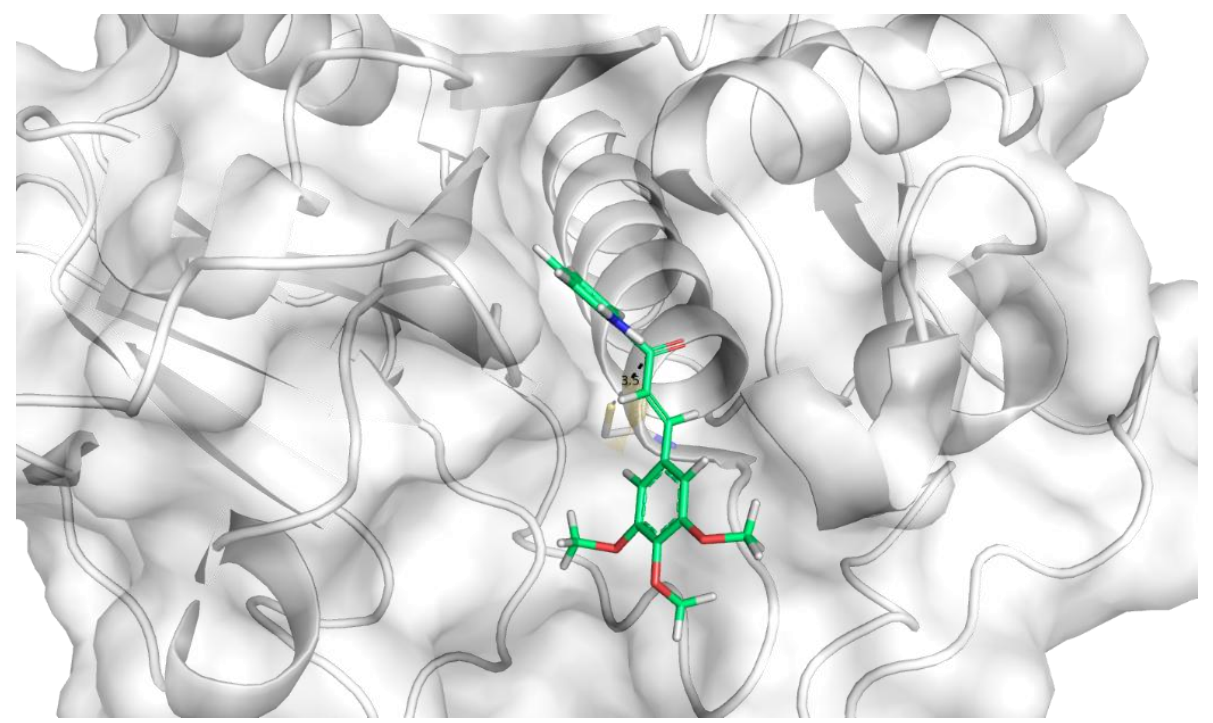

Figura 31. Pose melhor ranqueada no estudo docking para o composto 19. 
Observa-se pelas imagens que, embora as caracterizações por raios- $X$ indicassem somente a estrutura 16 do acervo com conformação s-trans, 0 estudo de docagem molecular, levando em consideração os melhores ranquementos das estruturas de acordo com o anteriormente descrito por Leach e colaboradores, ${ }^{31}$ proporcionou posições diferenciadas para a estrutura 16, sendo s-cis.

Conformações diferentes das observadas na caracterização por raios-X também são evidenciadas na docagem molecular para 9, 11, 13, 14 e 15. Na análise por raios-X são apontadas as conformações s-cis e a docagem molecular tem orientações espaciais das chalconas como $s$-trans.

Entretanto, apesar do apontado acima, o estudo de docagem molecular leva em consideração as melhores poses espaciais das estruturas de acordo com o sítio da proteína, em estrutura cristalográfica.

\subsubsection{Ensaios de Inibição com a Cruzaína de T. cruzi}

Os ensaios de inibição foram realizados em parceria com o Prof. Dr. Gustavo Henrique Goulart Trossini-USP.

Todas as chalconas testadas apresentaram inibição da cruzaína a 100 $\mu \mathrm{M}$, com exceção da estrutura 11, que apresentou se insolúvel, Tabela 1.Devese destacar que, os testes seguiram a metodologia adotada por Blau e colaboradores, $^{32}$ estes testes são com a forma epimastigota do T. cruzi. Embora a forma tripomastigota seja a responsável pela infecção no ser humano, os estudos ${ }^{33}$ apontam que, geralmente, compostos ativos contra a forma epimastigota frequentemente correspondem aos compostos com atividade antitripomastigota.

\footnotetext{
${ }^{32}$ Blau, L.; Menegon, R. F.; Trossini, G. H. G.; Molino, J. V.; Vital, D. G.; Cicarelli, R. M. B.; Passerini, G. D.; Bosquesi, P. L.; Chung, M. C.; Eur. J. Med Chem. 2013, 67, 142.

${ }^{33}$ a) Caputto, M. E.; Ciccareli, A.; Frank, F.; Moglioni, A. G.; Moltrasio, G. Y.; Veja, D.; Lombardo, E.; Finkielsztein, L. M.; Eur. J. Med. Chem. 2012, 55, 155. b) Carneiro, P. F.; Nascimento, S. B.; Pinto, A. V.; Pinto, M. C. F. R.; Lechuga, G. C.; Santos, D. O.; Júnior, H. M. S.; Resende, J. A. L. C.; Bourguignon, S. C.; Ferreira, V. F.; Bioorg. Med. Chem. 2012, 20, 4995. c) Carvalho, S. O.; Feitosa, L. O.; Soares, M.; Costa, T. E. M. M.; Henriques, M. G.; Salomão, K.; Castro, S. L.; Kaiser, M.; Brun, R.; Wardell, J. M.; Wardell, S. M. S. V.; Trossini, G. H. G.; Andricopulo, A. D.; Silva, E. F.; Fraga, C. A. M.; Eur. J. Med. Chem. 2012, 54, 512.
} 
Tabela 1. Resultados dos ensaios de inibição da cruzaína na concentração de $100 \mu \mathrm{M}$.

\begin{tabular}{|c|c|c|c|c|c|}
\hline Chalconas & Estruturas & $\begin{array}{c}\text { \% Inibição } \\
\text { da cruzaína a } \\
100 \mu \mathrm{M}\end{array}$ & Chalconas & Estruturas & $\begin{array}{c}\text { \% Inibição da } \\
\text { cruzaína a } \\
100 \mu \mathrm{M}\end{array}$ \\
\hline 9 & & 180 & 15 & & 31,0 \\
\hline 10 & & 22,5 & 16 & & 31,5 \\
\hline 11 & & insolúvel & 17 & & 18,0 \\
\hline 12 & & 29,0 & 18 & & 61,0 \\
\hline 13 & & 23,0 & 19 & & 33,7 \\
\hline 14 & & 50,0 & & & \\
\hline
\end{tabular}

As estruturas 14 e 18 se mostraram promissoras inibidoras de cruzaína, por inibirem a enzima em 50 e $61 \%$ respectivamente. Para essas estruturas, ensaios de determinação de $\mathrm{IC}_{50}$ (o comportamento tripanocida) serão realizados. A Figura 32 apresenta os dados organizados na forma de gráfico com relação à atividade de inibição à cruzaína. 


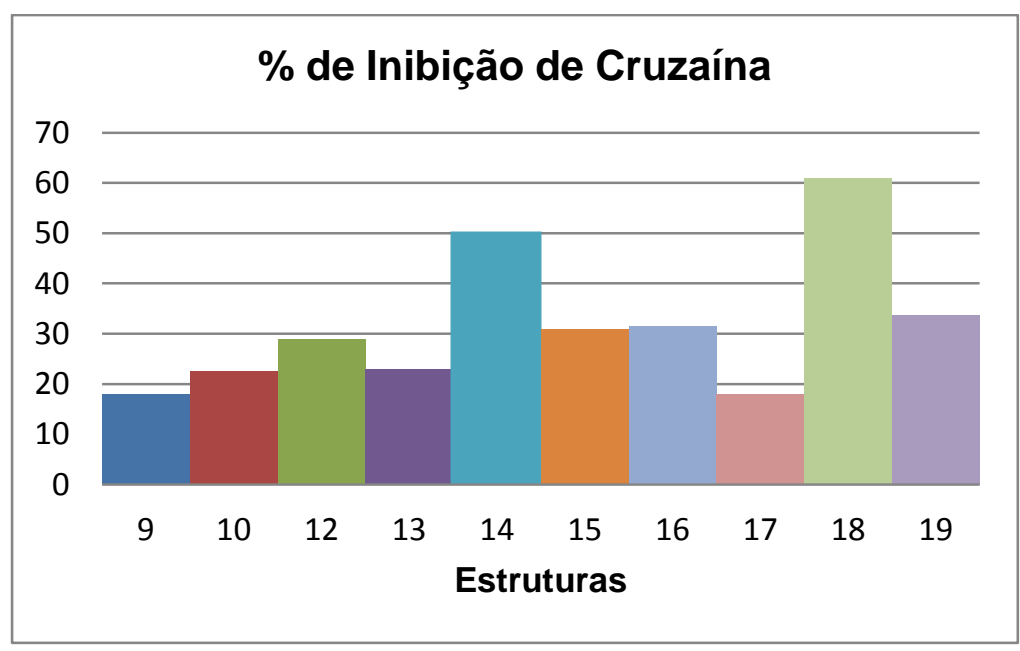

Figura 32. Gráfico da porcentagem de inibição da cruzaína para as estruturas testadas; a estrutura 11 não foi solúvel.

Na pesquisa de Blau e colaboradores, ${ }^{32}$ as estruturas investigadas são tiosemicarbazonas e os testes in vitro para a inibição da cruzaína ocorreram na concentração de $10 \mu \mathrm{M}$ (10 vezes menor que a concentração adotada para as chalconas do acervo). O trabalho desenvolvido para 12 compostos apresenta três deles (Figura 33) com valores de inibição de 50, 55 e 65\%, indicando as maiores potencialidades para o acervo.

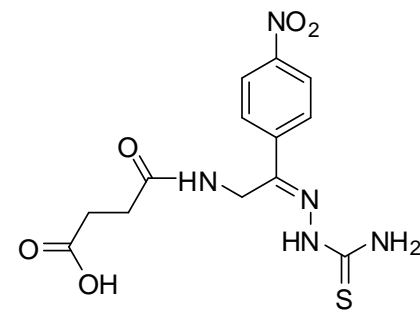

$50 \%$

-amino-1-(4-nitro)acetofenona tiosemicarbazona amida de hemisuccinato

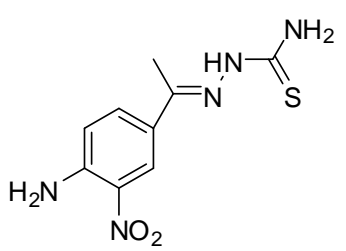

$55 \%$

4-amino-3-nitroacetof enona

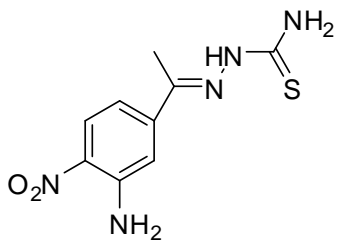

3-amino-4-nitroacetofenona tiosemicarbazona

Figura 33. Tiosemicarbazonas desenvolvidas no trabalho de Blau e colaboradores ${ }^{32}$ e seus respectivos valores de inibição à cruzaina em $10 \mu \mathrm{M}$.

Os resultados para as tiosemicarbazonas, apresentados acima, permitem afirmar que os valores dos testes in vitro de inibição paras os compostos 14 e 18 do estudo realizado para os derivados de chalcona são potencialmente promissores na perspectiva de uso em terapias à doença de Chagas. Entretanto, estudos posteriores devem ser realizados para a determinação de atividade antitripanocida $\left(\mathrm{IC}_{50}\right)$ corroborando, futuramente, para melhor elucidação acerca do comportamento do acervo sintetizado. 
Outro fator investigado foi a coloração emitida pelas chalconas. A justificativa se dá pela forma de monitoramento da análise (espectrofluorimetria) para a determinação da inibição da cruzaína. O padrão para monitoramento foi o cloridrato de Z-Phe-Arg-aminometilcumarina (Z-FRAMC), a adição deste substrato aumenta a fluorescência (355 nm excitação e 460 nm emissão). O gráfico presente na Figura 34 permite afirmar que não há sobreposição da banda luminescente de emissão do padrão com a emissão das chalconas em DMSO (solvente empregado para solubilização), destacando as chalconas 14 e $18 \mathrm{com}$ as emissões ocorrendo em, aproximadamente, $560 \mathrm{~nm}$ para 14 e $582 \mathrm{~nm}$ para 18, com cores verde e laranja, respectivamente.

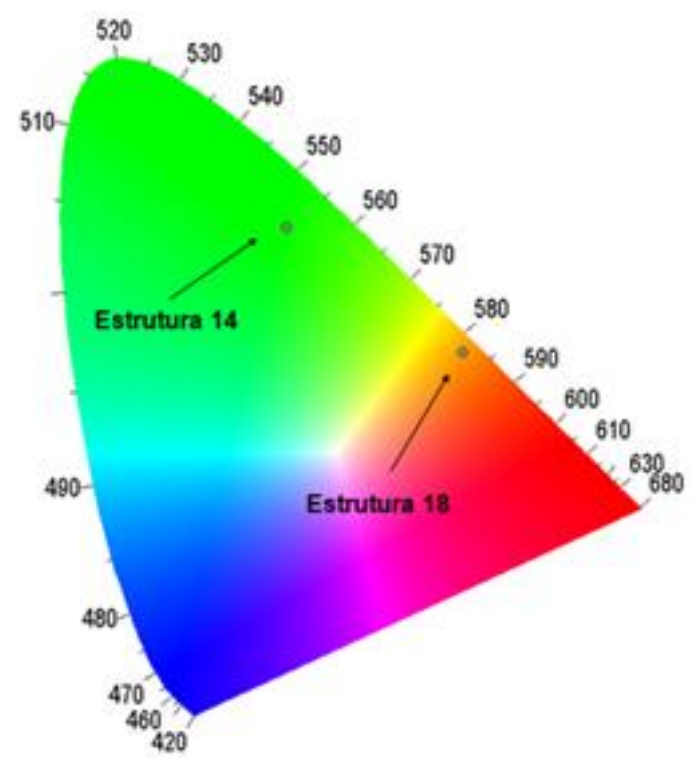

Figura 34. A cor verde e a laranja emitida pelas estruturas 14 e 18 pode ser caracterizada a partir das seguintes coordenadas no diagrama de cromaticidade CIE 1931: (x: 0,287; y: 0,617) e (x: 0,508; y: 0,460), respectivamente.

\subsection{Avaliação Fotofísica}

A avaliação da fotofísica dos derivados foi realizada mediante a análise de absorção e de emissão dos mesmos. Para tal, foram realizadas análises de espectrofotometria e espectrofluorimetria em diferentes solventes: tolueno, acetonitrila, diclorometano, etanol, metanol, dimetilsulfóxido, acetato e hexano.

Nessa etapa do estudo fotofísico, as chalconas foram analisadas em soluções nos respectivos solventes em concentrações de $10 \mu \mathrm{M}$. Água também foi testada, mas as chalconas estudadas não apresentaram boa solubilidade, sendo este solvente descartado após a aquisição dos espectros de absorção. 
$\mathrm{Na}$ Figura 35 tem-se os solvatogramas obtidos para a análise de absorção e de emissão para a chalcona 9. Os demais espectros de absorção e emissão de todos os derivados encontram-se nos anexos (Seção 8.2).
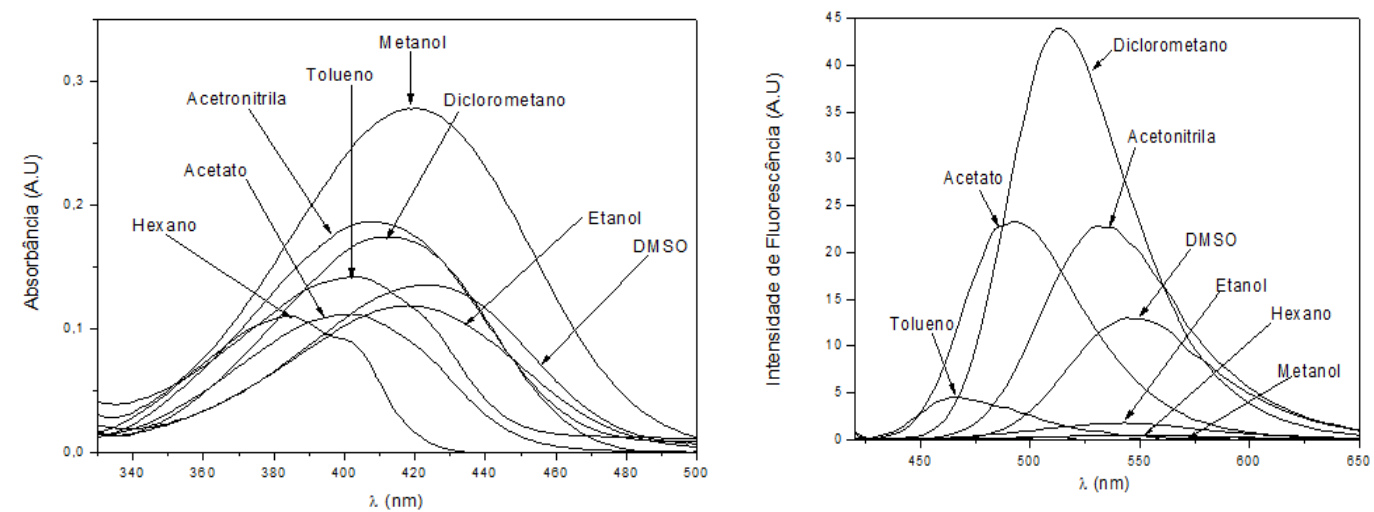

Figura 35. Gráficos de absorção (esquerda) e emissão (direita) para a chalcona 9.

De modo geral, a maioria das estruturas apresentou maior intensidade de absorbância em metanol $(9,13,16)$ e acetato de etila $(\mathbf{1 2}, 17,18)$. Quanto à intensidade de fluorescência ficaram evidenciados o diclorometano $(\mathbf{9}, \mathbf{1 0}, 14$, $15,18)$ e etanol $(11,12,13,17)$.

Segundo o princípio de Franck-Condon todas as transições energéticas são verticais, ${ }^{14}$ ou seja, ocorrem sem modificação de posicionamento do núcleo. Como consequência, a transição com maior probabilidade de ocorrência na absorção se dá entre o estado fundamental $\left(S_{0}\right)$ para o excitado $\left(S_{1}\right)$, portanto a transição recíproca é esperada na emissão. Em resumo, há uma imagem espelhada do espectro de absorção para a emissão, valendo salientar: quando as escalas são ajustadas. Esse fenômeno é observado na Figura 35 para a chalcona 9.

Os solventes polares apresentam bandas deslocadas para maiores comprimentos de onda, quando comparados com solventes não polares, ou seja, quando as curvas são consideradas, diz-se que a curva do metanol tem um efeito de deslocamento para o vermelho (red shift).

Quando esse comportamento é observado no espectro de absorção para solventes polares próticos (etanol e metanol), fica indicado que a transição 
permitida é $\pi-\pi^{*}$ com transferência de carga. ${ }^{34}$ Todas as chalconas possuem esse comportamento na absorção, quando comparados hexano e metanol.

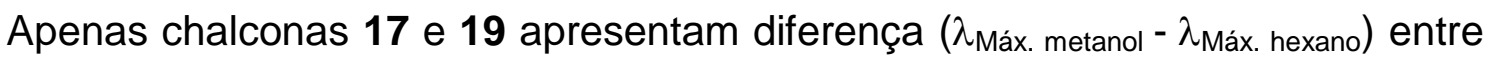
os solventes comparados de poucos nanômetros, 4 e 7 , respectivamente.

No trabalho de Pannipara e colaboradores, ${ }^{34}$ o fenômeno de red shift na emissão é de 85 e 70nm (diferença entre metanol e heptano) para as duas espécies (Figura 36) investigadas, BNP e BTP, respectivamente. Neste fato há indicação de envolvimento de fenômeno de foto indução na transferência interna de carga (ICT). No estado excitado singleto $\left(S_{1}\right)$ a carga do grupo doador de elétrons é direcionada para o ceto grupo (aceptor de elétrons) gerando um grande momento de dipolo. Portanto, o estado excitado singleto $\left(S_{1}\right)$ em comparação com o estado fundamental $\left(S_{0}\right)$ tem maior momento de dipolo $(\mu)$. Esse comportamento é notado para as chalconas $13(92 \mathrm{~nm})$ e 14 (120 nm), quando comparados metanol e hexano.
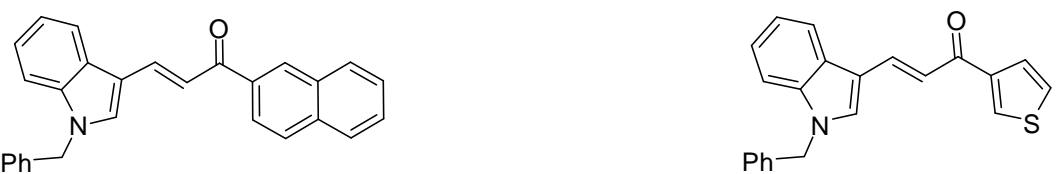

3-(1-Benzil-1 H-indol-3-il)-1-(naftaleno-2-il)prop-2-en-1-ona 3-(1-Benzil-1 $H$-indol-3-il)-1-(tiof en-3-il)prop-2-en-1-ona Figura 36. BNP e BTP, estruturas investigada no trabalho de Pannipara e colaboradores.

As chalconas 9 (26 nm), $10(27 \mathrm{~nm}), 11(22 \mathrm{~nm}), 12(32 \mathrm{~nm}), 15(4 \mathrm{~nm})$, $16(18 \mathrm{~nm}), 18(54 \mathrm{~nm})$ e $19(53 \mathrm{~nm})$, também apresentam estado singleto $\left(\mathrm{S}_{1}\right)$ com maior momento de dipolo que o estado singleto fundamental $\left(\mathrm{S}_{0}\right)$. Entretanto o comportamento da estrutura 17 indica um comportamento contrário quando comparadas as linhas de emissão para hexano e metanol. A linha do metanol não está deslocada para maior comprimento de onda, e sim para comprimento de onda menor, indicando um blue shift. ${ }^{12,18}$ (deslocamento para o azul). Consequentemente, o estado excitado singleto $\left(S_{1}\right)$ da chalcona 17 tem momento de dipolo menor que o seu estado singleto fundamental $\left(S_{0}\right)$, não sendo esse comportamento característico de processo de transferência interna de carga (ICT).

Mais uma observação com relação às linhas de emissão também é pertinente. Algumas das moléculas do acervo apresentam dupla emissão, ou

${ }^{34}$ Pannipara, M.; Asiri, A. M.; Alarmy, K. A.; Arshad, M. N.; El-Daly, S. A.; Spectrochim. Acta, Part A 2015, 136, 1893. 
seja, duas bandas. Esse comportamento é característico das chalconas 11, 12, 13, 16, 19. Segundo Pannipara e colaboradores, ${ }^{34}$ a dupla emissão é característica das chalconas e quaisquer outros compostos que apresentem sistemas de elétrons $\pi$ conjugados com grupos doadores e aceptores na estrutura molecular, ou seja, o sistema D-A-D. A primeira banda (menor comprimento de onda) na dupla emissão é referente ao surgimento de um estado localmente excitado (LE) e a segunda banda (maior comprimento de onda) está associada ao processo de transferência interna de carga (ICT).

Entretanto, moléculas que possuem o grupo $\mathrm{N}, \mathrm{N}$ - dimetilamino nas suas estruturas já são descritas na literatura ${ }^{12,18,35}$ por outro mecanismo de transferência interna de carga (ICT), sendo este a transferência de carga na estrutura torcida (TICT), já citado anteriormente. O deslocamento para maiores comprimentos de onda em comparação do solvente apolar (hexano) com um polar (metanol), seguido de decréscimo na intensidade de fluorescência pode ser explicada pela mudança ICT para TICT na relaxação fotônica da molécula. Esse comportamento é observado nas chalconas 12 a 19.

Vale ressaltar que independentemente da polaridade do solvente, as ligações de hidrogênio devem ser consideradas, uma vez que favorecem deslocamentos para comprimentos de onda maiores (red shift) e menor intensidade de fluorescência, ${ }^{34,}{ }^{35}$ assim como influenciam os processos de relaxação radiativa do fluoróforo em questão.

Outro parâmetro obtido no estudo UV-vis é o deslocamento de Stokes. Ele é obtido pela diferença entre os comprimentos de onda máximos observados para absorção e emissão, para um mesmo solvente. Esse proporciona informações importantes sobre o estado de excitação. Quanto maior o valor deste fica indicado que o estado excitado $\left(S_{1}\right)$ é mais estabilizado, pelo solvente analisado. Em consequência dessa estabilização, maiores comprimentos de onda são atingidos. ${ }^{14}$ As chalconas $13,14,15$ e 18 apresentam valores do deslocamento de Stokes elevados (64-148 nm).

Resumindo e sistematizando os resultados obtidos pelo estudo UV-vis (absorção e emissão) das 11 chalconas do acervo foi gerada a Tabela 2, com

\footnotetext{
${ }^{35}$ Kumar, H.; Chattopadhyay, A.; Prasath, R.; Devaraji, V.; Joshi, R.; Bhavana, P.; Saini, P.; Gohsh, S. K.; J. Phys. Chem. B 2014, 118, 7257.
} 
os maiores comprimentos de onda na absorção e na emissão ( $\left.\lambda_{\max }\right)$, deslocamento de Stokes e coeficiente de absortividade molar $(\varepsilon)$.

Tabela 2. Dados resultantes do estudo fotofísico das onze chalconas em concentração $10 \mu \mathrm{M}$.

\begin{tabular}{|c|c|c|c|c|c|}
\hline Chalcona & Solvente & $\begin{array}{c}\lambda_{\max }(\mathrm{abs}) \\
(\mathrm{nm})\end{array}$ & $\log \varepsilon(\varepsilon)$ & $\begin{array}{c}\lambda_{\max }(\mathrm{em}) \\
(\mathrm{nm})\end{array}$ & $\begin{array}{c}\text { Deslocamento } \\
\text { de Stokes } \\
(\mathrm{nm})\end{array}$ \\
\hline \multirow{8}{*}{9} & AcOEt & 399 & 4,05 (18650) & 492 & 93 \\
\hline & $\mathrm{MeCN}^{\mathrm{a}}$ & 408 & $4,27(18650)$ & 530 & 122 \\
\hline & $\mathrm{CH}_{2} \mathrm{Cl}_{2}$ & 411 & $4,24(17410)$ & 514 & 103 \\
\hline & $\mathrm{MeOH}$ & 420 & $4,45(27950)$ & 556 & 136 \\
\hline & $\mathrm{EtOH}$ & 421 & 4,07 (11790) & 542 & 121 \\
\hline & DMSO & 423 & $4,13(13530)$ & 548 & 125 \\
\hline & Hexano & 384 & $4,04(11000)$ & 530 & 146 \\
\hline & PhMe & 402 & $4,15(14150)$ & 466 & 64 \\
\hline \multirow{8}{*}{10} & AcOEt & 406 & $4,26(18220)$ & 509 & 103 \\
\hline & $\mathrm{MeCN}^{\mathrm{a}}$ & 413 & $4,29(19320)$ & 553 & 140 \\
\hline & $\mathrm{CH}_{2} \mathrm{Cl}_{2}$ & 418 & $4,26(18280)$ & 531 & 113 \\
\hline & $\mathrm{MeOH}$ & 427 & $4,23(16920)$ & 578 & 151 \\
\hline & $\mathrm{EtOH}$ & 424 & $4,24(17390)$ & 559 & 135 \\
\hline & DMSO & 430 & $4,24(17380)$ & 567 & 137 \\
\hline & Hexano & 389 & $3,94(8790)$ & 551 & 162 \\
\hline & PhMe & 408 & $4,23(16860)$ & 481 & 73 \\
\hline \multirow{8}{*}{11} & AcOEt & 434 & $4,13(13370)$ & 499 & 65 \\
\hline & $\mathrm{MeCN}^{\mathrm{a}}$ & 439 & $4,38(23760)$ & 531 & 92 \\
\hline & $\mathrm{CH}_{2} \mathrm{Cl}_{2}$ & 446 & 4,49 (31030) & 516 & 70 \\
\hline & $\mathrm{MeOH}$ & 448 & $4,32(20900)$ & 517 & 69 \\
\hline & $\mathrm{EtOH}$ & 445 & $4,12(13220)$ & 513 & 68 \\
\hline & DMSO & 455 & $4,14(13670)$ & 554 & 99 \\
\hline & Hexano & 418 & $3,64(4340)$ & 495 & 77 \\
\hline & $\mathrm{PhMe}$ & 439 & $3,86(7290)$ & 583 & 144 \\
\hline \multirow{8}{*}{12} & AcOEt & 428 & $4,32(20790)$ & 517 & 89 \\
\hline & $\mathrm{MeCN}^{\mathrm{a}}$ & 435 & $4,24(17540)$ & 578 & 143 \\
\hline & $\mathrm{CH}_{2} \mathrm{Cl}_{2}$ & 437 & $4,23(16850)$ & 590 & 153 \\
\hline & $\mathrm{MeOH}$ & 435 & $4,17(14850)$ & 586 & 151 \\
\hline & $\mathrm{EtOH}$ & 433 & $4,16(14520)$ & 576 & 143 \\
\hline & DMSO & 451 & $4,17(14900)$ & 549 & 98 \\
\hline & Hexano & 409 & $4,20(15850)$ & 554 & 145 \\
\hline & PhMe & 429 & $4,05(11100)$ & 490 & 61 \\
\hline \multirow{8}{*}{13} & AcOEt & 401 & $4,10(12540)$ & 493 & 92 \\
\hline & $\mathrm{MeCN}^{\mathrm{a}}$ & 408 & 4,09 (12390) & 537 & 129 \\
\hline & $\mathrm{CH}_{2} \mathrm{Cl}_{2}$ & 414 & $4,15(14050)$ & 519 & 105 \\
\hline & $\mathrm{MeOH}$ & 420 & $4,20(15970)$ & 545 & 125 \\
\hline & $\mathrm{EtOH}$ & 417 & $3,96(9130)$ & 545 & 128 \\
\hline & DMSO & 423 & $4,10(12660)$ & 543 & 120 \\
\hline & Hexano & 389 & $3,70(5050)$ & 453 & 64 \\
\hline & PhMe & 405 & 3,95 (8970) & 473 & 68 \\
\hline
\end{tabular}




\begin{tabular}{|c|c|c|c|c|c|}
\hline Chalcona & Solvente & $\begin{array}{c}\lambda_{\max }(\mathrm{abs}) \\
(\mathrm{nm})\end{array}$ & $\log \varepsilon(\varepsilon)$ & $\begin{array}{c}\lambda_{\max }(\mathrm{em}) \\
(\mathrm{nm})\end{array}$ & $\begin{array}{l}\text { Deslocamento } \\
\text { de Stokes } \\
(\mathrm{nm})\end{array}$ \\
\hline \multirow{8}{*}{14} & AcOEt & 396 & $4,14(13770)$ & 491 & 95 \\
\hline & $\mathrm{MeCN}^{a}$ & 406 & $4,22(16590)$ & 529 & 123 \\
\hline & $\mathrm{CH}_{2} \mathrm{Cl}_{2}$ & 413 & $4,09(12300)$ & 515 & 102 \\
\hline & $\mathrm{MeOH}$ & 414 & $4,25(17620)$ & 551 & 137 \\
\hline & $\mathrm{EtOH}$ & 414 & $4,01(10220)$ & 535 & 121 \\
\hline & DMSO & 418 & 4,07 (11670) & 535 & 117 \\
\hline & Hexano & 383 & $4,01(10290)$ & 431 & 48 \\
\hline & $\mathrm{PhMe}$ & 401 & $4,12(13250)$ & 463 & 62 \\
\hline \multirow{8}{*}{15} & AcOEt & 407 & $4,19(15550)$ & 505 & 98 \\
\hline & $\mathrm{MeCN}^{a}$ & 415 & $3,83(7010)$ & 549 & 134 \\
\hline & $\mathrm{CH}_{2} \mathrm{Cl}_{2}$ & 420 & $4,19(15380)$ & 527 & 107 \\
\hline & $\mathrm{MeOH}$ & 428 & 4,25 (17690) & 543 & 115 \\
\hline & $\mathrm{EtOH}$ & 425 & 3,99 (9810) & 547 & 122 \\
\hline & DMSO & 430 & $4,27(18460)$ & 563 & 133 \\
\hline & Hexano & 391 & 4,09 (12310) & 539 & 148 \\
\hline & $\mathrm{PhMe}$ & 409 & $4,44(27340)$ & 473 & 64 \\
\hline \multirow{8}{*}{16} & AcOEt & 396 & 4,45 (28320) & 483 & 87 \\
\hline & $\mathrm{MeCN}^{\mathrm{a}}$ & 404 & $4,30(20120)$ & 519 & 115 \\
\hline & $\mathrm{CH}_{2} \mathrm{Cl}_{2}$ & 409 & $4,24(17300)$ & 505 & 96 \\
\hline & $\mathrm{MeOH}$ & 418 & $4,57(37150)$ & 519 & 101 \\
\hline & $\mathrm{EtOH}$ & 414 & $4,23(16940)$ & 541 & 127 \\
\hline & DMSO & 417 & $3,75(5570)$ & 529 & 112 \\
\hline & Hexano & 379 & $4,28(19240)$ & 501 & 122 \\
\hline & $\mathrm{PhMe}$ & 399 & $4,08(11890)$ & 459 & 60 \\
\hline \multirow{8}{*}{17} & AcOEt & 370 & $4,21(16390)$ & 500 & 130 \\
\hline & $\mathrm{MeCN}^{\mathrm{a}}$ & 369 & $3,99(9860)$ & 439 & 70 \\
\hline & $\mathrm{CH}_{2} \mathrm{Cl}_{2}$ & 368 & $4,02(10470)$ & 530 & 162 \\
\hline & $\mathrm{MeOH}$ & 362 & $3,95(8980)$ & 507 & 145 \\
\hline & $\mathrm{EtOH}$ & 366 & $3,83(6690)$ & 469 & 103 \\
\hline & DMSO & 373 & $4,11(12960)$ & 446 & 73 \\
\hline & Hexano & 358 & $4,17(14720)$ & 537 & 179 \\
\hline & $\mathrm{PhMe}$ & 371 & $3,89(7850)$ & 436 & 65 \\
\hline \multirow{8}{*}{18} & AcOEt & 413 & $4,42(26270)$ & 521 & 108 \\
\hline & $\mathrm{MeCN}^{a}$ & 423 & $4,26(18300)$ & 563 & 140 \\
\hline & $\mathrm{CH}_{2} \mathrm{Cl}_{2}$ & 431 & $4,08(12020)$ & 546 & 115 \\
\hline & $\mathrm{MeOH}$ & 434 & $4,29(19310)$ & 581 & 147 \\
\hline & $\mathrm{EtOH}$ & 431 & $4,31(20270)$ & 577 & 146 \\
\hline & DMSO & 437 & $4,15(14160)$ & 581 & 144 \\
\hline & Hexano & 395 & $4,42(26370)$ & 527 & 132 \\
\hline & $\mathrm{PhMe}$ & 417 & $4,30(20040)$ & 491 & 74 \\
\hline \multirow{8}{*}{19} & AcOEt & 392 & $3,93(8520)$ & 502 & 110 \\
\hline & $\mathrm{MeCN}^{\mathrm{a}}$ & 396 & $3,78(5980)$ & 450 & 54 \\
\hline & $\mathrm{CH}_{2} \mathrm{Cl}_{2}$ & 396 & $3,85(7020)$ & 509 & 113 \\
\hline & $\mathrm{MeOH}$ & 396 & $3,89(7760)$ & 492 & 96 \\
\hline & $\mathrm{EtOH}$ & 399 & $3,14(1370)$ & 485 & 86 \\
\hline & DMSO & 416 & $3,51(3210)$ & 478 & 62 \\
\hline & Hexano & 388 & $3,71(5100)$ & 439 & 51 \\
\hline & PhMe & 391 & $3,87(7370)$ & 443 & 52 \\
\hline
\end{tabular}


$\mathrm{Na}$ Tabela 2 visualiza-se que os maiores valores de deslocamentos de Stokes são encontrados nos solventes próticos de maior polaridade para composto 16 em etanol e 18 em metanol. Seguidos de 12 e 19 em diclorometano (solvente polar), 13 e 14 em acetonitrila (solvente polar aprótico).

Apesar das observações realizadas anteriormente, não há nenhum esclarecimento, até o presente momento, mais contundente com relação ao processo de transferência de carga e com relação ao processo de relaxação radiativa das estruturas serem fluorescentes, uma vez que esses fatores são de interesse na investigação realizada no acervo.

Um parâmetro comumente adotado para conclusões acerca do processo de transferência interna de carga é o gráfico de Lippert-Mataga. O gráfico de Lippert-Mataga realizado estabelece uma relação entre o deslocamento de Stokes (Tabela 2) e os parâmetros de polaridade de $\operatorname{Reichardt}^{16},\left(\boldsymbol{E}_{T}^{N}\right)$, Tabela 3.

Tabela 3. Valores de $\boldsymbol{E}_{T}^{N}$ dos solventes utilizados no estudo.

\begin{tabular}{|c|c|}
\hline Solvente & $\mathrm{E}_{\mathrm{T}}^{\mathrm{N}}$ \\
\hline AcOEt & 0,253 \\
\hline $\mathbf{M e C N}^{\mathbf{a}}$ & 0,460 \\
\hline $\mathbf{C H}_{\mathbf{2}} \mathbf{C l}_{\mathbf{2}}$ & 0,309 \\
\hline $\mathbf{M e O H}$ & 0,762 \\
\hline EtOH & 0,654 \\
\hline DMSO & 0,444 \\
\hline Hexane & 0,009 \\
\hline PhMe & 0,099 \\
\hline
\end{tabular}

Segundo Pannipara e colabororadores, ${ }^{34,36}$ o gráfico de Lippert-Mataga (deslocamento de Stokes versus $\Delta f$ - orientação de polarização do solvente) leva em consideração apenas os efeitos de dipolo-dipolo e não considera a polarização de moléculas solubilizadas. O parâmetro de polaridade surge na reconsideração da relação de Lippert-Mataga, ocorrendo por meio de uma derivação. $^{12,14,18}$

${ }^{36}$ Pannipara M.; Asiri, A. M.; Alamry, K. A.; Arshad, M. N.; El-Daly, S. A.; J. Fluoresc. 2014, 24, 1629. 
Entretanto, vale salientar que apesar da derivação e a consideração de polarização, a equação de Lippert- Mataga é apenas uma aproximação, uma vez que o solvente é tido como um meio contínuo, efeitos de polarização das moléculas investigadas (os fluoróforos) são ignorados e assume que os momentos de dipolo do estado excitado e o fundamental têm o mesmo direcionamento espacial. ${ }^{12,18}$

Os gráficos Lippert-Mataga foram construídos para se avaliar a contribuição do processo ICT do fluoróforo. A inclinação da reta é proporcional à diferença dos momentos de dipolo do estado excitado e do estado fundamental. Vide anexos (Seção 8.3).

Em termos práticos, tem-se como parâmetro a sensibilidade do solvente para um fluoróforo com a obtenção de um gráfico. Os fluoróforos mais sensíveis são os que têm uma grande mudança no momento dipolo no estado excitado e, por consequência, maior é a influência do solvente na estabilização no estado excitado, ou seja, os que apresentarem maior inclinação da reta. ${ }^{12,14}$ Em conclusão, as chalconas mais sensíveis da série são: 14 e 13. Tabela 4.

Tabela 4. Dados extraídos dos gráficos de Lippert- Mataga: equação da reta e fator de correlação $\left(R^{2}\right)$.

\begin{tabular}{|c|c|c|}
\hline Chalcona & Equação & $\mathbf{R}^{\mathbf{2}}$ \\
\hline $\mathbf{9}$ & $\mathrm{y}=5160,3+361,8 \mathrm{x}$ & 0,160 \\
\hline $\mathbf{1 0}$ & $\mathrm{y}=5467,3+394,0 \mathrm{x}$ & 0,160 \\
\hline $\mathbf{1 1}$ & $\mathrm{y}=4334,2-1823,0 \mathrm{x}$ & 0,150 \\
\hline $\mathbf{1 2}$ & $\mathrm{y}=4532,9+1437,1 \mathrm{x}$ & 0,060 \\
\hline $\mathbf{1 3}$ & $\mathrm{y}=3754,0+2974,9 \mathrm{x}$ & 0,730 \\
\hline $\mathbf{1 4}$ & $\mathrm{y}=3323,6+3935,6 \mathrm{x}$ & 0,820 \\
\hline $\mathbf{1 5}$ & $\mathrm{y}=5247,0-157,9 \mathrm{x}$ & 0,160 \\
\hline $\mathbf{1 6}$ & $\mathrm{y}=4867,6+282,5 \mathrm{x}$ & 0,160 \\
\hline $\mathbf{1 7}$ & $\mathrm{y}=6773,0-937,7 \mathrm{x}$ & 0,150 \\
\hline $\mathbf{1 8}$ & $\mathrm{y}=4922,2+1249,0 \mathrm{x}$ & 0,002 \\
\hline $\mathbf{1 9}$ & $\mathrm{y}=3543,9+1458,5 \mathrm{x}$ & 0,050 \\
\hline
\end{tabular}

O fator de correlação linear, $\mathrm{R}^{2}$, indica a influência do processo ICT na molécula. Valores acima de 0,7 significam alta estabilização no processo ICT, ou seja, não ocorrem distorções espaciais significativas no estado excitado da molécula. Pode-se observar que para a série em estudo somente duas estruturas, 13 e 14, apresentam eficiência no processo ICT. 
Pode se inferir que as demais estruturas têm a relaxação por mecanismos não radiativos, observando que o processo de transferência interna de carga (ICT) não é pronunciado.

Para maior elucidação acerca de chalconas contendo o grupo N,Ndimetilamino, o trabalho teórico de Komarova e colaboradores $^{37}$ traz $^{3}$ considerações relevantes ao estudo, com relação aos mecanismos de relaxação radiativa, que podem ocorrer por meio de fosforescência (fenômeno não investigado no acervo de chalconas).

Segundo Komarova ${ }^{37}$, as chalconas não possuem estrutura planar no seu estado fundamental e existem dois ângulos torcionais na sua estrutura, um denominado $\theta$, referente ao anel aromático proveniente da acetofenona $(A)$ empregada na síntese e um segundo $\phi$, do fragmento do benzaldeído (B). Figura 37.

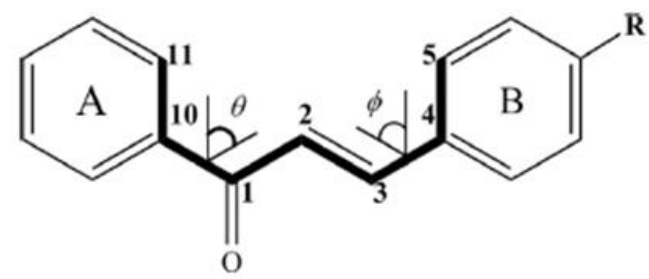

Figura 37. Ângulos torcionais para a chalcona com grupo N,N-dimetilamino, segundo Komarova e colaboradores. ${ }^{37}$

O ângulo $\theta$ é maior que $\phi$, o que subsidia o fato do anel aromático $B$ ser mais conjugado com a ponte ceto-vinílica que o anel $A$. Os cálculos do grupo demonstraram que o ângulo $\theta$ não sofre grandes variações decorrentes do efeito dipolo-dipolo nem mesmo em solventes polares. Em contrapartida solventes polares modificam demasiadamente o comportamento do anel B (contendo o grupo $\mathrm{N}, \mathrm{N}$-dimetilamino), afetando diretamente o ângulo $\phi$. Foi observado que, a estrutura assume, em etanol, estrutura planar, o que é um pré-requisito para a ocorrência da luminescência.

Apesar de ser esperado um aumento no efeito luminescente isto não é observado em solventes polares próticos, uma vez que ocorre o favorecimento do estado tripleto (fosforescência), ou seja, interconversão intersistemas no diagrama de Jablonski.

${ }^{37}$ Komarova, K. G.; Sakipov, S.N.; Plotnikov, V.G.; Alfimov, M.V.; J.Lumi. 2015, $164,57$. 
Outro parâmetro muito importante no estudo fotofísico é o rendimento quântico. ${ }^{34,36} \mathrm{O}$ rendimento quântico é uma relação entre número de fótons emitidos pelo fluorófolo dividido pelo total de fótons absorvidos por este, como mencionado anteriormente. A partir da determinação deste parâmetro fotofísico, aplicações como marcação celular são vislumbradas. ${ }^{11,38}$

Para a determinação do rendimento quântico utilizou-se sulfato de quinina como padrão de comparação. Esta metodologia já está amplamente discutida na literatura ${ }^{12,18,32,36,39}$

A leitura de absorção é realizada na solução de sulfato de quinina e confronta-se a curva obtida com a curva de absorção do fluorófolo (chalcona) em acetonitrila, a fim de aferir o intercepto, ou seja, o ponto isosbéstico. No ponto isobéstico as soluções têm a mesma concentração e coeficiente de absortividade molar igual. Com o valor do ponto isosbéstico (em $\mathrm{nm}$ ) a solução de quinina e soluções em acetonitrila de cada chalcona foram excitadas e os espectros de emissão obtidos. A partir dos espectros de emissão, as áreas são integradas e obtém se o rendimento quântico com relação ao sulfato de quinina.

A seguinte relação matemática é utilizada: ${ }^{12,18}$

$$
\Phi_{\mathrm{x}}=\Phi_{\mathrm{sq}}\left(\operatorname{Grad}_{\mathrm{x}} / \mathrm{Grad}_{\mathrm{sq}}\right)\left(\mathrm{n}_{\mathrm{x}}{ }^{2} / \mathrm{\eta}_{\mathrm{sq}}{ }^{2}\right) \quad \mathrm{Eq} 1
$$

Sendo $\Phi_{\text {sq }}$ o rendimento quântico descrito para o sulfato de quinina, o termo Grad é referente ao gradiente da área integrada de fluorescência e $\eta$ o índice de refração do solvente. Todos os termos assimilados com " $x$ " são referentes à amostra que se quer determinar o valor de rendimento quântico. Especificamente, para este trabalho, as chalconas.

O valor adotado de referência para a solução de sulfato de quinina foi de 0,50 e os resultados obtidos encontram-se na Tabela 5.

\footnotetext{
${ }^{38}$ Lee, S.; Kang, N.; Park, S.; Yun, S.; Chandran, Y.; Chang, T.; Chem. Commun. 2012, 48, 6681.

${ }^{39}$ Velapoldi, R. A.; Tonnesen, H. H.; J. Fluores. 2004, 14, 465.
} 
Tabela 5. Dados de rendimento quântico obtidos pela metodologia do isosbéstico.

\begin{tabular}{|c|c|c|}
\hline Chalconas & Ponto isosbéstico (nm) & Rendimento quântico (Ф) \\
\hline $\mathbf{9}$ & 338,0 & 0,030 \\
\hline $\mathbf{1 0}$ & 348,4 & 0,060 \\
\hline $\mathbf{1 1}$ & 254,5 & 0,002 \\
\hline $\mathbf{1 2}$ & 365,1 & 0,004 \\
\hline $\mathbf{1 3}$ & 356,4 & 0,110 \\
\hline $\mathbf{1 4}$ & 342,0 & 0,100 \\
\hline $\mathbf{1 5}$ & 365,1 & 0,110 \\
\hline $\mathbf{1 6}$ & 340,0 & 0,140 \\
\hline $\mathbf{1 7}$ & 306,6 & 0,010 \\
\hline $\mathbf{1 8}$ & 356,7 & 0,010 \\
\hline $\mathbf{1 9}$ & 260,8 & 0,008 \\
\hline
\end{tabular}

As chalconas que apresentaram melhor rendimento quântico $(\phi)$, nesta metodologia, de acordo com a Tabela 5 foram 13, 15 e 16, sendo respectivamente, 0,$11 ; 0,11$ e 0,14 . Valores relativamente baixos.

Entretanto, Lackowicz ${ }^{12}$ apresenta considerações acerca do uso do sulfato de quinina como referência: não há um comportamento linear desse referencial com relação à valores de comprimentos de onda usados para a excitação. Portanto trabalhos comparativos com as soluções de sulfato de quinina devem ser estabelecidos nos valores de $350 \mathrm{~nm}$ e $366 \mathrm{~nm}$ para a excitação, com valores de rendimento quântico de 0,577 e 0,53 \pm 0,023, respectivamente.

Avaliando as considerações acima apontadas o estudo de rendimento quântico foi novamente realizado. As chalconas em acetonitrila foram comparadas ao sulfato de quinina e o comprimento de onda para a excitação foi o de 366nm. A escolha se deu em função da proximidade do valor (366 nm) com a usada nas lâmpadas de laboratório para acompanhamento em CCD, sendo de $365 \mathrm{~nm}$. As determinações foram realizadas de acordo com a relação matemática anteriormente descrita e os dados encontram-se na Tabela 6. 
Tabela 6. Dados de rendimento quântico para as chalconas, comparativo com sulfato de quinina e com excitação em $366 \mathrm{~nm}$, acompanhadas de erro.

\begin{tabular}{|c|c|c|}
\hline Chalcona & $\mathbf{\Phi}$ & Erro \\
\hline $\mathbf{9}$ & 0,562 & 0,193 \\
\hline $\mathbf{1 0}$ & 0,362 & 0,005 \\
\hline $\mathbf{1 1}$ & 0,013 & 0,007 \\
\hline $\mathbf{1 2}$ & 0,016 & 0,006 \\
\hline $\mathbf{1 3}$ & 0,617 & 0,111 \\
\hline $\mathbf{1 4}$ & 0,697 & 0,021 \\
\hline $\mathbf{1 5}$ & 0,406 & 0,009 \\
\hline $\mathbf{1 6}$ & 0,871 & 0,075 \\
\hline $\mathbf{1 7}$ & 0,013 & 0,007 \\
\hline $\mathbf{1 8}$ & 0,070 & 0,012 \\
\hline $\mathbf{1 9}$ & 0,014 & 0,008 \\
\hline
\end{tabular}

Os dados encontram-se organizados com erro para cada determinação de rendimento quântico, decorrente das determinações terem se dado em triplicata. O erro é o desvio padrão entre os valores obtidos pela equação matemática (já descrita) para a determinação do valor de rendimento quântico das amostras investigadas. Pode-se verificar que essa determinação de rendimento quântico, apresentada na Tabela 6, é muito discrepante dos valores apresentados na Tabela 5. Vale ressaltar, que a metodologia para a aquisição dos resultados apresentados na Tabela 6 é melhor respaldado na literatura. ${ }^{12,}$ $18,32,34,36$

Os resultados indicam a chalcona 16 com o maior rendimento quântico do acervo produzido, $\Phi=0,871 \pm 0,075$. Esse resultado é concordante com o planejado na síntese das chalconas de acordo com o design D-A-D (doadoraceptor-doador), uma vez que em posicionamento para no anel aromático $A$ (precursor sintético proveniente da acetofenona), tem-se o grupo metoxi ($\mathrm{OCH}_{3}$ ), sendo um doador de elétrons para a arquitetura molecular dessa chalcona.

Concordante com o design D-A-D há também as estruturas 13 e $14 \mathrm{com}$ grupos doadores de elétrons nas posições meta do anel $A$, sendo respectivamente, grupo hidroxi $(-\mathrm{OH})$ e grupo amino $\left(-\mathrm{NH}_{2}\right)$.

Adotando como modelo a chalcona 9, devido a sua simplificação estrutural não contando com substituições no anel $A$, pode-se estabelecer 
relações. Quando com a chalcona 10 a presença do anel aromático na posição para no anel $A$ tem efeito desativador do design $D-A-D$, portanto é evidenciado um efeito retirador de elétrons. A mesma relação pode ser traçada com a chalcona 15, uma vez que halogênios são descritos por possuírem efeito doador de densidade eletrônica e também retirador, para a arquitetura adotada (-Cl em para no anel A) o caráter retirador é característico. A inserção de heteroátomo no anel $A$, como observado na chalcona 18 não se mostrou eficiente para o design D-A-D. Com relação à estrutura 11 fica evidente o efeito retirador de densidade eletrônica promovido pelo grupo nitro $\left(-\mathrm{NO}_{2}\right)$ na posição para do anel $A$.

Já as estruturas 12, 17 e 19 têm em comum a presença de grupos hidroxi $(-\mathrm{OH})$, para as duas primeiras e grupo amino $\left(-\mathrm{NH}_{2}\right)$ na última, em posição orto no anel $A$. Os resultados de rendimento quântico foram baixos, quando comparados com as demais chalconas, podendo ser justificados pela perda do design D-A-D para a estrutura já que ligações de hidrogênio intramolecular são favorecidas. ${ }^{40} \mathrm{O}$ trabalho de Jagadeesh e colaboradores ${ }^{40}$ foi realizado com hidroxichalconas, para chalconas contendo o grupo hidroxi na posição orto (ou 2'-hidroxi) no anel A apresenta esse comportamento, ocorrendo inclusive isomerização da molécula de conformação cis para trans também influenciando propriedades espectroscópicas.

Em resumo, as chalconas que apresentaram grupos doadores no planejamento de molécula com design D-A-D (ou push-pull) são as mais promissoras para exploração de propriedades fotônicas, como: dispositivos óticos não lineares, ${ }^{41,42}$ para a compreensão de processos fotoquímicos, ${ }^{43,44} \mathrm{e}$ sensor químico. ${ }^{45,46}$

\footnotetext{
${ }^{40}$ Jagadeesh, M.; Lavanya, M.; Babu, B. H.; Hong, K.; Ma, R.; Kim, J.; Kim, T. K.; Spectrochim. Acta, Part A 2015, 150, 557.

41 Arias, A.C.; MacKenzie, J.D.; McCulloch, I.; Rivnay, J.; Salleo, A.; Chem. Rev. 2010, 110,3.

42 Rahulan, K.M.; Balamurugan, S.; Meena, K.S.; Yeap, G.; Kanakam, C.C.; Opt. Laser Technol. 2014, 56, 142.

${ }^{43}$ Grabowski, Z.R.; Rotkiewicz, K.; Rettig, W.; Chem. Rev. 2003, 103, 3899.

${ }^{44}$ Chipem, F.A.S.; Mishra, A.; Krishnamoorthy, G.; Phys. Chem. Chem. Phys. 2012, 14, 8775.

${ }^{45}$ Li, Q.; Peng, M.; Li, H.; Zhong, C.; Zhang, L.; Cheng, X.; Peng, X.; Wang, Q.; Qin, J.; Li, Z.; Org. Lett. 2012, 14, 2094.

${ }^{46}$ Fayed, T. A.; Chem. Phys. 2006, 324, 631.
} 


\section{Microfios}

A técnica de electrospinning tem tido investigações interessantes na ciência, no sentido de aquisição de materiais, com ênfase para redes poliméricas como precursoras, com potencialidades tecnológicas das mais variadas possíveis. Entre elas pode-se citar: sensores ópticos, biossensores, membranas de filtração, sistema de administração de medicamentos, entre outras. ${ }^{47,48}$

O interesse em redes poliméricas é justificado na busca de estruturas ultraleves, porém resistentes para o desenvolvimento de novos dispositivos, assim como o grande apelo na obtenção de sistemas miniaturizados. ${ }^{49}$

A técnica de electrospinning consiste na utilização de alta voltagem (de 10 a 20 kV) para produção de fibras de pequenos nanômetros a mais largas que $5 \mu \mathrm{m}$. A alta voltagem é usada para que ocorra o carregamento elétrico da solução polimérica na ponta da seringa, sendo a esta preenchida com a solução. A ponta da seringa serve como um eletrodo e o contra eletrodo é conectado ao anteparo de eletrodeposição. Com a aplicação da alta voltagem o campo eletrostático é forte o suficiente para acelerar o polímero eletronicamente carregado (na ponta da seringa) na direção do coletor. ${ }^{49}, 50$ Destacando-se que durante esse processo o solvente evapora e há a deposição de fibras.

O sistema é bem simples e, por isso, tem se tornado muito atraente. A seringa de calibre com material em seu interior pode ter sua vazão controlada por uma bomba de injeção. Na ponta da agulha é aplicado um gradiente de alta tensão gerada por uma fonte de alimentação, sendo gerado o cone de Taylor. ${ }^{49}$ As fibras formadas são aceleradas na direção de um coletor metálico, no qual se depositam, Figura 38.

\footnotetext{
${ }^{47}$ Agrarwal, S.; Greiner, A.; Wendorff, J. H.; Prog. Polym. Sci. 2013, 38, 963.

48 Davis, B. W.; Niammont, N.; Hare, C. D.; Sukwattanasinitt, M.; Cheng, Q.; ACS Appl. Mater. Interfaces, 2010, 2, 1798.

49 Baji, A.; Mai, Y.; Wong, S.; Abtahi, M.; Chen, P.; Compos. Sci. Technol. 2010, 70, 703.

${ }^{50}$ Chakraborty, S.; Liao, I. C.; Adler, A.; Leong, K. W.; Adv Drug Deliv Rev. 2009, 61,1043.
} 


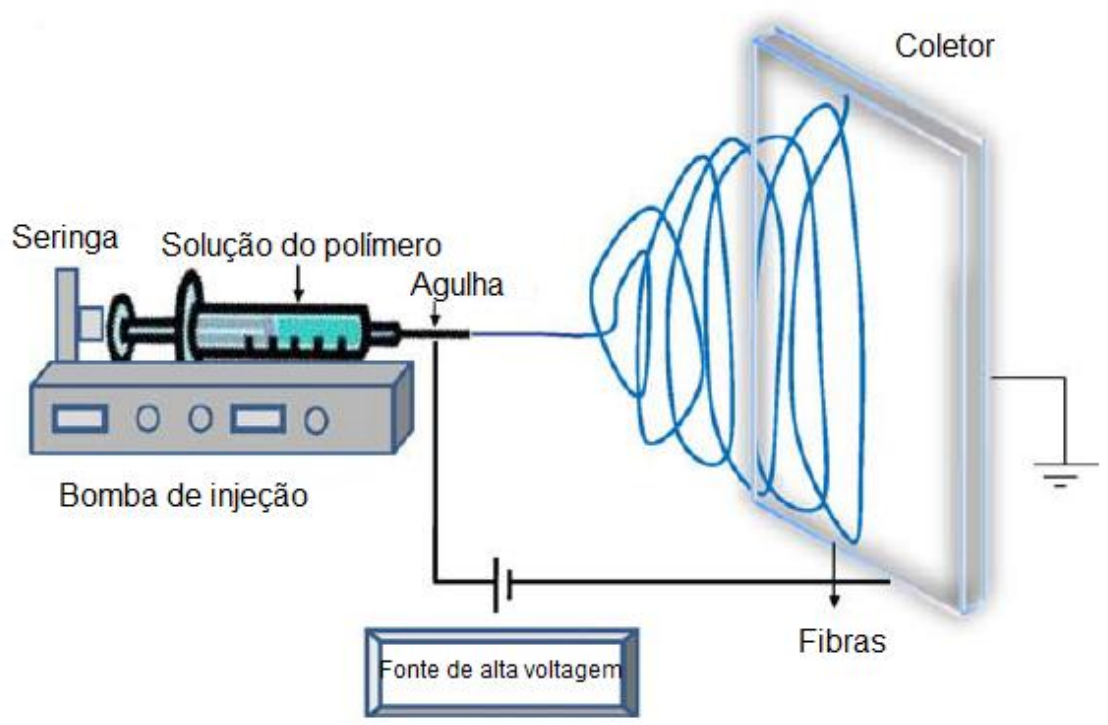

Figura 38. Configuração típica de electrospinning vertical usado para a produção de microfios. Imagem adaptada da referência $51 .{ }^{51}$

A produção de microfios ou nanofios (dependendo da dimensão das fibras adquiridas) se dá por meio da técnica de electrospinning, sendo um dos métodos mais simples e econômicos para produção dessas fibras. Os materiais obtidos apresentam elevada área superficial e possibilitam um controle hierárquico eficiente na fabricação de nanoestruturas complexas. ${ }^{52,53}$

A possibilidade de emprego da técnica concomitante com a pesquisa desenvolvida e explanada anteriormente, se dá no uso do acervo das chalconas fluorescentes produzidas para a aquisição, via dispersão em matriz polimérica, no desenvolvimento de materiais com uma dimensão (1D) que possam ser explorados no desenvolvimento de sensores, diodos, laser, armazenamento de dados, por exemplo. ${ }^{47}$

Ao final das eletrodeposições as imagens obtidas são similares às apresentadas no trabalho de Chai e colaboradores,$^{54}$ em que se observa claramente a dispersão do material na rede polimérica, no caso PVP (pilovinilpirrolidona).

\footnotetext{
${ }^{51}$ Bhardwaj, N.; Kundu, S. C.; Biotechnol. Adv. 2010, 28, 325.

${ }^{52}$ Chen, J. S.; Xu, L.; Xing, R. Q.; Song, J.; Song, H. W.; Liu, D. L.; Zhou, J. Electrochem. Commun. 2012, 20, 75.

${ }^{53}$ Sahay, R.; Kumar, P. S.; Sridhar, R.; Sundaramurthy, J.; Venugopal, J.; Mhaisalkar, S. G.; Ramakrishna, S.; J. Mater. Chem. 2012, 22, 12953.

${ }^{54}$ Chai, J. H; Wu, Q. S.; Belstein. J. Nanotechnol. 2013, 4,189.
} 


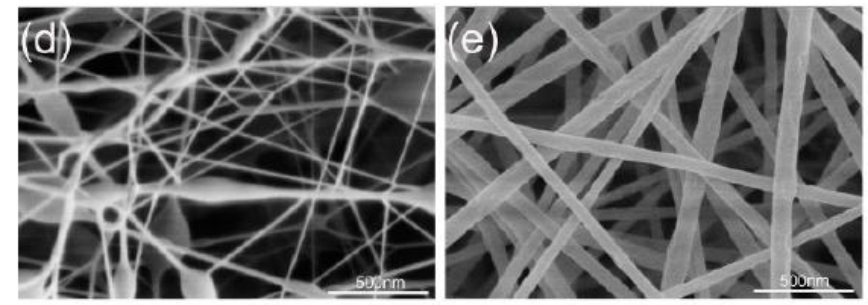

Figura 39. MEV de microfios produzidos com ferroceno/PVP, com $25 \%$ e $30 \%$, respectivamente d) e e). Voltagem de $10 \mathrm{kV}$ e distância de $15 \mathrm{~cm} .{ }^{54}$

\subsection{Metodologia}

Inicialmente foram testadas soluções de 20, 30 e 40, 50 e 60\% de PVP (polivinilpirrolidona) em etanol, porcentagem para relação massa/massa. Após testes no sistema de electrospining, a solução de $60 \%$ apresentou melhor viscosidade para a execução dos microfios. As condições de trabalho foram adequadas de forma que a distância entre o sistema de deposição (placas de microscópio) e injeção (ponta da agulha) fosse de $10 \mathrm{~cm}$. A diferença de potencial aplicada ao sistema foi de $10 \mathrm{kV}$ e a vazão condicionada na bomba de injeção foi de $2,4 \mathrm{ml} / \mathrm{h}$, vide Figura 40.
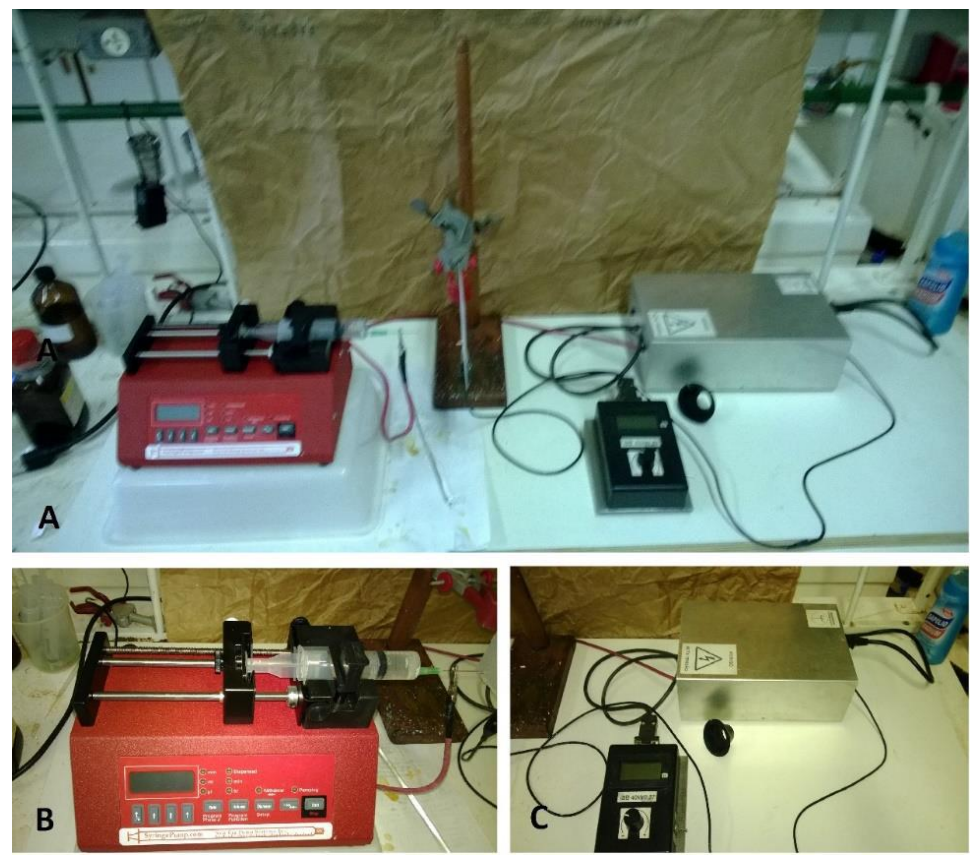

Figura 40. Sistema de electrospinning completo (A), bomba ide injeção usada para controlar o fluxo de vazão da solução do polímero (B) e fonte de alta tensão $(C){ }^{55}$

55 Dissertação de Mestrado da Universidade de Brasília, aluno Matheus Serra de Holanda, 2012, 21. 
O uso de chalcona para dopagem da matriz polimérica ficou condicionada a $1 \%$ com relação à massa de PVP adotada no preparo da solução descrita acima, exceto para a estrutura 12, cuja dopagem adotada foi a 0,5\%, devido a problemas de solubilidade.

Placas de microscópio foram cortadas $(1,3 \times 1,7 \mathrm{~cm})$ e a limpeza, com o intuito de garantir a inexistência de gordura na superfície, foi executada na sequência: água, etanol, acetato, clorofórmio e hexano, por cinco minutos cada solvente, em ultrassom.

Os sistemas para deposição dos microfios foram construídos em arame. Um em formato de retângulo e o outro como infinito (com um elo aberto) onde a placa de microscópio foi fixada por meio de dois conectores do tipo jacaré, Figura 41.

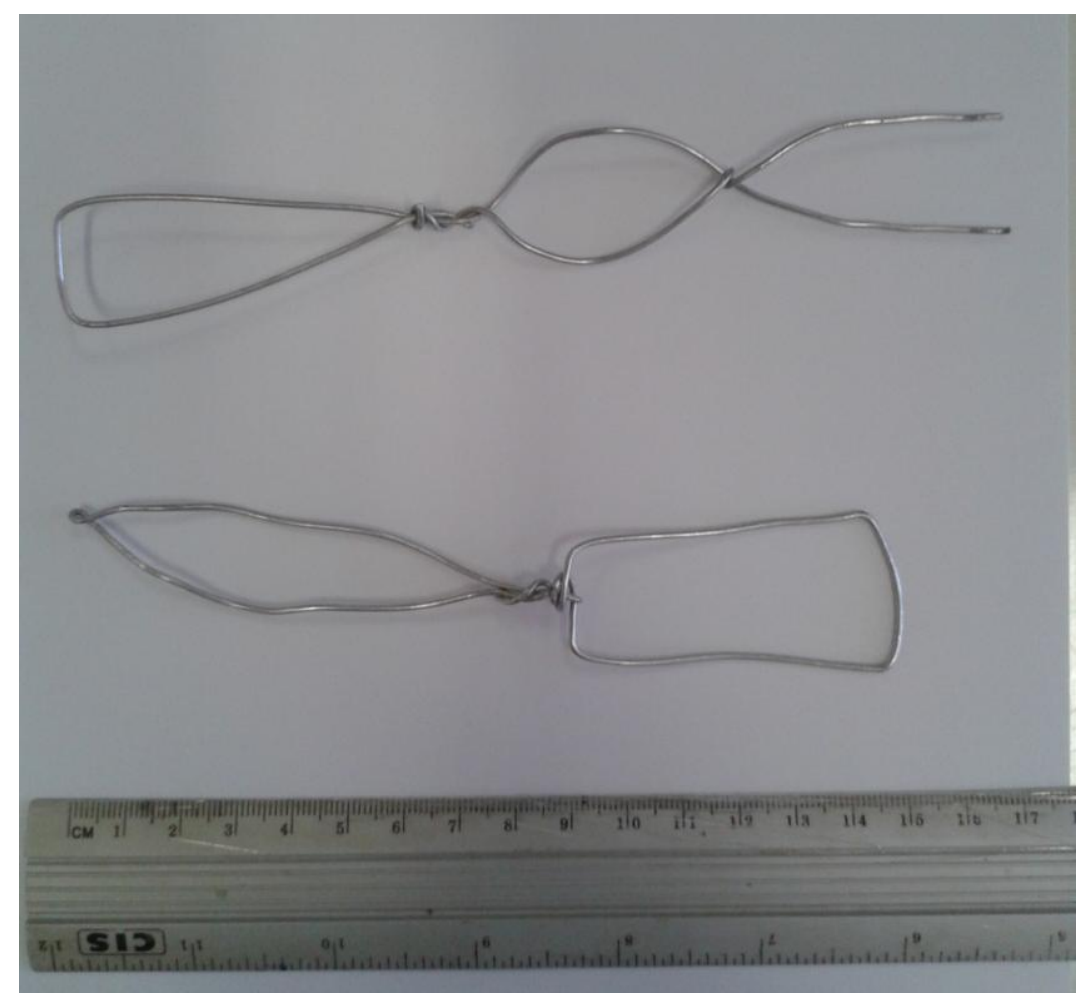

Figura 41. Sistemas construídos em arame para depósito dos microfios nas placas de microscópio.

\subsection{Resultados}

As placas com os microfios geradas ao fim da eletrodeposição foram submetidas à análise por miscroscopia eletrônica de varredura (MEV) e foram 
obtidas informações acerca da rede polimérica e dispersão das chalconas no polímero em questão, no caso a polivinilpirrolidona (PVP).

Na Figura 42, é apresentada a imagem gerada pela análise de MEV para a chalcona 14. Os comprimentos dos microfios foram entre 0,96 a 2,28 $\mu \mathrm{m}$. Esse padrão de espessura foi observado nas demais fibras geradas para a série de chalconas.

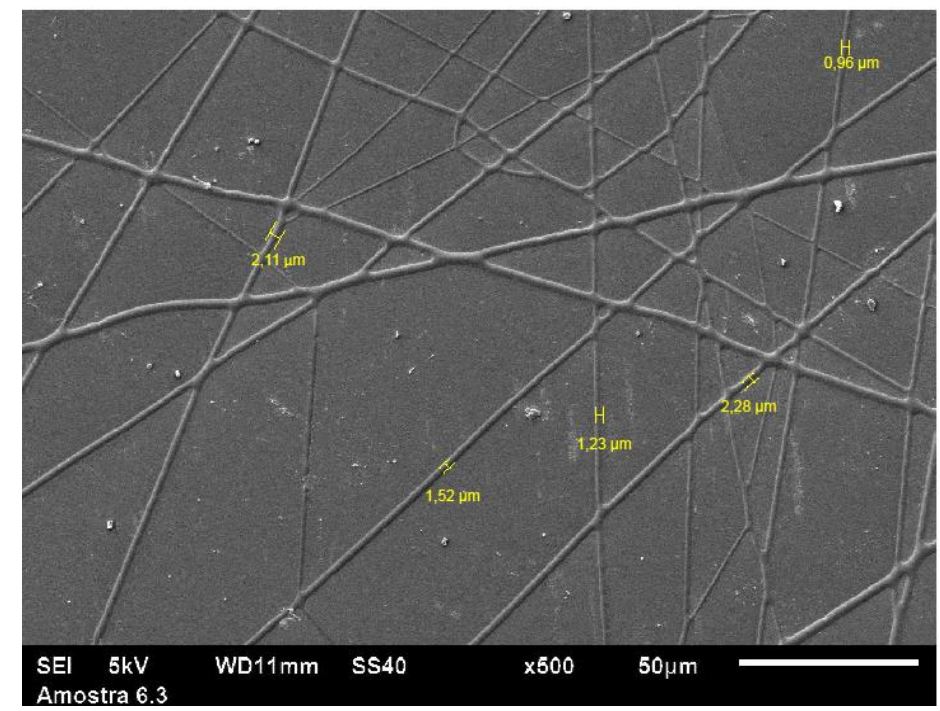

Figura 42. Imagem de MEV para a chalcona 14.

Placas com redes poliméricas mais abundantes permitiram as imagens seguintes, Figura 43 e 44, e, consequentemente, a obtenção de dados estatísticos da espessura das fibras. Como resultado final foi gerado o gráfico de distribuição para as placas.
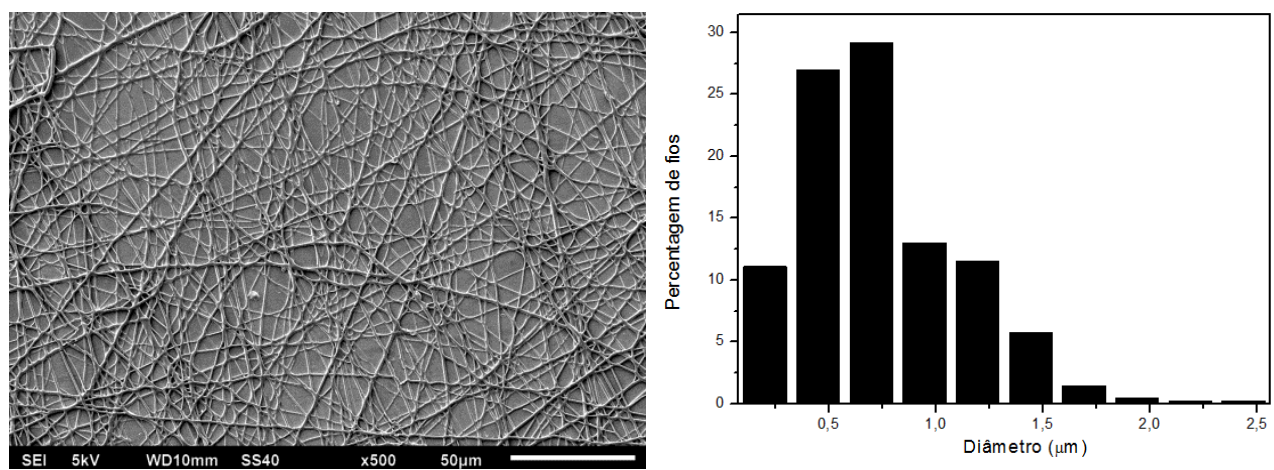

Figura 43. MEV com escala de $50 \mu \mathrm{m}$ da chalcona 16 e gráfico de distribuição percentual do material obtido. 

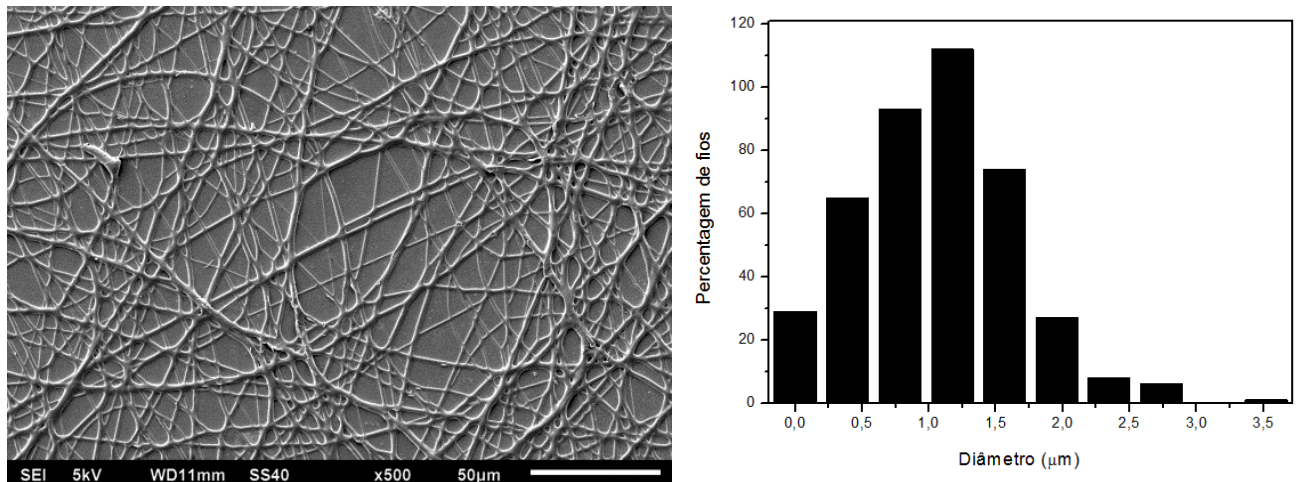

Figura 44. MEV com escala de $50 \mu \mathrm{m}$ da chalcona 19 e gráfico de distribuição percentual do material obtido.

Os microfios apresentam morfologias bem definidas ${ }^{56}$ e a distribuição das fibras têm percentagens mais acentuadas por volta de 0,5 a 1,5 $\mu \mathrm{m}$, a depender das interações entre a chalcona e polímero.

De forma geral, a técnica de electrospinning apresentou se eficiente para a obtenção do material PVP-chalcona na forma de microfibras, observados os diâmetros.

Para maior elucidação sobre os materiais formados (PVP-chalcona) foram realizadas leituras de emissão com excitação em 365 nm, já que esse comprimento de onda é correspondente ao comprimento de onda usado na lâmpada para o monitoramento das chalconas na rotina de laboratório e observa-se, normalmente, muita luminescência dessas em CCD.

Gotas do material foram depositadas sobre placas de microscópio (1,3 x $1,7 \mathrm{~cm}$ ) e deixadas secando à temperatura ambiente de um dia para o outro. Os sólidos obtidos foram fotografados sob lâmpada com comprimento de onda para a excitação de 365 , Figura 45 . A chalcona 18 , não foi realizada, pois a mesma degrada (coloração laranja passa a roxa) no preparo da solução polimérica, devido ao uso de solvente.

${ }^{56}$ Melo, E. F.; Santana, N. C.; Alves, K. G. B.; Sá, G. F.; Melo, C. P.; Rodrigues, M. O.; Júnior, S. A.; J. Mater. Chem. C, 2013, 1, 7574. 

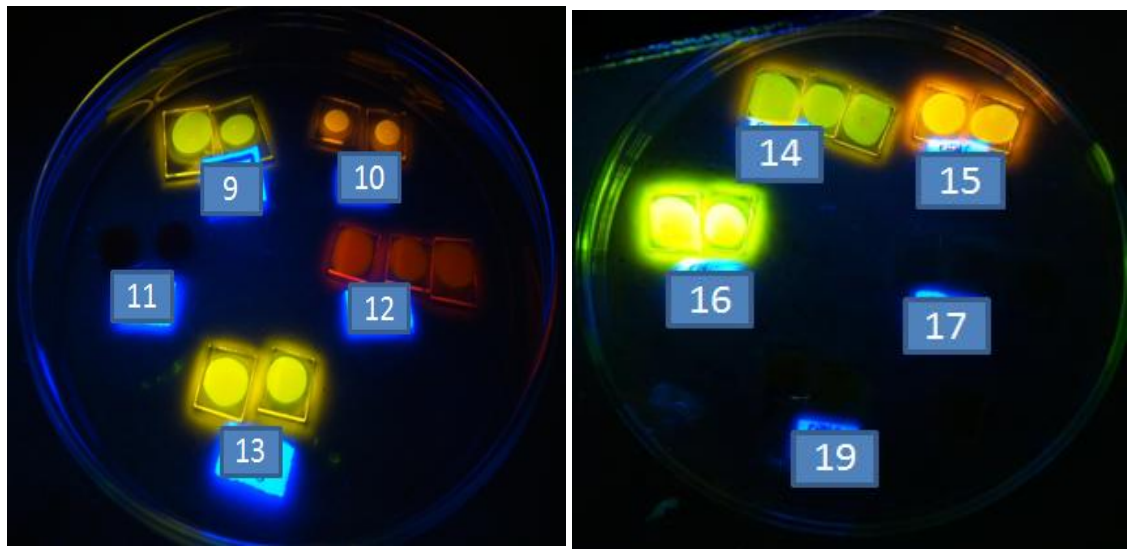

Figura 45. Imagens das placas de microscópio com o material PVP/chalcona irradiadas a 365 $\mathrm{nm}$. A indicação foi realizada com o mesmo número designado as chalconas sintetizadas.

Vale salientar que as estruturas 11, 17 e 19 não apresentam atividade luminescente, devido ao design D-A-D não ser favorecido por grupos hidroxi e amino na posição orto do anel $\mathrm{A}$ da chalcona, já discutido anteriormente.

Para quantificação e maiores esclarecimentos acerca da atividade luminescente dos materiais, os espectros de emissão no comprimento de onda da lâmpada (365 nm) foram realizados, Figura 46. E os comprimentos máximos de emissão para os materiais encontram-se descritos na Tabela 7.

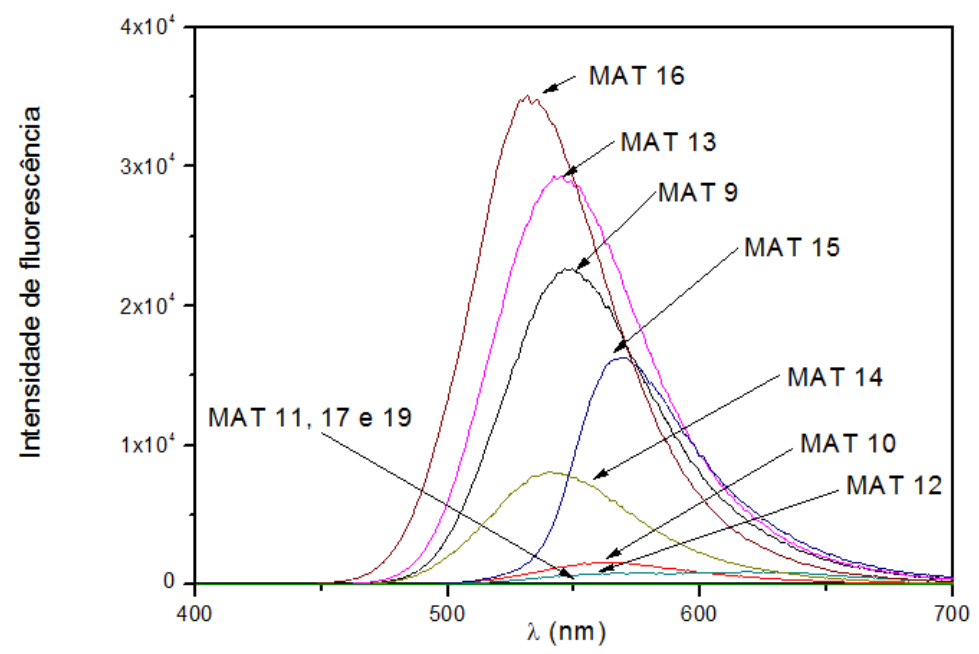

Figura 46. Espectro de emissão do material sólido PVP/chalcona. As etiquetas MAT são designações referentes aos materiais PVP/chalcona, os números do acervo foi mantido nas designações, visando compreensão didática. 
Tabela 7. Comprimentos de onda máximos obtidos com irradiação em $365 \mathrm{~nm}$ para os materiais PVP/chalcona, designados como MAT

\begin{tabular}{|c|c|}
\hline MAT & $\lambda_{\max }(\mathbf{e m})(\mathbf{n m})$ \\
\hline $\mathbf{9}$ & 550 \\
\hline $\mathbf{1 0}$ & 559 \\
\hline $\mathbf{1 1}$ & --- \\
\hline $\mathbf{1 2}$ & 569 \\
\hline $\mathbf{1 3}$ & 543 \\
\hline $\mathbf{1 4}$ & 543 \\
\hline $\mathbf{1 5}$ & 569 \\
\hline $\mathbf{1 6}$ & 533 \\
\hline $\mathbf{1 7}$ & --- \\
\hline $\mathbf{1 9}$ & --- \\
\hline
\end{tabular}

De acordo com a Tabela 7 e o observado na Figura 46 é possível afirmar que a rede polimérica não acarretou melhoria no processo ICT dessas chalconas $(11,17,19)$, uma vez que o arranjo estrutural delas, já discutido anteriormente, não favorecem mecanismos radiativos na emissão.

Quanto às demais chalconas, a fim de afirmar qualquer parâmetro decorrente do material obtido, mais análises devem ser realizadas. Não é possível traçar quadros comparativos com os dados presentes na Tabela 2, onde os comprimentos de onda máximos foram obtidos em soluções de solventes diversos, já sabendo que o comportamento de relaxação radiativa é alterado em decorrência da vizinhança ao fluorófolo. ${ }^{12,18}$

São esperados valores superiores de rendimento quântico para os materiais (MAT) em relação às chalconas (Tabela 6), como observado no estudo de Danko e colaboradores, ${ }^{17}$ já apresentado anteriormente. Muito embora a rede polimérica utilizada tenha sido PVC diferente da aqui estudada, PVP. Outros estudos já apontam o PVP como base polimérica na síntese de materiais/compósitos com atividade luminescente. ${ }^{47}$ 


\section{Conclusões e Perspectivas}

Os resultados de docking indicam complementaridade molecular entre a cruzaína e os derivados sintetizados. As poses melhor ranqueadas sugerem interação entre grupos aromáticos e o Bolso S2 da cruzaína, o qual tem afinidade por grupos polares e aromáticos, corroborando com a literatura. Outra observação é que o grupo carbonila da maioria das estruturas, exceto 15 , se apresenta com uma distância favorável ao ataque pela Cys25 da cruzaína, resíduo catalítico responsável pelo mecanismo de ação proposto.

Nos ensaios de inibição da cruzaína em dose de $100 \mu \mathrm{M}$, a maioria das chalconas apresentou alguma inibição da enzima. A chalcona 11 foi insolúvel, impossibilitando determinação da atividade. As estruturas 14 e 18 são promissoras inibidoras de cruzaína, e merecem ser mais bem avaliadas por estudos cinéticos, assim como atividade antitripanocida $\left(\mathrm{IC}_{50}\right)$.

No estudo fotofísico o parâmetro de Lippert-Mataga nos indicou que as estruturas 13 e 14 são estabilizadas após a excitação, com $R^{2}$ 0,73 e 0,82, respectivamente, indicando que o processo de ICT é eficiente nessas estruturas.

Quanto aos rendimentos quânticos, 9, 10, 13, 14, 15 e 16 apresentaram bons resultados (tendo como comparativo o sulfato de quinina) indicando que 0 design D-A-D adotado para as chalconas foi efetivo e, portanto, com essas moléculas são lançadas perspectivas maiores com relação à produção de materiais fotônicos, por meio da técnica de electrospinning já que a mesma se apresentou eficiente em nossa abordagem.

Outra perspectiva que pode ser explorada para as chalconas citadas acima é referente ao uso como marcador biológico ou biossensor para doença de Chagas, podendo ser, para o último caso, concomitante ou não ao uso de redes poliméricas, no desenvolvimento do artefato.

Análises acerca do rendimento quântico do material (PVP-chalcona) devem ser realizadas para maiores perspectivas. 


\section{Parte Experimental}

\subsection{Métodos Analíticos}

\subsubsection{Ressonância Magnética Nuclear}

Os espectros de ressonância magnética nuclear de hidrogênio $(300 \mathrm{MHz})$ e carbono $(75 \mathrm{MHz})$ foram obtidos em aparelho Varian Mercury Plus $300 \mathrm{MHz}$, $7,05 \mathrm{~T}$. Já a ressonância magnética nuclear de hidrogênio $(600 \mathrm{MHz})$ e carbono (150 MHz) foram obtidos em aparelho Bruker Avance III HD $600 \mathrm{MHz}, 14,1 \mathrm{~T}$. Todas as chalconas foram solubilizadas em $\mathrm{CDCl}_{3}$. Os deslocamentos químicos $(\delta)$ expressados em ppm (parte por milhão), assumindo como referência interna o TMS. Os dados espectroscópicos referentes aos espectros de RMN ${ }^{1} \mathrm{H}$ estão organizados segundo a convenção: $\delta$ deslocamento químico [número de hidrogênios, multiplicidade, constante de acoplamento em $\mathrm{Hz}$ ]. As abreviações das multiplicidades dos sinais nos espectros de RMN ${ }^{1} \mathrm{H}$ foram utilizadas segundo a convenção: $s$ (simpleto), $d$ (dupleto), $t$ (tripleto), $q$ (quadrupleto), qt (quintupleto), st (sextupleto), $\mathrm{m}$ (multipleto) $\mathrm{e} \mathrm{dd}$ (duplodupleto).

\subsubsection{Estudo Fotofísico}

Para as leituras de absorção e emissão, partiu-se de solução estoque das chalconas a concentração de $10^{-2} \mathrm{~mol} \mathrm{~L}^{-1}$ em diclorometano. Uma alíquota de $4 \mu \mathrm{l}$ (por meio de pipeta automática, DIGIPET 0,5-10 $\mu \mathrm{L}$ ) era transferida para cubeta e então diluída com $4 \mathrm{ml}$ (usando pipeta automática DIGIPET 1,0- 5,0 $\mathrm{ml}$ ) do solvente escolhido, obtendo-se por fim a concentração de $10^{-5} \mathrm{~mol} \mathrm{~L}^{-1}$ para aquisição dos gráficos.

O estudo foi executado com oito solventes, a saber: tolueno, acetonitrila, diclorometano, etanol, metanol, dimetilsulfóxido, acetato e hexano. Todos os solventes P.A., com exceção dos dois últimos que são destilados.

Para a absorção as análises foram feitas no aparelho Varian Cary 50Bio UV- visible Spectrophotometer, com velocidade média e leitura de branco. 
As medidas de emissão foram realizadas em ambiente climatizado a 26 ${ }^{\circ} \mathrm{C}$, no aparelho Varian-Cary Fluorescence Spectrophotometer com velocidade lenta a rápida e fenda de 2,5 a 5,0.

Para a determinação de rendimento quântico utilizou-se o comparativo com a solução sulfato de quinina. A solução foi preparada a partir do cloridrato de quinina, solubilizado em solução de ácido sulfúrico a $1 \mathrm{M}$, para a obtenção na concentração de $10^{-5} \mathrm{~mol} \mathrm{~L}^{-1}$.

As soluções estoques das chalconas foram obtidas como descrito anteriormente. A partir delas, diluições (da mesma forma descrita anteriormente) foram realizadas de modo a obterem-se soluções com concentração $10^{-5} \mathrm{~mol} \mathrm{~L}^{-1}$ em acetonitrila, para cada chalcona.

As análises foram realizadas com fonte de excitação em $366 \mathrm{~nm}$ (valor de referência para o sulfato de quinina) ${ }^{12,18}$ em equipamento Fluorolog Horiba com leitura a cada $1 \mathrm{~nm}$ e fenda de 2,5 . Os dados foram coletados na forma de gráficos corrigidos, obtidos no próprio equipamento e a leitura foi lateral.

Com as curvas obtidas, as áreas absolutas foram determinadas para uso na relação matemática:

$$
\Phi_{\mathrm{x}}=\Phi_{\mathrm{sq}}\left(\operatorname{Grad}_{\mathrm{x}} / \mathrm{Grad}_{\mathrm{sq}}\right)\left(\mathrm{\eta}_{\mathrm{x}}^{2} / \mathrm{\eta}_{\mathrm{sq}}{ }^{2}\right) \quad \mathrm{Eq} 1
$$

Sendo $\Phi_{\text {sq }}$ o rendimento quântico descrito para o sulfato de quinina, o termo Grad é referente ao gradiente da área integrada de fluorescência e $\eta$ o índice de refração do solvente. Todos os termos assimilados com " $x$ " são referentes à amostra que se quer determinar o valor de rendimento quântico.

Vale salientar que o índice de refração da solução sulfato de quinina e do solvente acetonitrila são iguais, portanto o último termo da equação se torna 1, simplificando os cálculos.

As análises foram realizadas em triplicata, em três dias diferentes. E o desvio padrão (erro) foi determinado para os valores de rendimento quântico determinados.

\subsection{Caracterização por Raios-X}


As análises foram realizadas pela Prof ${ }^{a} \mathrm{Dr}^{\mathrm{a}}$ Claudia Gatto, IQ-UnB. Os dados de difração de raios- $X$ foram coletados num aparelho Bruker CCD SMART APEX II com difratômetro de cristal único com radiação de Mo ka $(0,71073 \AA$ ). SADABS foi usado para adequar os dados e realizar a correção multi-scan de base. As estruturas foram resolvidas através de métodos diretos, utilizando SHELXS-97 e posterior análise do mapa de diferença de Fourrier gerando as posições dos átomos que não eram hidrogênio; o refinamento foi realizado usando SHELXL-97.

\subsection{Estudos de Docking}

Para os estudos de docking foi utilizada a estrutura cristalográfica da cruzaína (pdb: 1ME4) de melhor definição, 1,2 ̊̊ (0,12 nm). Realizaram-se os estudos no programa GOLD em computador PC Linux, seguindo os seguintes passos:

1. Isolamento e análise da estrutura cristalográfica da cruzaína do Protein Data Bank (PDB);

2. Preparação da proteína para estudo de docking;

3. Preparação dos ligantes, bioisósteros, para estudo de docking;

4. Realização do docking com os programas GOLD e FlexX, de modo a avaliar a melhor resposta;

5. Validação do estudo de docking;

6. Análise dos resultados.

\subsubsection{Ensaios de Inibição com a Cruzaína de T. cruzi}

Os compostos foram submetidos a ensaios de inibição seguindo em dose única de $100 \mu \mathrm{M}$ metodologia descrita por Blau e colaboradores. ${ }^{32}$ A cruzaína $(0,4$ $\mathrm{nM})$ previamente purificada, foi incubada em uma cubeta contendo tampão acetato de sódio (100 mM) em pH 5,5, 5 mM DTT e 0,01\% ou 0,001\% de Triton X-100 por 5 minutos em temperatura ambiente. O inibidor foi adicionado na cubeta, permanecendo por 5 minutos de incubação. $O$ substrato fluorescente 2,5 $\mathrm{MM}$ (cloridrato de Z-Phe-Arg-aminometilcumarina (Z-FR-AMC)) também foi adicionado. A adição do substrato aumenta a fluorescência (355 nm 
excitação e $460 \mathrm{~nm}$ emissão) e esse aumento foi acompanhado por espectrofluorimetria por 5 min (espectrofluorímetro de microplaca, Infinite 200, Tecan). Preparou-se uma solução em DMSO de $10 \mu \mathrm{M}$ para as 11 chalconas como solução estoque. A partir desta solução foram realizadas dissoluções em tampão fosfato até a concentração necessária para os ensaios. Os ensaios foram realizados em duplicata em experimentos independentes. A atividade do inibidor foi medida pela fluorescência remanescente em relação ao controle.

\subsection{Síntese das Chalconas}

\subsubsection{Procedimento Geral}

\section{Síntese das chalconas 9-17 e 19.}

Em um erlenmeyer (125 ml) em banho de gelo são preparados $4 \mathrm{ml}$ de uma solução de hidróxido de sódio $(\mathrm{NaOH})$ a 10\%. Em seguida a cetona aromática é acrescentada (5 mmol) e são esperados de 15 a 20 minutos para 0 acréscimo, com banho de gelo a $0^{\circ} \mathrm{C}$, do aldeído aromático $(5 \mathrm{mmol})$. A reação ocorre overnight. $\mathrm{Na}$ sequência, adiciona-se ácido $(\mathrm{HCl}, 1 \mathrm{M})$ até que se atinja $\mathrm{pH}$ neutro. O sólido formado foi coletado e purificado via recristalização (por evaporação direta) em etanol e/ou metanol ou coluna cromatográfica em gradiente com uma mistura de AcOEt/Hexano de 10\% a 20\% como eluente. Quando não houve formação de sólido, o óleo formado foi lavado com $30 \mathrm{ml}$ (3x $10 \mathrm{~mL})$ de diclorometano e à fase orgânica foi adicionado sulfato de sódio anidro. Após filtração, a solução foi rotaevaporada e o óleo residual foi purificado por coluna cromatográfica em gradiente com uma mistura de AcOEt/Hexano de $10 \%$ a $20 \%$ como eluente

As chalconas $9,11,12,14,15,16,17$ e 18 foram purificadas via recristalização e as chalconas 10, 13 foram purificadas por coluna cromatográfica.

\section{Síntese da chalcona 18.}

O preparo da chalcona 18 se dá de forma diferenciada devido à sensibilidade da 2-acetilpiridina. Quantidades equimolares da 2-acetilpiridina e do 4-N,Ndimetilaminobenzaldeído são misturadas e dissolvidas em $5 \mathrm{ml}$ de solvente. $\mathrm{Na}$ sequência, uma solução de $40 \%$ de hidróxido de sódio é adicionada (4 ml). A 
reação ocorreu em temperatura ambiente, durante $12 \mathrm{~h}$. A reação então foi colocada em banho de gelo e acidificada com $\mathrm{HCl}, 1 \mathrm{M}$. O sólido obtido foi coletado e purificado via recristalização em diclorometano à temperatura reduzida (geladeira). ${ }^{57}$

\subsection{Dados Espectroscópicos}

(E)-3-(4-(dimetilamino)fenil)-1-fenilprop-2-en-1-ona (9)

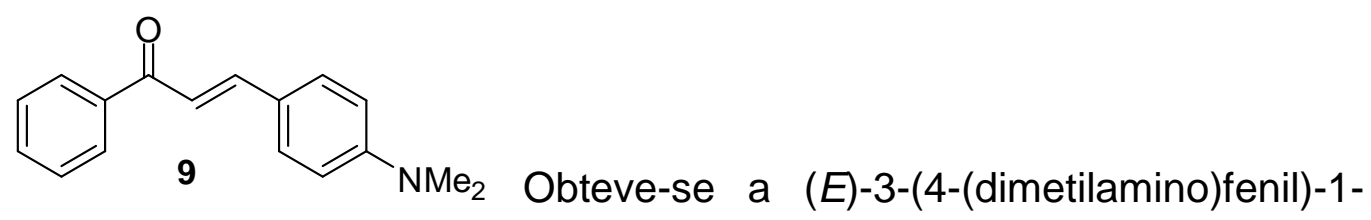
fenilprop-2-en-1-ona seguindo o procedimento geral descrito na síntese das chalconas, utilizando-se 4-(dimetilamino)benzaldeído (746 mg; $5 \mathrm{mmol}$ ) e feniletanona (601 mg; $5 \mathrm{mmol}$ ) comerciais. A estrutura 9 foi obtida em $80 \%$ de rendimento, após purificação por recristalização em etanol, como um sólido amarelo (p.f.=110-112 $\stackrel{\circ}{ } \mathrm{C})$.

(E.1.) $\mathrm{RMN}^{1} \mathrm{H}\left(300 \mathrm{MHz}, \mathrm{CDCl}_{3}\right): \delta 8,11(1 \mathrm{H}, \mathrm{d}, J 9,0 \mathrm{~Hz}), 7,83(1 \mathrm{H}, \mathrm{d}, J$ $15,5 \mathrm{~Hz}), 7,71(2 \mathrm{H}, \mathrm{d}, J$ 9,0 Hz), 7,65 (2H, d, J 9,0 Hz), 7,57 (2H, d, J 9,0 Hz), 7,4 (1H, d, J 15,5 Hz), 6,71 (2H, d, J 9,0 Hz), 3,05 (6H, s).

(E.2.) $\mathrm{RMN}{ }^{13} \mathrm{C}\left(75 \mathrm{MHz}, \mathrm{CDCl}_{3}\right): \delta 190,6,151,9,145,8,139,0,132,01$, $130,4,128,4,128,3,116,9,111,8,40,1$.

\section{(E)-1-(bifenil-4-il)-3-(4-(dimetilamino)fenil)prop-2-en-1-ona (10)}

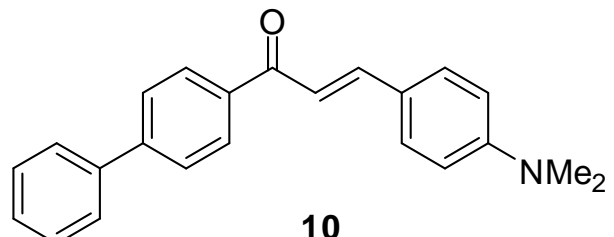

10

Obteve-se a (E)-1-(bifenil-4-il)-3-(4(dimetilamino)fenil)prop-2-en-1-ona seguindo o procedimento geral descrito na síntese das chalconas, utilizando-se 4-(dimetilamino)benzaldeído (746mg; 5 mmol) e 4-acetilfenil (981mg; 5 mmol) comerciais. A estrutura 10 foi obtida em

${ }^{57}$ Jyothi, M. V.; Venkatesh, P.; Orient. J. Chem. 2012, 28, 1437. 
$66 \%$ de rendimento, após purificação por coluna cromatográfica a $10 \%$ AcOEt/Hexano, como um sólido amarelo (p.f.=155-157 ํ).

(E.3.) $\mathrm{RMN}{ }^{1} \mathrm{H}\left(300 \mathrm{MHz}, \mathrm{CDCl}_{3}\right): \delta 8,01(1 \mathrm{H}, \mathrm{d}, J 3,0 \mathrm{~Hz}), 7,99(1 \mathrm{H}, \mathrm{m})$, 7,80 (1H, d, J 15,0Hz), 7,57-7,46 (8H, m), 7,33 (2H, d, J 15,0 Hz), 6,68 (2H, d, J $9.0 \mathrm{~Hz}), 3,03(6 \mathrm{H}, \mathrm{s})$.

(E)-3-(4-(dimetilamino)fenil)-1-(4-nitrofenil)prop-2-en-1-ona (11)

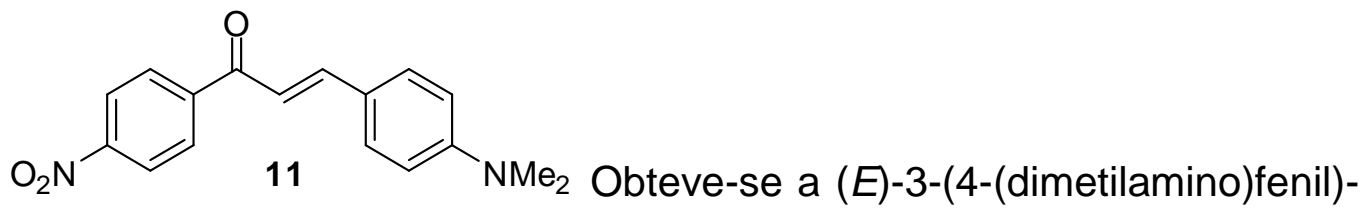
1-(4-nitrofenil)prop-2-en-1-ona seguindo o procedimento geral descrito na síntese das chalconas, utilizando-se 4-(dimetilamino)benzaldeído (746 mg; 5 mmol) e 1-(4-nitrofenil)etanona (826 mg; $5 \mathrm{mmol}$ ) comerciais. A estrutura 11 foi obtida em $72 \%$ de rendimento, após purificação por recristalização em etanol, como um sólido vermelho (p.f.= 225-227 $\left.{ }^{\circ} \mathrm{C}\right)$.

(E.4.) $\mathrm{RMN}^{1} \mathrm{H}\left(300 \mathrm{MHz}, \mathrm{CDCl}_{3}\right): \delta 8,33(2 \mathrm{H}, \mathrm{d}, J 5,0 \mathrm{~Hz}), 8,11(2 \mathrm{H}, \mathrm{d}, J$ 9,0 Hz), 7,82 (1H, d, J 15,0 Hz), 7,57 (2H, d, J 8,8 Hz), 7,27 (1H, d, J 15,0 Hz), $6,73(2 \mathrm{H}, \mathrm{d}, J 9,1 \mathrm{~Hz}), 3,06(6 \mathrm{H}, \mathrm{s})$.

(E.5.) $\mathrm{RMN}{ }^{13} \mathrm{C}\left(75 \mathrm{MHz}, \mathrm{CDCl}_{3}\right): \delta 188,9,152,5,147,9,144,3,130,9$, $129,1,128,3,124,0,123,7,122,0,115,9,111,8,40,1$.

\section{(E)-3-(4-(dimetilamino)fenil)-1-(2-hidroxifenil)prop-2-en-1-ona (12)}

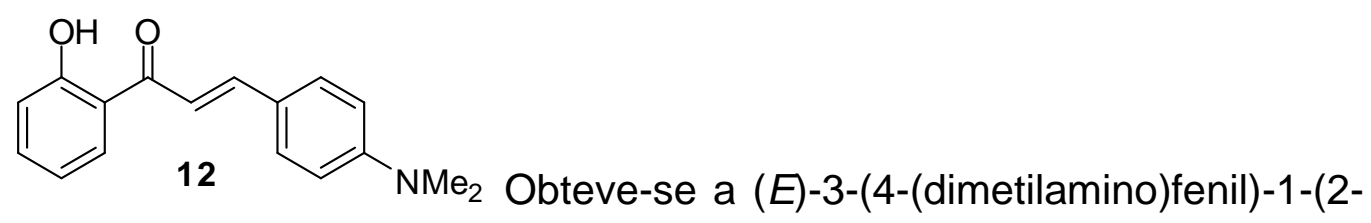
hidroxifenil)prop-2-en-1-ona seguindo o procedimento geral descrito na síntese das chalconas, utilizando-se 4-(dimetilamino)benzaldeído (746 mg; 5 mmol) e 1-(2-hidroxifenil)etanona (681 mg; $5 \mathrm{mmol}$ ) comerciais. A estrutura 12 foi obtida na forma de óleo. Este foi lavado com $30 \mathrm{ml}(3 \times 10 \mathrm{~mL})$ de diclorometano e à fase orgânica adicionou-se sulfato de sódio anidro. Após filtração foi rotaevaporado e purificado por recristalização em etanol, obtendo-se $78 \%$ de rendimento. Sólido roxo (p.f.=162-164 ํ). 
(E.6.) $\mathrm{RMN}^{1} \mathrm{H}\left(300 \mathrm{MHz}, \mathrm{CDCl}_{3}\right): \delta 13,18(1 \mathrm{H}, \mathrm{s}), 7,91(1 \mathrm{H}, \mathrm{s}), 7,92(1 \mathrm{H}$, d, J 15,0 Hz), 7,57 (2H, d, J 9,0 Hz), 7,46 (1H, d, J 15,0 Hz), 7,46 (1H, s), 7,0 $(1 \mathrm{H}, \mathrm{d}, J 9,0 \mathrm{~Hz}), 6,92(1 \mathrm{H}, \mathrm{s}), 6,72(2 \mathrm{H}, \mathrm{d}, J 9.0 \mathrm{~Hz}), 3,06(6 \mathrm{H}, \mathrm{s})$.

(E.7.) $\mathrm{RMN}{ }^{13} \mathrm{C}\left(75 \mathrm{MHz}, \mathrm{CDCl}_{3}\right): \delta 193,5,171,3,163,5,146,5,135,6$, $130,8,129,3,120,4,118,5,118,5,111,4,111,9,40,2$.

(E)-3-(4-(dimetilamino)fenil)-1-(3-hidroxifenil)prop-2-en-1-ona (13)

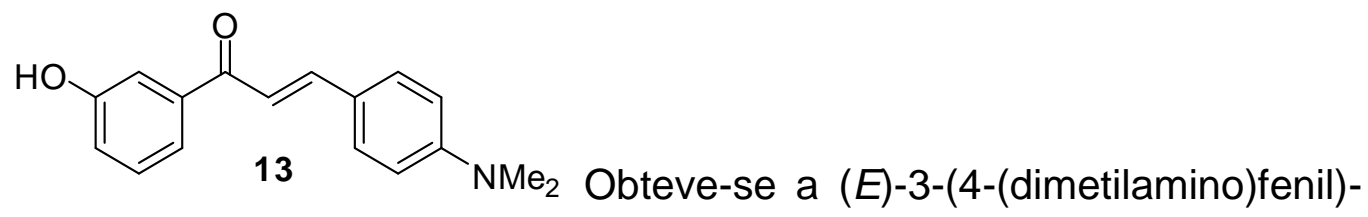
1-(3-hidroxifenil)prop-2-en-1-ona seguindo o procedimento geral descrito na síntese das chalconas, utilizando-se 4-(dimetilamino)benzaldeído (746 mg; 5 mmol) e 1-(3-hidroxifenil)etanona (681 mg; 5 mmol) comerciais. A estrutura 13 foi obtida em $72 \%$ de rendimento, após purificação por coluna cromatográfica a 20\% AcOEt/Hexano, como um sólido laranja (p.f.=173-175 9 C).

(E.8.) $\mathrm{RMN}^{1} \mathrm{H}\left(300 \mathrm{MHz}, \mathrm{CDCl}_{3}\right): \delta 7,80(1 \mathrm{H}, \mathrm{d}, J 15.0 \mathrm{~Hz}), 7,59-7,53$ $(4 \mathrm{H}, \mathrm{m}), 7,37(1 \mathrm{H}, \mathrm{d}, J 6.0 \mathrm{~Hz}), 7,32(1 \mathrm{H}, \mathrm{d}, J 15.0 \mathrm{~Hz}), 7,08(1 \mathrm{H}, \mathrm{dd}, J$ 2,2 e 7,8 $\mathrm{Hz}), 6,73(2 \mathrm{H}, \mathrm{d}, \mathrm{J} 8,8 \mathrm{~Hz}), 3,05(6 \mathrm{H}, \mathrm{s})$.

(E.9.) $\mathrm{RMN}{ }^{13} \mathrm{C}\left(150 \mathrm{MHz}, \mathrm{CDCl}_{3}\right): \delta$ 190,6, 190,5, 156,3, 146,3, 140,5, $130,6,129,7,120,7,119,7,116,8,115,1,111,90,111,0,40,2,40,1$.

\section{(E)-1-(3-aminofenil)-3-(4-(dimetilamino)fenil)prop-2-en-1-ona (14)}

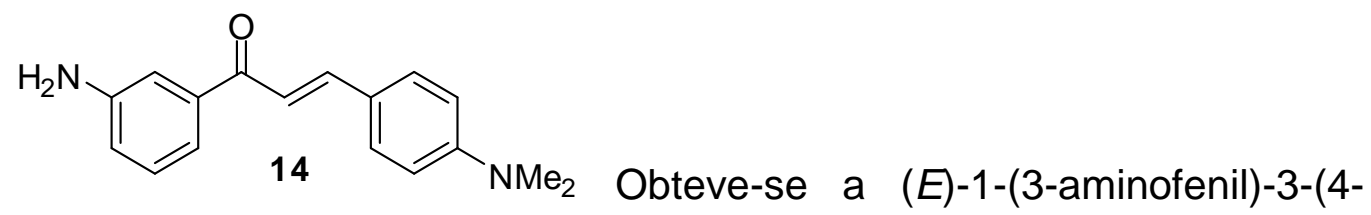
(dimetilamino)fenil)prop-2-en-1-ona seguindo o procedimento geral descrito na síntese das chalconas, utilizando-se 4-(dimetilamino)benzaldeído (746mg; 5 mmol) e 1-(3-aminofenil)etanona (676 mg; $5 \mathrm{mmol})$ comerciais. A estrutura 14 foi obtida em $52 \%$ de rendimento, após purificação por recristalização em etanol, como um sólido laranja (p.f.=142-144 ํㅡ). 
(E.10.) $\mathrm{RMN}^{1} \mathrm{H}\left(300 \mathrm{MHz}, \mathrm{CDCl}_{3}\right): \delta 7,76(1 \mathrm{H}, \mathrm{d}, J 15.0 \mathrm{~Hz}), 7,52(2 \mathrm{H}, \mathrm{d}$, J 9,0 Hz), 7,40 (2H, m), 7,28 (1H, d, J $15.0 \mathrm{~Hz})$, 6,95 (2H, m), 6,69 (2H, d, J 9.0 $\mathrm{Hz}), 3,03(6 \mathrm{H}, \mathrm{s}), 3,0(2 \mathrm{H}, \mathrm{s})$.

(E.11.) $\mathrm{RMN}{ }^{13} \mathrm{C}\left(75 \mathrm{MHz}, \mathrm{CDCl}_{3}\right): \delta$ 190,7, 151,8, 145,7, 145,1, 140,1, $130,4,129,3,122,9,119,6,117,1,112,0,40,9,40,3,40,2$.

(E)-1-(4-clorofenil)-3-(4-(dimetilamino)fenil)prop-2-en-1-ona (15)

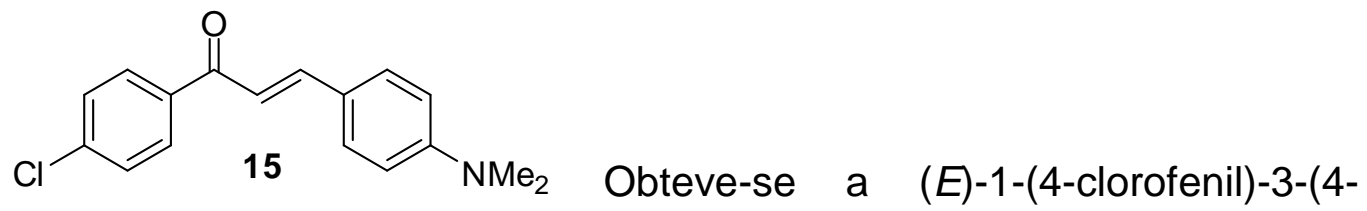
(dimetilamino)fenil)prop-2-en-1-ona seguindo o procedimento geral descrito na síntese das chalconas, utilizando-se 4-(dimetilamino)benzaldeído (746 mg; 5 mmol) e 1-(4-clorofenil)etanona (773 mg; $5 \mathrm{mmol}$ ) comerciais. A estrutura 15 foi obtida em 52\% de rendimento, após purificação por recristalização em etanol, como um sólido amarelo (p.f.=140-142 ํㅡ).

(E.12.) $\mathrm{RMN}^{1} \mathrm{H}\left(300 \mathrm{MHz}, \mathrm{CDCl}_{3}\right): \delta 7,94(2 \mathrm{H}, \mathrm{m}), 7,79(1 \mathrm{H}, \mathrm{d}, J 15,2$ $\mathrm{Hz}), 7,54(2 \mathrm{H}, \mathrm{d}, J 5,0 \mathrm{~Hz}), 7,44(2 \mathrm{H}, \mathrm{m}), 7,28(1 \mathrm{H}, \mathrm{d}, J 15,2 \mathrm{~Hz}), 6,68(2 \mathrm{H}, \mathrm{d}, J$ $5 \mathrm{~Hz}), 3,04(6 \mathrm{H}, \mathrm{s})$.

(E.13.) $\mathrm{RMN}{ }^{13} \mathrm{C}\left(75 \mathrm{MHz}, \mathrm{CDCl}_{3}\right): \delta 189,2,152,1,146,3,138,4,137,3$, $130,5,129,7,128,7,122,3,116,1,111,7,40,1$.

(E)-3-(4-(dimetilamino)fenil)-1-(4-metoxifenil)prop-2-en-1-ona (16)

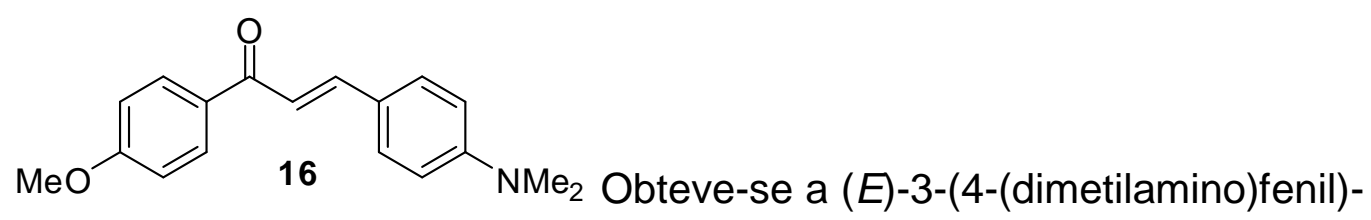
1-(4-metoxifenil)prop-2-en-1-ona seguindo o procedimento geral descrito na síntese das chalconas, utilizando-se 4-(dimetilamino)benzaldeído (746 mg; 5 mmol) e 1-(4-metoxifenil)etanona (751 mg; $5 \mathrm{mmol})$ comerciais. A estrutura 16 foi obtida em $85 \%$ de rendimento, após purificação por recristalização em etanol, como um sólido amarelo (p.f.=128-129 ${ }^{\circ} \mathrm{C}$ ). 
(E.14.) $\mathrm{RMN}^{1} \mathrm{H}\left(300 \mathrm{MHz}, \mathrm{CDCl}_{3}\right): \delta 8,03(2 \mathrm{H}, \mathrm{d}, J$ 7,9 Hz), 7,79 (1H, d, J 15,5 Hz), 7,55 (2H, d, J 6,0 Hz), 7,36 (1H, d, J $15.5 \mathrm{~Hz}), 6,97(2 \mathrm{H}, \mathrm{d}, J 6.0$ $\mathrm{Hz}), 6,71(2 \mathrm{H}, \mathrm{d}, J$ 9,0 Hz), 3,88 (3H, s), 3,04 (6H, s).

(E.15.) RMN ${ }^{13} \mathrm{C}\left(75 \mathrm{MHz}, \mathrm{CDCl}_{3}\right): \delta 188,9,162,9,144,9,131,8,130,5$, $130,2,116,8,113,6,111,9,55,5,40,2$.

(E)-1-(2-hidroxifenil)-3-(3,4,5-trimetoxifenil)prop-2-en-1-ona (17)<smiles>COc1cc(/C=C/C(=O)c2ccccc2O)cc(OC)c1OC</smiles>

Obteve-se a (E)-1-(2-hidroxifenil)-3-(3,4,5trimetoxifenil)prop-2-en-1-ona seguindo o procedimento geral descrito na síntese das chalconas, utilizando-se 3,4,5-trimetoxibenzaldeído (981mg; 5 mmol) e 1-(2-hidroxifenil)etanona (681 mg; 5 mmol) comerciais. A estrutura 17 foi obtida em $60 \%$ de rendimento, após purificação por recristalização em etanol, como um sólido amarelo (p.f.=150-152 ํㅡ).

(E.16.) $\mathrm{RMN}^{1} \mathrm{H}\left(300 \mathrm{MHz}, \mathrm{CDCl}_{3}\right): \delta 12,87(1 \mathrm{H}, \mathrm{s}), 7,93(1 \mathrm{H}, \mathrm{dd}, \mathrm{J} 1,6 \mathrm{e}$ 8,1 Hz), 7,83 (1H, d, J 15,5 Hz), 7,53 (1H, d, J 15.5 Hz), 7,49-7,46 (1H, m), 7,02 $(2 \mathrm{H}, \mathrm{dd}, \mathrm{J} 9,0$ e 1,2 Hz), 6,97-6,92 (1H, m), 6,89 (2H, s), 3,93 (9H, s).

(E.17.) $\mathrm{RMN}{ }^{13} \mathrm{C}\left(75 \mathrm{MHz}, \mathrm{CDCl}_{3}\right): \delta 193,5,163,6,153,5,145,6,136,4$, $130,0,129,6,120,0,119,2,105,9,56,3,56,2$.

(E)-3-(4-(dimetilamino)fenil)-1-(piridin-2-il)prop-2-en-1-ona (18)

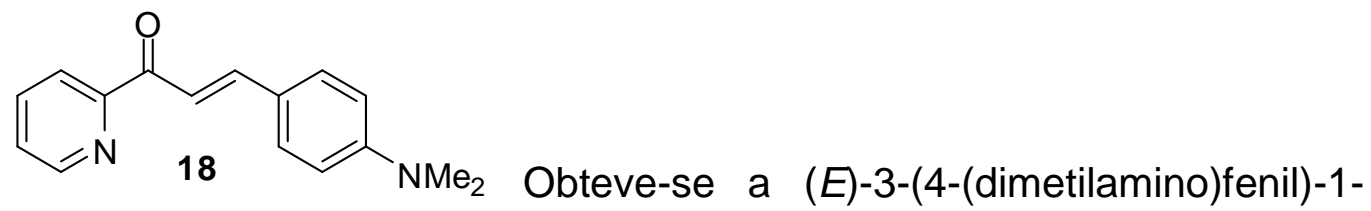
(piridin-2-il)prop-2-en-1-ona, a partir das quantidades equimolares do 4(dimetilamino)benzaldeído (981mg; 5 mmol) e 1-(piridin-2-il)etanona (606mg; $5 \mathrm{mmol}$ ) comerciais, misturados em $5 \mathrm{ml}$ de etanol. Na sequência uma solução a $40 \%$ de hidróxido de sódio é adicionada e a reação ocorre a temperatura ambiente por $12 \mathrm{~h}$. A reação é então neutralizada em banho de gelo com solução de ácido clorídrico $1 \mathrm{M}$. O sólido obtido é coletado e secado. A estrutura 
18 foi obtida em $93 \%$ de rendimento, como um sólido laranja fluorescente. (Degrada a $\left.128^{\circ} \mathrm{C}\right)$.

(E.18.) $\mathrm{RMN}^{1} \mathrm{H}\left(600 \mathrm{MHz}, \mathrm{CDCl}_{3}\right): \delta 8,74(1 \mathrm{H}, \mathrm{m}), 8.19(1 \mathrm{H}, \mathrm{m}), 8,1(1 \mathrm{H}$, d, J 15,8 Hz), 7,95 (1H, d, J 15,8 Hz), 7,87-7,84 (1H, td, J 7,7, 7,7 e 1,8 Hz), $7,67(2 \mathrm{H}, \mathrm{d}, \mathrm{J} 12.0 \mathrm{~Hz}), 7,48-7,46(1 \mathrm{H}, \mathrm{m}), 6,75(1 \mathrm{H}, \mathrm{s}), 3,06(6 \mathrm{H}, \mathrm{s})$.

(E)-1-(2-aminofenil)-3-(3,4,5-trimetoxifenil)prop-2-en-1-ona (19)<smiles>COc1cc(/C=C/C(=O)c2ccccc2N)cc(OC)c1OC</smiles>

Obteve-se a (E)-1-(2-aminofenil)-3-(3,4,5trimetoxifenil)prop-2-en-1-ona seguindo o procedimento geral descrito na síntese das chalconas, utilizando-se 3,4,5-trimetoxibenzaldeído (981mg; 5 mmol) e 1-(2-aminofenil)etanona (676 mg; 5 mmol) comerciais. A estrutura 19 foi obtida em $73 \%$ de rendimento, após purificação por recristalização em etanol, como um sólido amarelo (p.f.=132-134 ํㅡ).

(E.19.) $\mathrm{RMN}^{1} \mathrm{H}\left(300 \mathrm{MHz}, \mathrm{CDCl}_{3}\right): \delta 7,87(1 \mathrm{H}, \mathrm{d}, J 8,2 \mathrm{~Hz}), 7,66(1 \mathrm{H}, \mathrm{d}$, J $15.0 \mathrm{~Hz}), 7,49(1 \mathrm{H}, \mathrm{d}, J$ 15,0 Hz), 7,33-7,26 (3H, m), 6,85 (1H, s), 6,75 (1H, d, J $6 \mathrm{~Hz}), 3,92(9 \mathrm{H}, \mathrm{s}), 3,90(2 \mathrm{H}, \mathrm{s})$.

\subsection{Dados Cristalográficos}

(E)-3-(4-(dimetilamino)fenil)-1-fenilprop-2-en-1-ona (9)<smiles>CN(C)c1ccc(/C=C/C(=O)c2ccccc2)cc1</smiles> 


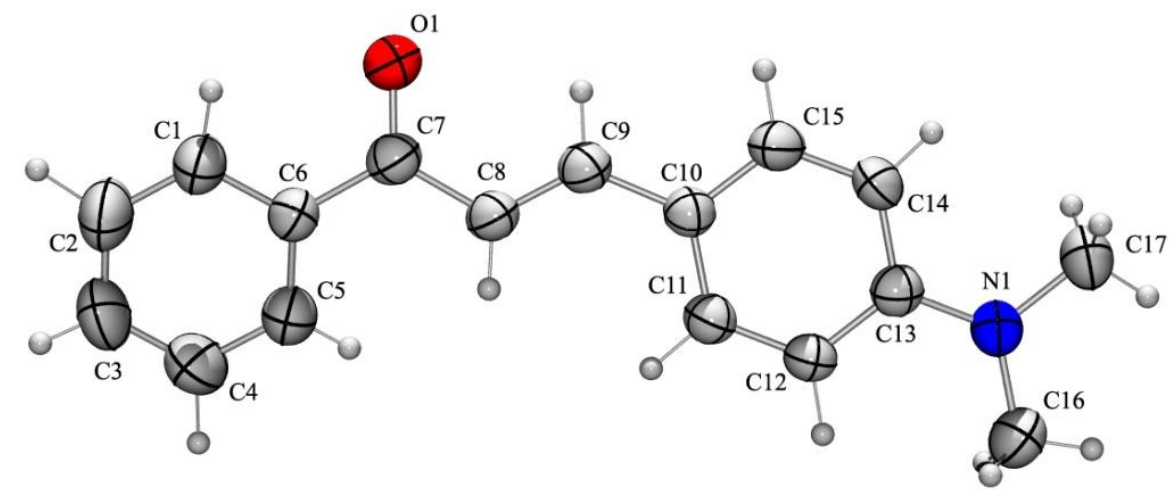

Figura 47. Estrutura 9 resolvida por difração de raios-X.

Tabela 8. Dados cristalográficos do composto 9.

\begin{tabular}{|c|c|}
\hline Código de identificação & 9 \\
\hline Fórmula empírica & $\mathrm{C}_{17} \mathrm{H}_{17} \mathrm{NO}$ \\
\hline Massa molecular & 251,32 \\
\hline Grupo espacial & $\mathrm{P} 2_{1} / \mathrm{c}$ \\
\hline Dimensões da célula unitária & $\begin{array}{ll}\text { a } 13,1990(8) \AA & \alpha 90,00^{\circ} \\
\text { b } 11,8332(7) \AA & \beta 109,548(4)^{\circ} \\
\text { c } 9,5650(6) \AA & \vee 90,00^{\circ}\end{array}$ \\
\hline Volume & $1407,82 \AA^{3}$ \\
\hline
\end{tabular}

(E)-3-(4-(dimetilamino)fenil)-1-(4-nitrofenil)prop-2-en-1-ona (11)

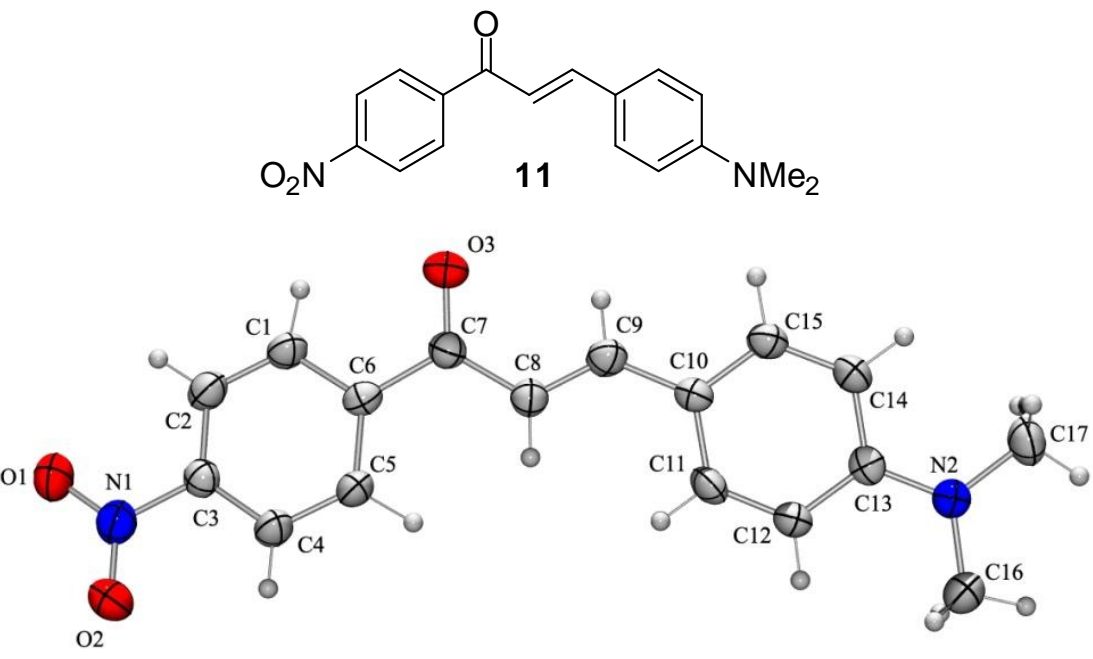

Figura 48. Estrutura 11 resolvida por difração de raios-X.

Tabela 9. Dados cristalográficos do composto 11.

Código de identificação 11 


\begin{tabular}{|c|c|}
\hline Fórmula empírica & $\mathrm{C}_{17} \mathrm{H}_{16} \mathrm{~N}_{2} \mathrm{O}_{3}$ \\
\hline Massa molecular & \multicolumn{2}{|c|}{296,32} \\
\hline Grupo espacial & $\mathrm{P} 2{ }_{1} 2{ }_{1} 2_{1}$ \\
\hline Dimensões da célula unitária & a 4,0180(8) $\AA \quad \alpha 90,00^{\circ}$ \\
& b 11,277(2) $\AA \quad \beta 90,00^{\circ}$ \\
& c 32,281(6) $\AA \quad$ v $90,00^{\circ}$ \\
\hline Volume & \multicolumn{2}{|c|}{$1462.68 \AA^{3}$} \\
\hline
\end{tabular}

(E)-3-(4-(dimetilamino)fenil)-1-(2-hidroxifenil)prop-2-en-1-ona (12)<smiles>CN(C)c1ccc(/C=C/C(=O)c2ccccc2O)cc1</smiles>

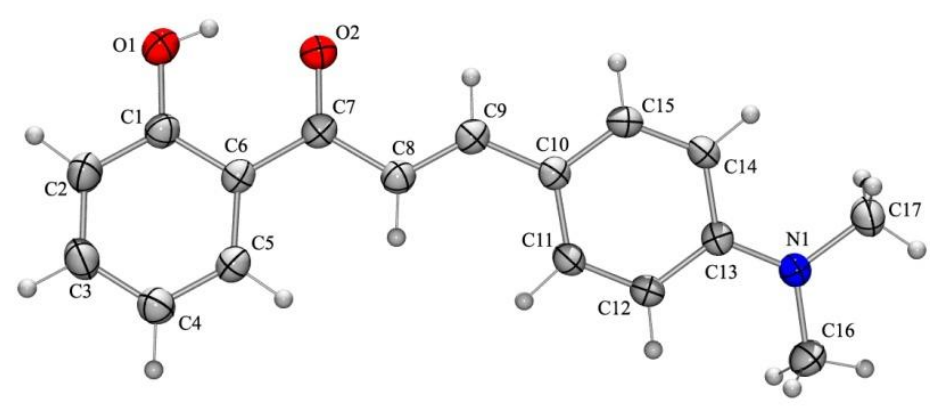

Figura 49. Estrutura 12 resolvida por difração de raios-X.

Tabela 10. Dados cristalográficos do composto 12.

\begin{tabular}{|c|c|}
\hline Código de identificação & 12 \\
\hline Fórmula empírica & \multicolumn{1}{|c|}{$\mathrm{C}_{17} \mathrm{H}_{17} \mathrm{NO}_{2}$} \\
\hline Massa molecular & \multicolumn{2}{|c|}{267,32} \\
\hline Grupo espacial & $\mathrm{P} 2{ }_{1} / \mathrm{C}$ \\
\hline Dimensões da célula unitária & a 12,1149(5) $\AA \quad \alpha 90,00^{\circ}$ \\
& b 10,2802(4) $\AA \quad \beta 115,880(3)^{\circ}$ \\
& c 12,5050(5) $\AA \quad$ v $90,00^{\circ}$ \\
\hline Volume & \multicolumn{2}{|c|}{$1401,22 \AA^{3}$} \\
\hline
\end{tabular}

(E)-3-(4-(dimetilamino)fenil)-1-(3-hidroxifenil)prop-2-en-1-ona (13) 
<smiles>CN(C)c1ccc(/C=C/C(=O)c2cccc(O)c2)cc1</smiles>

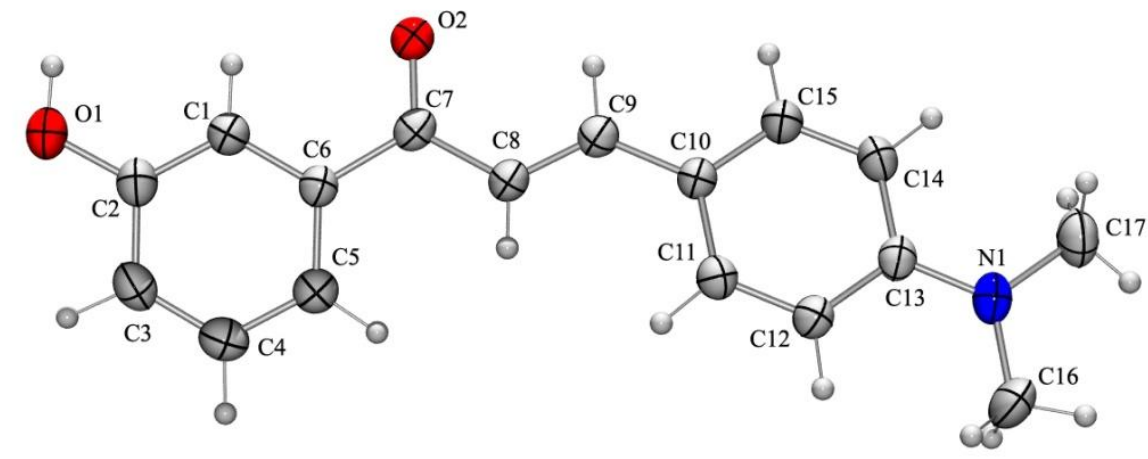

Figura 50. Estrutura 13 resolvida por difração de raios-X.

Tabela 11. Dados cristalográficos do composto 13.

\begin{tabular}{|c|c|}
\hline Código de identificação & 13 \\
\hline Fórmula empírica & $\mathrm{C}_{17} \mathrm{H}_{17} \mathrm{NO}_{2}$ \\
\hline Massa molecular & 267,32 \\
\hline Grupo espacial & $\mathrm{P} 2{ }_{1} / \mathrm{c}$ \\
\hline Dimensões da célula unitária & $\begin{array}{ll}\text { a } 12,8623(12) \AA & \alpha 90,00^{\circ} \\
\text { b } 11,9600(10) \AA & \beta 106,470(6)^{\circ} \\
\text { c } 9,6048(9) \AA & \vee 90,00^{\circ}\end{array}$ \\
\hline Volume & $1416,91 \AA^{3}$ \\
\hline
\end{tabular}

(E)-1-(3-aminofenil)-3-(4-(dimetilamino)fenil)prop-2-en-1-ona (14)<smiles>CN(C)c1ccc(/C=C/C(=O)c2cccc(N)c2)cc1</smiles>

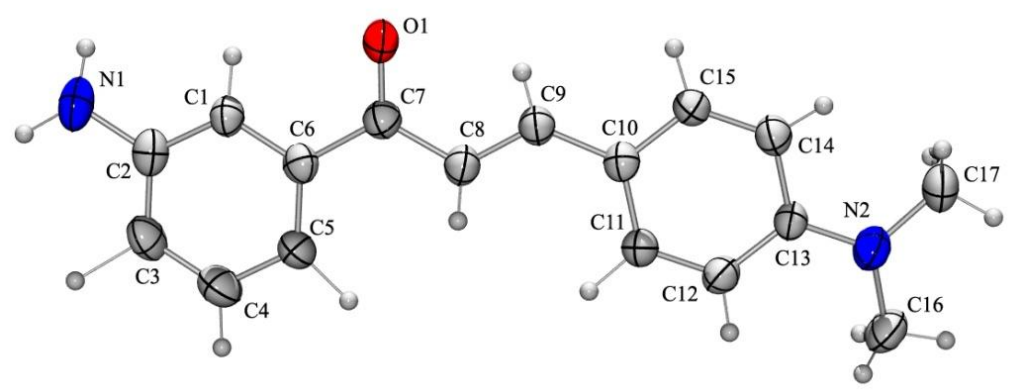

Figura 51. Estrutura 14 resolvida por difração de raios-X. 
Tabela 12. Dados cristalográficos do composto 14.

\begin{tabular}{|c|c|}
\hline Código de identificação & 14 \\
\hline Fórmula empírica & \multicolumn{1}{|c|}{$\mathrm{C}_{17} \mathrm{H}_{18} \mathrm{~N}_{2} \mathrm{O}$} \\
\hline Massa molecular & \multicolumn{2}{|c|}{266,34} \\
\hline Grupo espacial & $\mathrm{P} 22_{1}$ \\
\hline Dimensões da célula unitária & a 5,4885(4) $\AA \quad \alpha \quad 90,00^{\circ}$ \\
& b 8,2040(6) $\AA \quad \beta 99,210(5)^{\circ}$ \\
& c 16,5344(11) $\AA \quad$ v 90,00 \\
\hline Volume & \multicolumn{2}{|c|}{$734,907 \AA^{3}$} \\
\hline
\end{tabular}

(E)-1-(4-clorofenil)-3-(4-(dimetilamino)fenil)prop-2-en-1-ona (15)<smiles>CN(C)c1ccc(/C=C/C(=O)c2ccc(Cl)cc2)cc1</smiles>

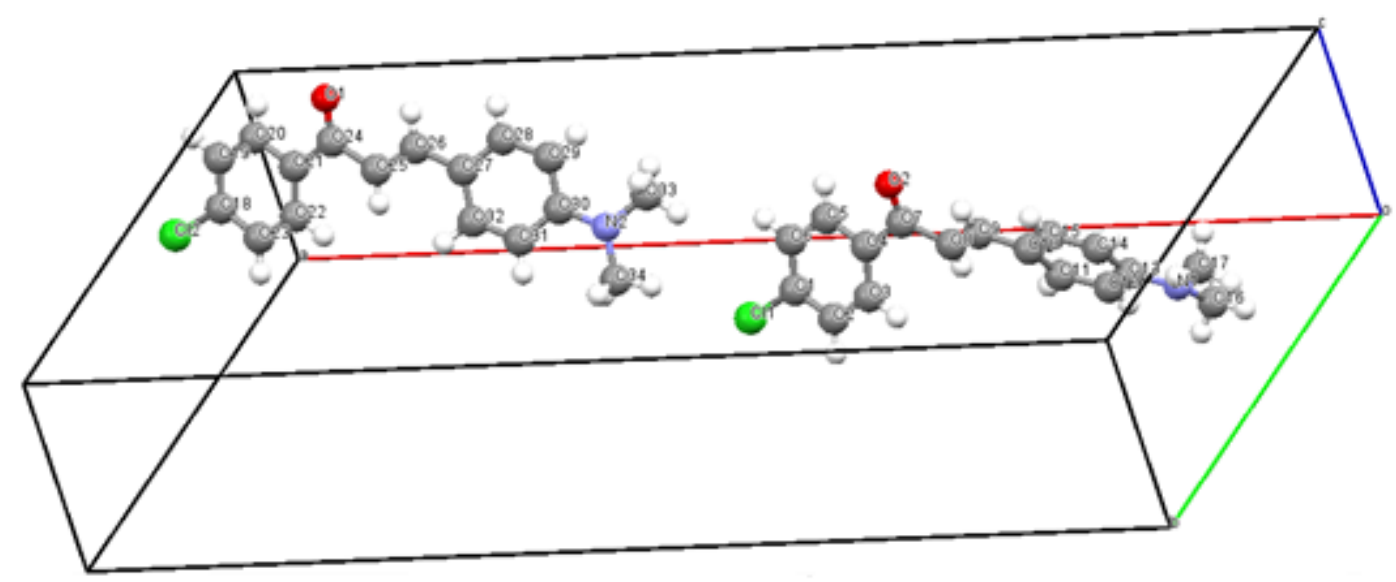

Figura 52. Estrutura 15 resolvida por difração de raios-X.

Tabela 13. Dados cristalográficos do composto 15.

\begin{tabular}{|c|c|}
\hline Código de identificação & 15 \\
\hline Fórmula empírica & $\mathrm{C}_{17} \mathrm{H}_{16} \mathrm{CINO}$ \\
\hline Massa molecular & 285,77 \\
\hline Grupo espacial & $\mathrm{P} 2{ }_{1} / \mathrm{c}$ \\
\hline Dimensões da célula unitária & $\begin{array}{ll}\text { a 33.2311(19) } \AA & \alpha 90,00^{\circ} \\
\text { b 14,5422(9) } \AA & \beta 92,072(4)^{\circ} \\
\text { c } 6,1089(4) \AA & \vee 90,00^{\circ}\end{array}$ \\
\hline Volume & $2950,22 \AA^{3}$ \\
\hline
\end{tabular}


(E)-3-(4-(dimetilamino)fenil)-1-(4-metoxifenil)prop-2-en-1-ona (16)

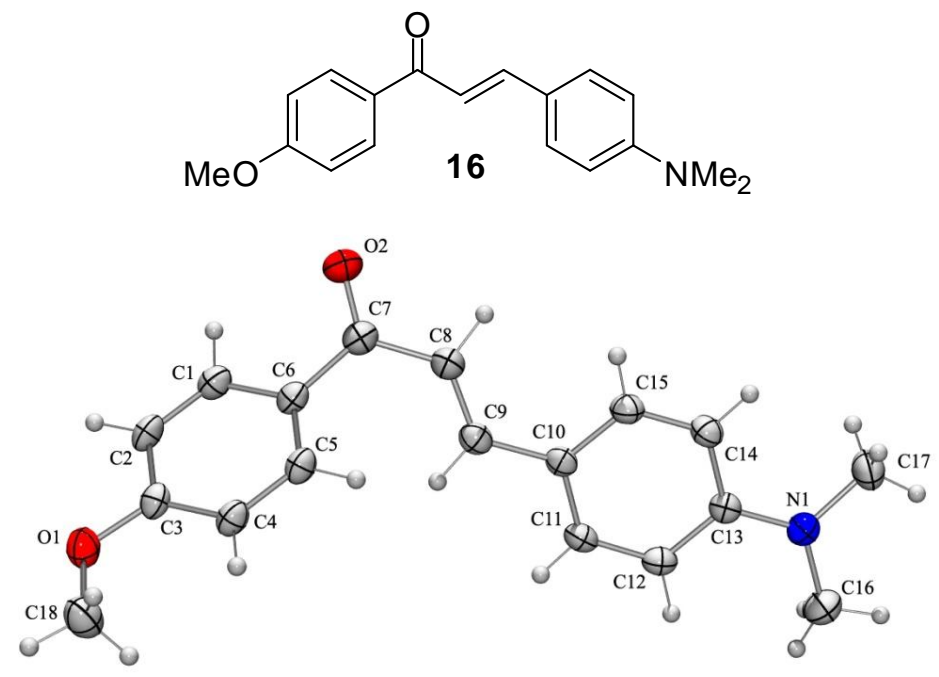

Figura 53. Estrutura 16 resolvida por difração de raios-X.

Tabela 14. Dados cristalográficos do composto 16.

\begin{tabular}{|c|c|}
\hline Código de identificação & 16 \\
\hline Fórmula empírica & $\mathrm{C}_{18} \mathrm{H}_{19} \mathrm{NO}_{2}$ \\
\hline Massa molecular & 281,35 \\
\hline Grupo espacial & $\mathrm{P} 2_{1}$ \\
\hline \multirow[t]{3}{*}{ Dimensões da célula unitária } & a $6,2812(3) \AA$ \\
\hline & b 7,5936(4) $\AA$ \\
\hline & c $15,9552(8) \AA$ \\
\hline Volume & $747,93 \AA^{3}$ \\
\hline
\end{tabular}

(E)-1-(2-hidroxifenil)-3-(3,4,5-trimetoxifenil)prop-2-en-1-ona (17)<smiles>COc1cc(/C=C/C(=O)c2ccccc2O)cc(OC)c1OC</smiles> 


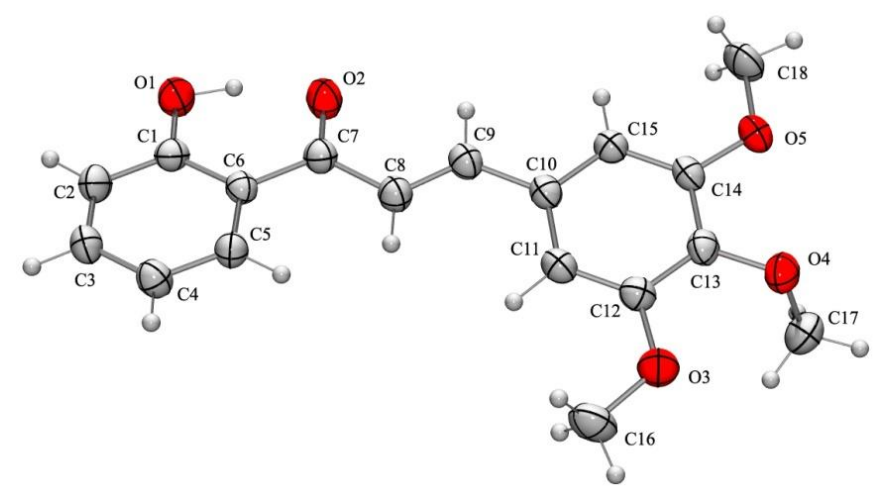

Figura 54. Estrutura 17 resolvida por difração de raios-X.

Tabela 15. Dados cristalográficos do composto 17.

\begin{tabular}{|c|c|}
\hline Código de identificação & 19 \\
\hline Fórmula empírica & $\mathrm{C}_{18} \mathrm{H}_{18} \mathrm{O}_{5}$ \\
\hline Massa molecular & 314,33 \\
\hline Grupo espacial & $\mathrm{P} 2{ }_{1} / \mathrm{c}$ \\
\hline Dimensões da célula unitária & $\begin{array}{ll}\text { a } 12,6529(13) \AA & \alpha 90,00^{\circ} \\
\text { b } 8,5929(9) \AA & \beta 107.929(8)^{\circ} \\
\text { c } 15,4160(18) \AA & \vee 90,00^{\circ}\end{array}$ \\
\hline Volume & $1594,71 \AA^{3}$ \\
\hline
\end{tabular}

(E)-3-(4-(dimetilamino)fenil)-1-(piridin-2-il)prop-2-en-1-ona (18)<smiles>CN(C)c1ccc(/C=C/C(=O)c2ccccn2)cc1</smiles>

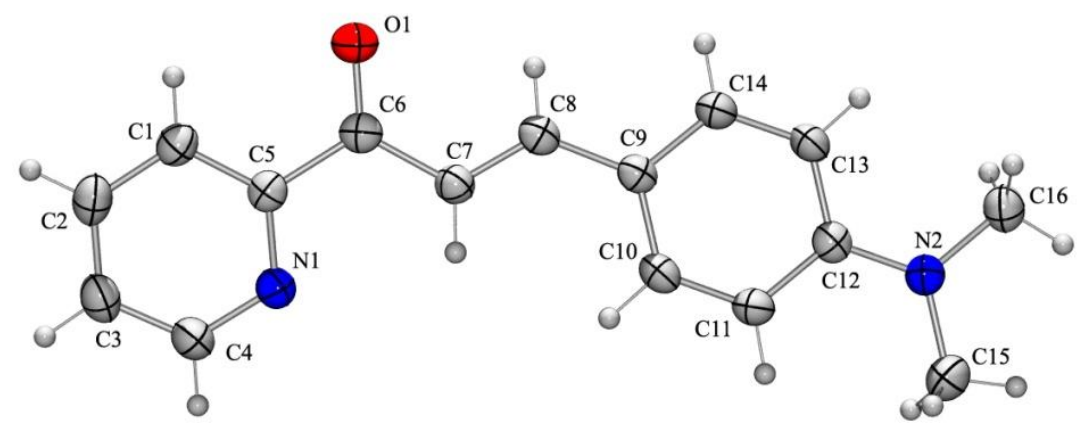

Figura 55. Estrutura 18 resolvida por difração de raios-X.

Tabela 16. Dados cristalográficos do composto 18. 


\begin{tabular}{|c|c|}
\hline Código de identificação & 18 \\
\hline Fórmula empírica & $\mathrm{C}_{16} \mathrm{H}_{16} \mathrm{~N}_{2} \mathrm{O}$ \\
\hline Massa molecular & 252,31 \\
\hline Grupo espacial & $\mathrm{P} 22_{1} / \mathrm{c}$ \\
\hline Dimensões da célula unitária & $\begin{array}{lc}\text { a } 23,5265(14) \AA & \alpha 90,00^{\circ} \\
\text { b 7,7610(5) } \AA & \beta 101,748(5)^{\circ} \\
\text { c } 15,2088(11) \AA & \vee 90,00^{\circ}\end{array}$ \\
\hline Volume & $2718,83 \AA^{3}$ \\
\hline
\end{tabular}

(E)-1-(2-aminofenil)-3-(3,4,5-trimetoxifenil)prop-2-en-1-ona (19)<smiles>COc1cc(/C=C/C(=O)c2ccccc2N)cc(OC)c1OC</smiles>

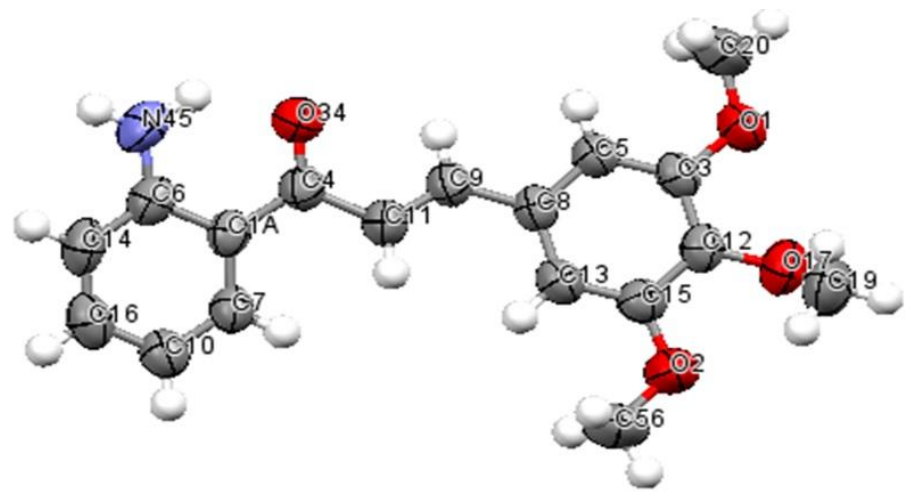

Figura 56. Estrutura 19 resolvida por difração de raios-X.

Tabela 17. Dados cristalográficos do composto 19.

\begin{tabular}{|c|cc|}
\hline Código de identificação & \multicolumn{1}{|c|}{$\mathrm{C}_{18} \mathrm{H}_{19} \mathrm{NO}_{4}$} \\
\hline Fórmula empírica & \multicolumn{2}{|c|}{313,35} \\
\hline Massa molecular & & $\mathrm{P} 2{ }_{1} / \mathrm{c}$ \\
\hline Grupo espacial & a $12.713 \AA$ & $\alpha 90,00^{\circ}$ \\
& b $8.649 \AA$ & $\beta 103.80$ \\
& c $15.231 \AA$ & $\vee 90,00^{\circ}$ \\
\hline Dimensões da célula unitária & & $1626.38 \AA^{3}$ \\
\hline
\end{tabular}




\section{Referências Bibliográficas}

1- Ni, L.; Meng, C.Q.; Sikorski, J. A.; Exp. Opn. 2004, 14, 1669.

2- Alvim, H. G. O.; Fagg, E. L.; Oliveira, A. L.; Oliveira, H. C. B.; Freitas, S. M., Xavier, M. A. E.; Soares, T. A.; Gomes, A. F.; Gozzo, F. C.; Silva, W. A.; Neto, B.A.D.; Org. Biomol. Chem. 2013, 11, 4764.

3- a) Aksöz, B. E.; Ertan, R.; J. Pharm. Sci. 2011, 36, 223. b) Liu, M.; Wilairat, P.; Croft, S. L.; Tan, A. L.; Go, M.; Bio. Med. Chem. 2003, 11, 2729. c) Mahapatra, D. K.; Bharti, S. K.; Asati, V.; Eur. J. Med. Chem. 2015, 98, 69. d) Mahapatra, D. K.; Bharti, S. K.; Asati, V.; Eur. J. Med. Chem. 2015, 101, 496.

4- Dao, T. T. H.; Linthorst, H. J. M.; Verpoorte, R.; Phytochem. Rev. 2011, 10, 397.

5- Lawrence, N. J.; Rennison, D.; McGown, A. T.; Ducki, S.; Gul, L. A.; Hadfield, J. A.; Khan, K.; J. Comb. Chem. 2001, 3, 421.

6- Kumar, N.; Jain, J. S.; Sinha, R.; Garg, V. K.; Bansal, S. K.; Der Pharm. Lett. 2009, 1, 169.

7- Lawrence, N. J.; Patterson, R. P.; Ooi L.; Cookc D.; Duckic, S.; Bioorg. Med. Chem. Lett. 2006, 16, 5844.

8- Lawrence, N. J.; Ducki, S.; Rennison, D.; Woo, M.; Kendall, A.; Chabert, J. F. D.; McGown, A. T.; Bioorg. Med. Chem. 2009, 17, 7698.

9- Borchhardt, D. M.; Mascarello A.; Chiaradia, L. D.; Nunes, R. J.; Oliva,G.; Yunes, R. A.; Andricopulo, A.D.; J. Braz. Chem. Soc. 2010, 21, 142.

10- Cui, M.; Ono, M.; Kimura, H.; Liu, B.L.; Saji, H.; Bioorg. Med. Chem. Lett. 2011, 21, 980.

11- Qu, W.; Choi, S.-R.; Hou, C.; Zhuang, Z.; Oya, S.; Zhang, W.; Kung, M.-P.; Manchandra, R.; Skovronsky, D. M.; Kung, H. F.; Bioorg.. Med. Chem. Lett. 2008, 18, 4823.

12- Lakowicz, J.R.; Principles of Fluorescence Spectroscopy, 3ํㅡㄹ ed.; Springer: Nova York, USA, 2006.

13- Lee, S. C.; Kang, N. Y.; Park, S. J.; Yun, S. W.; Chandran, Y.; Chang, Y. T.; Chem. Commun. 2012, 48, 6681.

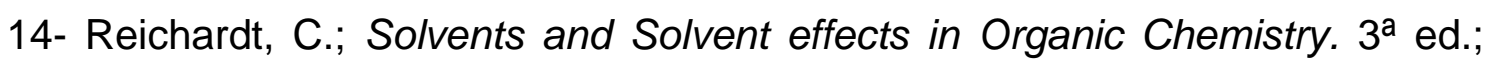
Wylei- VHC: Alemanha, Weinheim, 2004. 
15- Skoog, D. A.; West, D. M.; Hooler, F. J.; Stanley, R. C.; Fundamentos da Química Analítica, Tradução da 8ae ed.; Ed. Thomson: São Paulo, SP, 2008.

16- Reichardt, C.; Chem. Rev. 1994, 94, 2319.

17- Danko, M.; Andics, A.; Kosa, C.; Hrdlovic, P.; Vegh, D.; Dyes Pig. 2012, 92, 1257.

18- Valeur, B.; Molecular Fluorescence: Principles and Applications, WileyVCH: Alemanha, Weinheim, 2002.

19- Marwani, H.M.; Asiri, A. M.; Khan, S.A.; J. Lumi. 2013, 136, 296.

20- El-Daly, S.A.; Asiri, A. M.; Alamry, K.; Khan, S. A.; J. Lumi. 2013, 137, 6.

21- Nowakowska, Z.; Eur. J. Med. Chem., 2007, 42, 125.

22- Júnior, E. N. S., Jardim, G. A. M., Barreto, R. F. S. M., Castro, S. L., J. Braz. Chem. Soc., 2014, 25, 1780.

23- Noireau, F.; Diosque, P.; Jansen, A. M.; Vet. Res. 2009, 40, 26.

24- http://labspace.open.ac.uk/course/view.php?id=7590, acessado em: 1/9/14. 25- DIAS, J.C.P. e COURA, J.R., org. Clínica e terapêutica da doença de Chagas: uma abordagem prática para o clínico geral [online]. Rio de Janeiro. Ed.FIOCRUZ. 1997.

26-http://www.jornalufgonline.ufg.br/pages/44396-laboratorio-de-pesquisa-dadoenca-de-chagas-da-ufg-e-referencia-internacional, acessado em Novembro 2014.

27- Sajid, M.; McKerrow, J. H.; Mol. Biochem. Parasitol. 2002, 159, 1221.

28- Fayed, T. A.; Shaaban, M. H.; El-Nahass, M. N.; Hassan, F. M.; Micro. Meso. Mat. 2014, 198, 144.

29- Trossini, G. H. G.; Vital, D. G.; Arribas, M.; Lett. Drug Design Disc. 2014, $11,249$.

30- Du, X.; Guo, C.; Hansell, E.; Doyle, P.S.; Caffrey, C.R.; Holler, T.P.; McKerrow, J.H.; Cohen, F.E.; J. Med. Chem. 2002, 45, 2695.

31- Leach, A. R.; Shoichet, B. K.; Peishoff, C. E.; J. Med. Chem. 2006, 49, 5851.

32- Blau, L.; Menegon, R. F.; Trossini, G. H. G.; Molino, J. V.; Vital, D. G.; Cicarelli, R. M. B.; Passerini, G. D.; Bosquesi, P. L.; Chung, M. C.; Eur. J. Med Chem. 2013, 67, 142.

33- a) Caputto, M. E.; Ciccareli, A.; Frank, F.; Moglioni, A. G.; Moltrasio, G. Y.; Veja, D.; Lombardo, E.; Finkielsztein, L. M.; Eur. J. Med. Chem. 2012, 55, 155. 
b) Carneiro, P. F.; Nascimento, S. B.; Pinto, A. V.; Pinto, M. C. F. R.; Lechuga, G. C.; Santos, D. O.; Júnior, H. M. S.; Resende, J. A. L. C.; Bourguignon, S. C.; Ferreira, V. F.; Bioorg. Med. Chem. 2012, 20, 4995. c) Carvalho, S. O.; Feitosa, L. O.; Soares, M.; Costa, T. E. M. M.; Henriques, M. G.; Salomão, K.; Castro, S. L.; Kaiser, M.; Brun, R.; Wardell, J. M.; Wardell, S. M. S. V.; Trossini, G. H. G.; Andricopulo, A. D.; Silva, E. F.; Fraga, C. A. M.; Eur. J. Med. Chem. 2012, 54, 512.

34- Pannipara, M.; Asiri, A. M.; Alarmy, K. A.; Arshad, M. N.; El-Daly, S. A.; Spectrochim. Acta, Part A 2015, 136, 1893.

35- Kumar, H.; Chattopadhyay, A.; Prasath, R.; Devaraji, V.; Joshi, R.; Bhavana, P.; Saini, P.; Gohsh, S. K.; J. Phys. Chem. B 2014, 118, 7257.

36- Pannipara M.; Asiri, A. M.; Alamry, K. A.; Arshad, M. N.; El-Daly, S. A.; J. Fluoresc. 2014, 24, 1629.

37- Komarova, K. G.; Sakipov, S.N.; Plotnikov, V.G.; Alfimov, M.V.; J.Lumi. 2015, 164, 57.

38- Lee, S.; Kang, N.; Park, S.; Yun, S.; Chandran, Y.; Chang, T.; Chem. Commun. 2012, 48, 6681.

39- Velapoldi, R. A.; Tonnesen, H. H.; J. Fluores. 2004, 14, 465.

40- Jagadeesh, M.; Lavanya, M.; Babu, B. H.; Hong, K.; Ma, R.; Kim, J.; Kim, T. K.; Spectrochim. Acta, Part A 2015, 150, 557.

41- Arias, A.C.; MacKenzie, J.D.; McCulloch, I.; Rivnay, J.; Salleo, A.; Chem. Rev. 2010, 110,3.

42- Rahulan, K.M.; Balamurugan, S.; Meena, K.S.; Yeap, G.; Kanakam, C.C.; Opt. Laser Technol. 2014, 56, 142.

43- Grabowski, Z.R.; Rotkiewicz, K.; Rettig, W.; Chem. Rev. 2003, 103, 3899.

44- Chipem, F.A.S.; Mishra, A.; Krishnamoorthy, G.; Phys. Chem. Chem. Phys. 2012, 14, 8775.

45- Li, Q.; Peng, M.; Li, H.; Zhong, C.; Zhang, L.; Cheng, X.; Peng, X.; Wang, Q.; Qin, J.; Li, Z.; Org. Lett. 2012, 14, 2094.

46- Fayed, T. A.; Chem. Phys. 2006, 324, 631.

47- Agrarwal, S.; Greiner, A.; Wendorff, J. H.; Prog. Polym. Sci. 2013, 38, 963.

48- Davis, B. W.; Niammont, N.; Hare, C. D.; Sukwattanasinitt, M.; Cheng, Q.; ACS Appl. Mater. Interfaces, 2010, 2, 1798. 
49- Baji, A.; Mai, Y.; Wong, S.; Abtahi, M.; Chen, P.; Compos. Sci. Technol. 2010, 70, 703.

50- Chakraborty, S.; Liao, I. C.; Adler, A.; Leong, K. W.; Adv Drug Deliv Rev. 2009, 61,1043.

51- Bhardwaj, N.; Kundu, S. C.; Biotechnol. Adv. 2010, 28, 325.

52- Chen, J. S.; Xu, L.; Xing, R. Q.; Song, J.; Song, H. W.; Liu, D. L.; Zhou, J. Electrochem. Commun. 2012, 20, 75.

53- Sahay, R.; Kumar, P. S.; Sridhar, R.; Sundaramurthy, J.; Venugopal, J.; Mhaisalkar, S. G.; Ramakrishna, S.; J. Mater. Chem. 2012, 22, 12953.

54- Chai, J. H; Wu, Q. S.; Belstein. J. Nanotechnol. 2013, 4,189.

55- Dissertação de Mestrado da Universidade de Brasília, aluno Matheus Serra de Holanda, 2012, 21.

56- Melo, E. F.; Santana, N. C.; Alves, K. G. B.; Sá, G. F.; Melo, C. P.; Rodrigues, M. O.; Júnior, S. A.; J. Mater. Chem. C, 2013, 1, 7574.

57- Jyothi, M. V.; Venkatesh, P.; Orient. J. Chem. 2012, 28, 1437.

\section{Anexos}

8.1 Espectros de RMN ${ }^{1} \mathrm{He} \mathrm{e}^{13} \mathrm{C}$ 


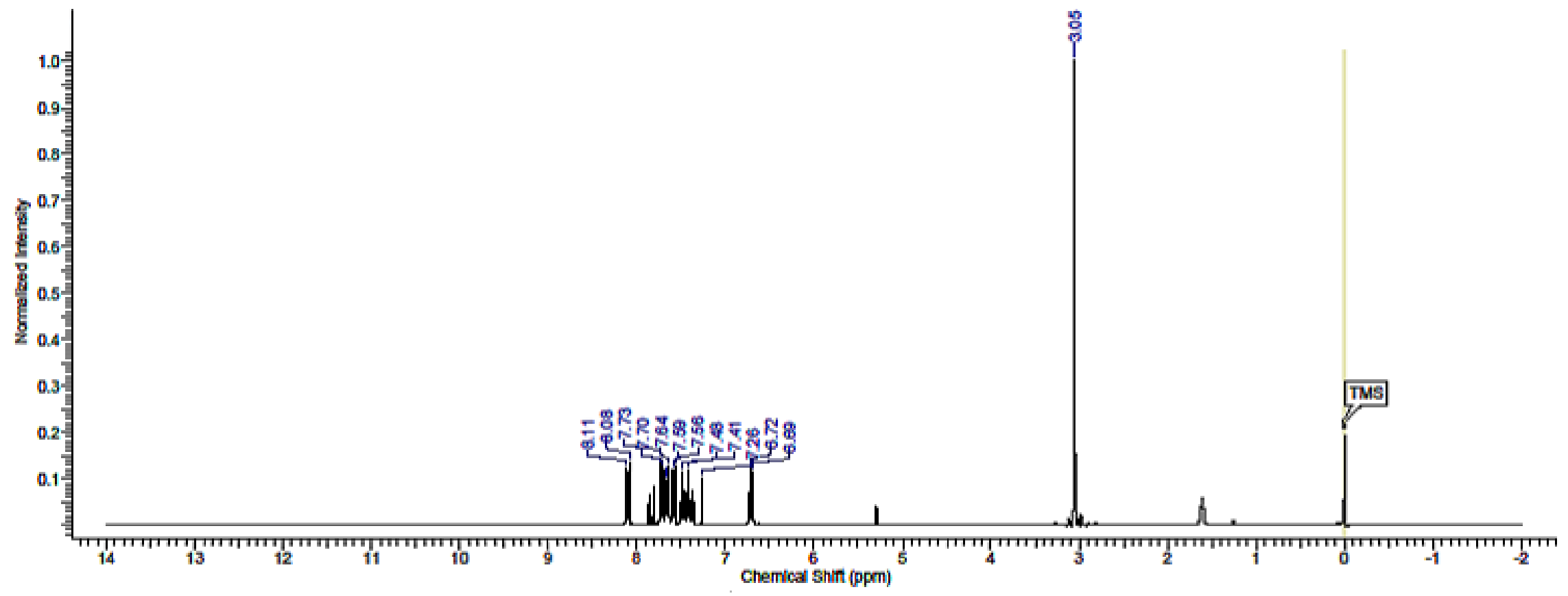

Espectro 1. Espectro de $\mathrm{RMN}^{1} \mathrm{H}\left(300 \mathrm{MHz}, \mathrm{CDCl}_{3}\right)$ da estrutura 9. 


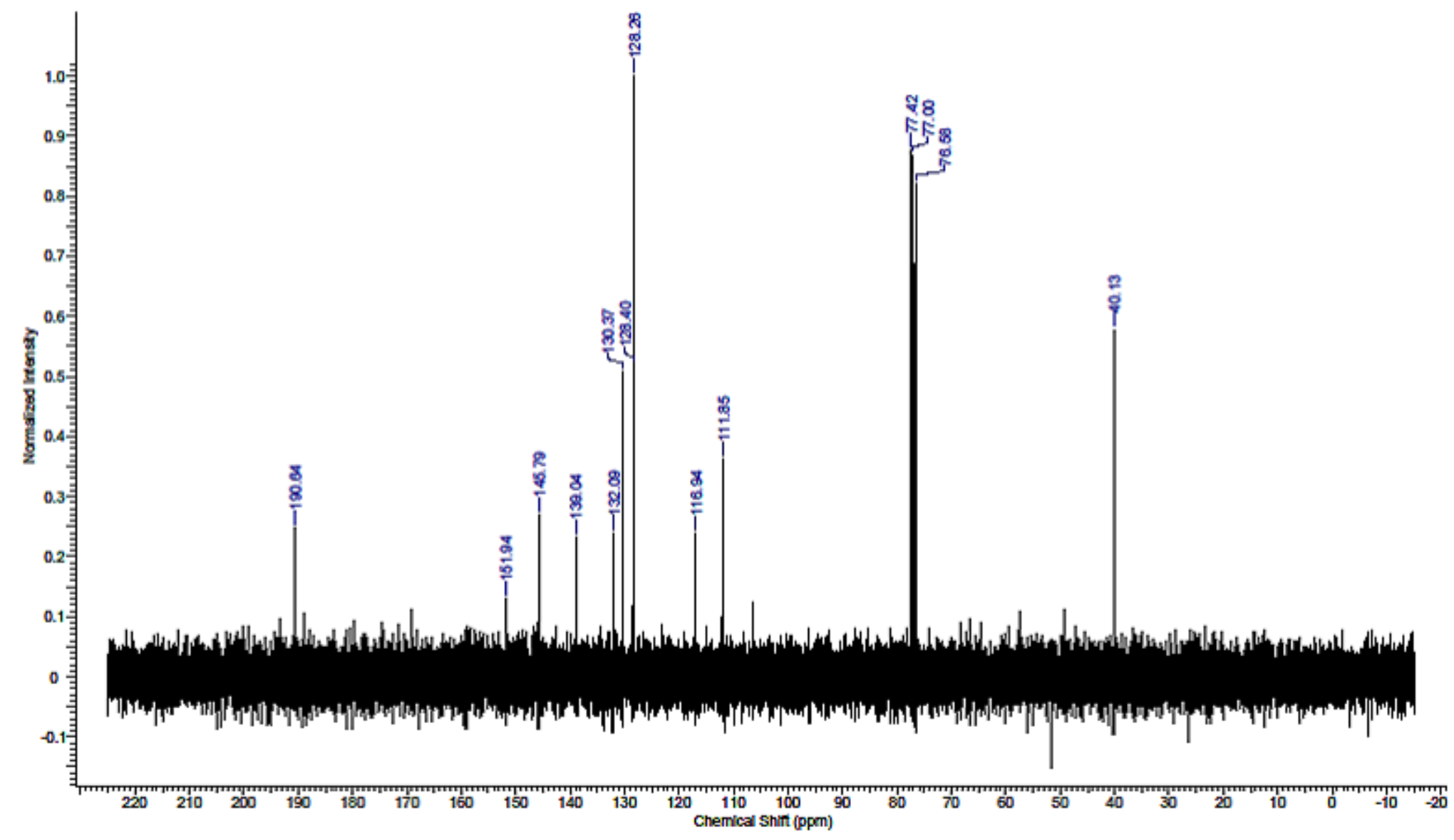

Espectro 2. Espectro de $\mathrm{RMN}{ }^{13} \mathrm{C}\left(75 \mathrm{MHz}, \mathrm{CDCl}_{3}\right)$ da estrutura 9 . 


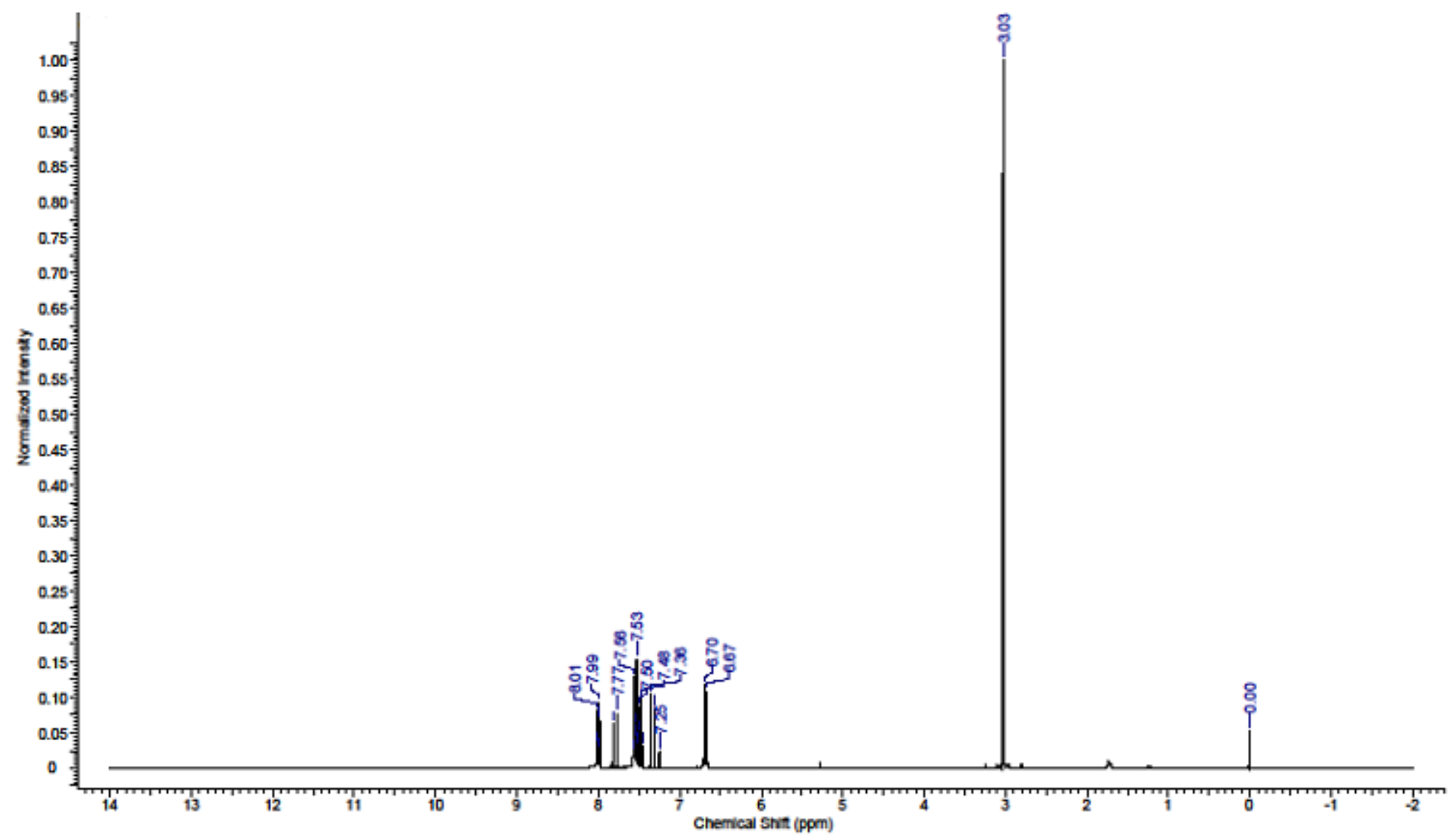

Espectro 3. Espectro de RMN ${ }^{\top} \mathrm{H}\left(300 \mathrm{MHz}, \mathrm{CDCl}_{3}\right)$ da estrutura 10. 


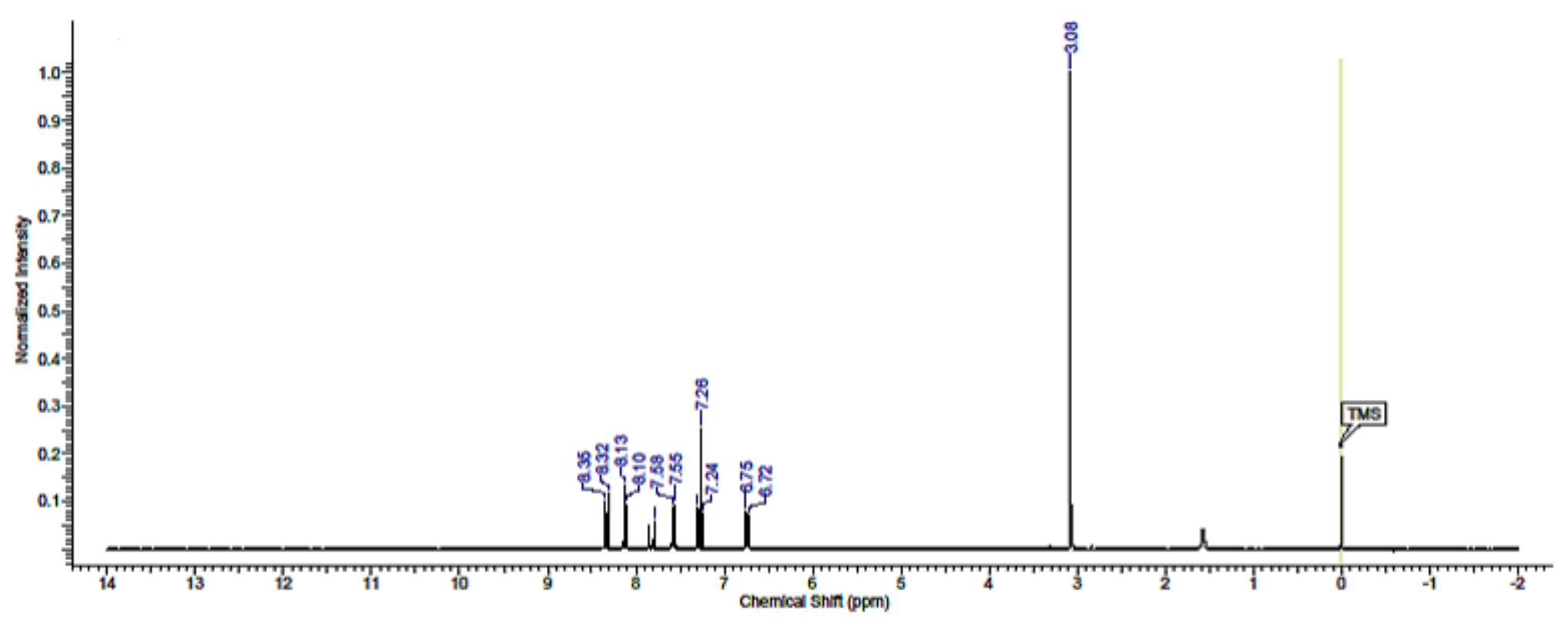

Espectro 4. Espectro de $\mathrm{RMN}^{1} \mathrm{H}\left(300 \mathrm{MHz}, \mathrm{CDCl}_{3}\right)$ da estrutura 11. 


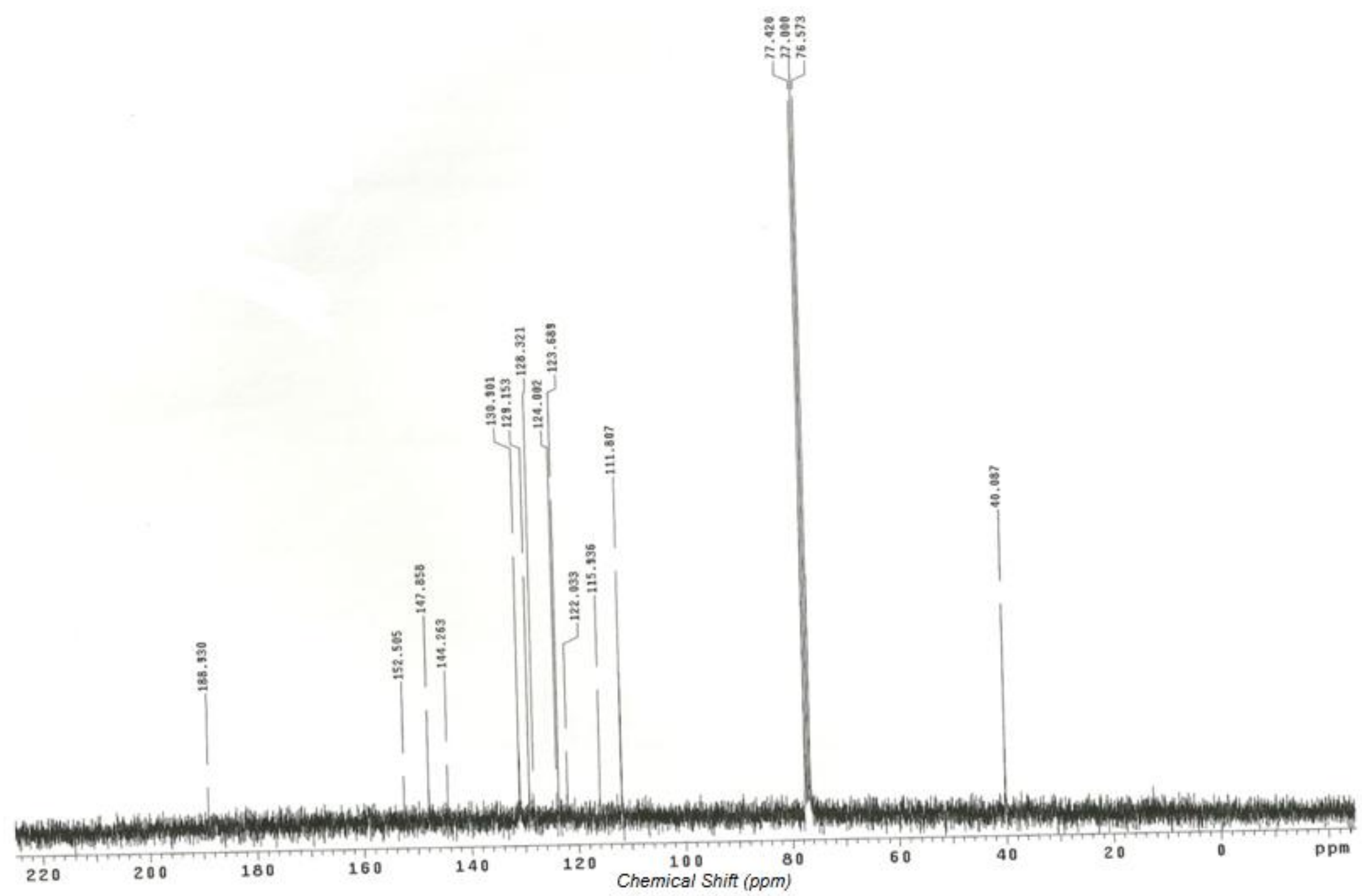

Espectro 5. Espectro de RMN ${ }^{13} \mathrm{C}\left(75 \mathrm{MHz}, \mathrm{CDCl}_{3}\right)$ da estrutura 11. 


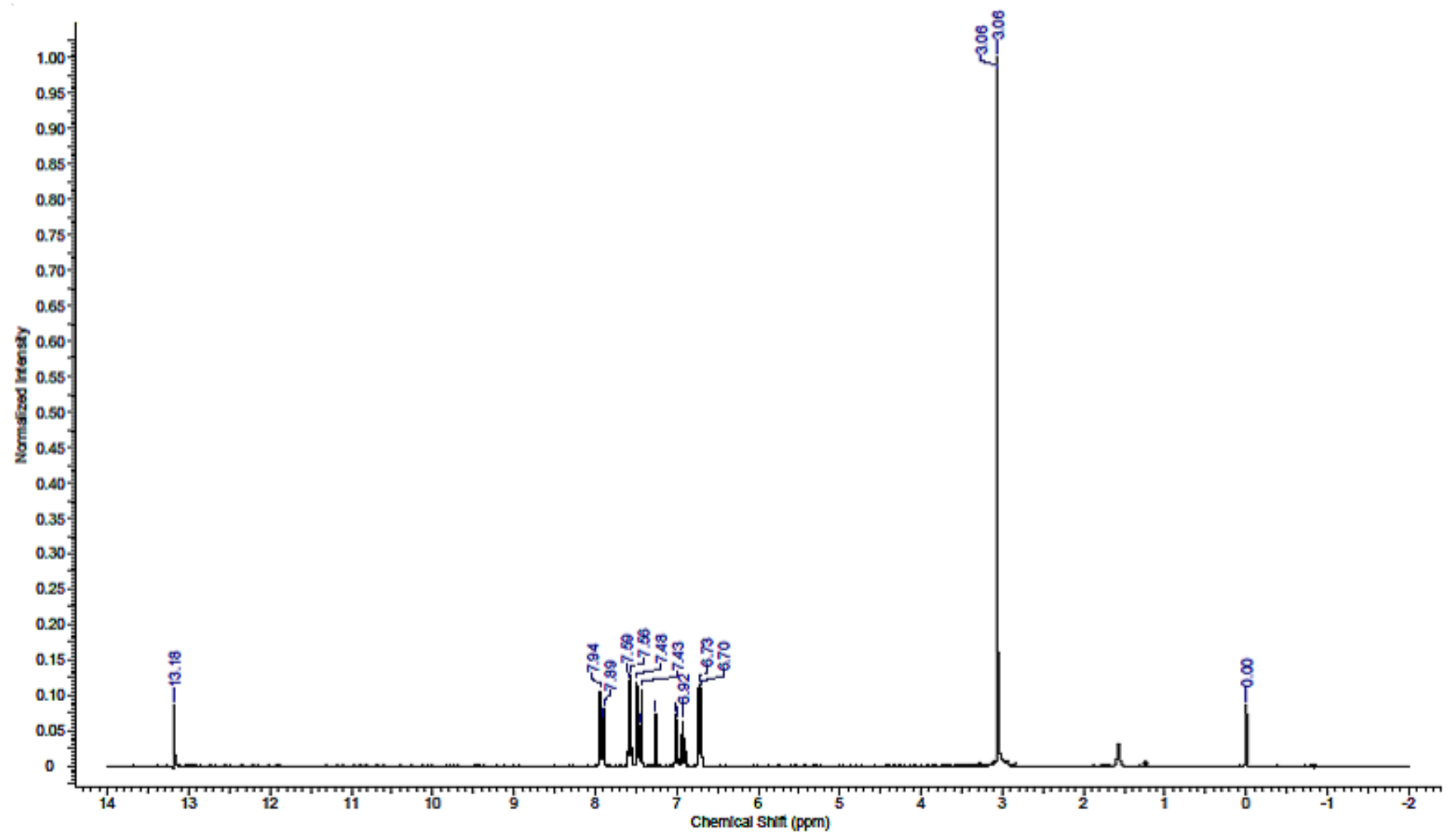

Espectro 6. Espectro de RMN ${ }^{\top} \mathrm{H}\left(300 \mathrm{MHz}, \mathrm{CDCl}_{3}\right)$ da estrutura 12. 


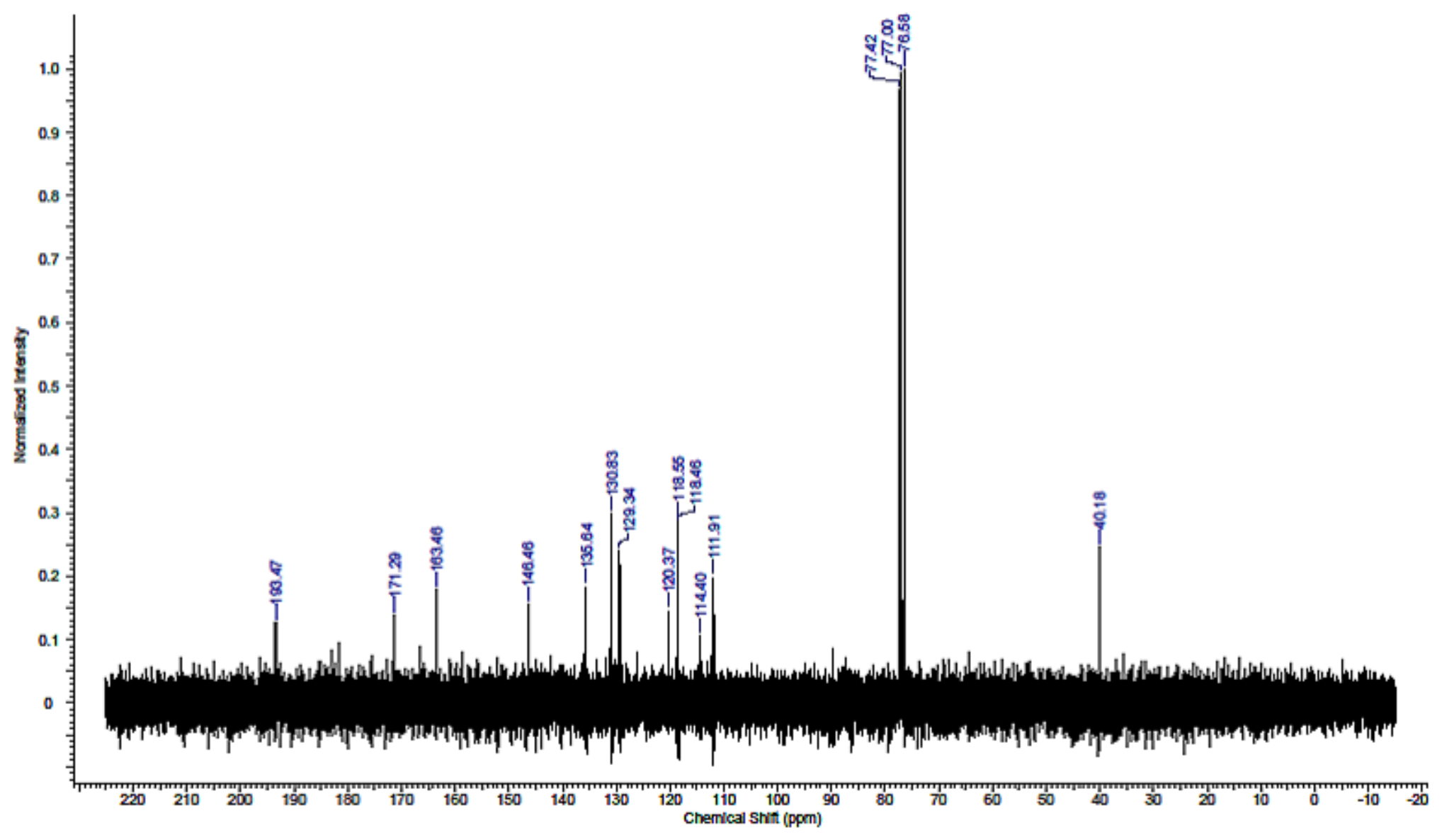

Espectro 7. Espectro de $\mathrm{RMN}{ }^{13} \mathrm{C}\left(75 \mathrm{MHz}, \mathrm{CDCl}_{3}\right)$ da estrutura 12. 


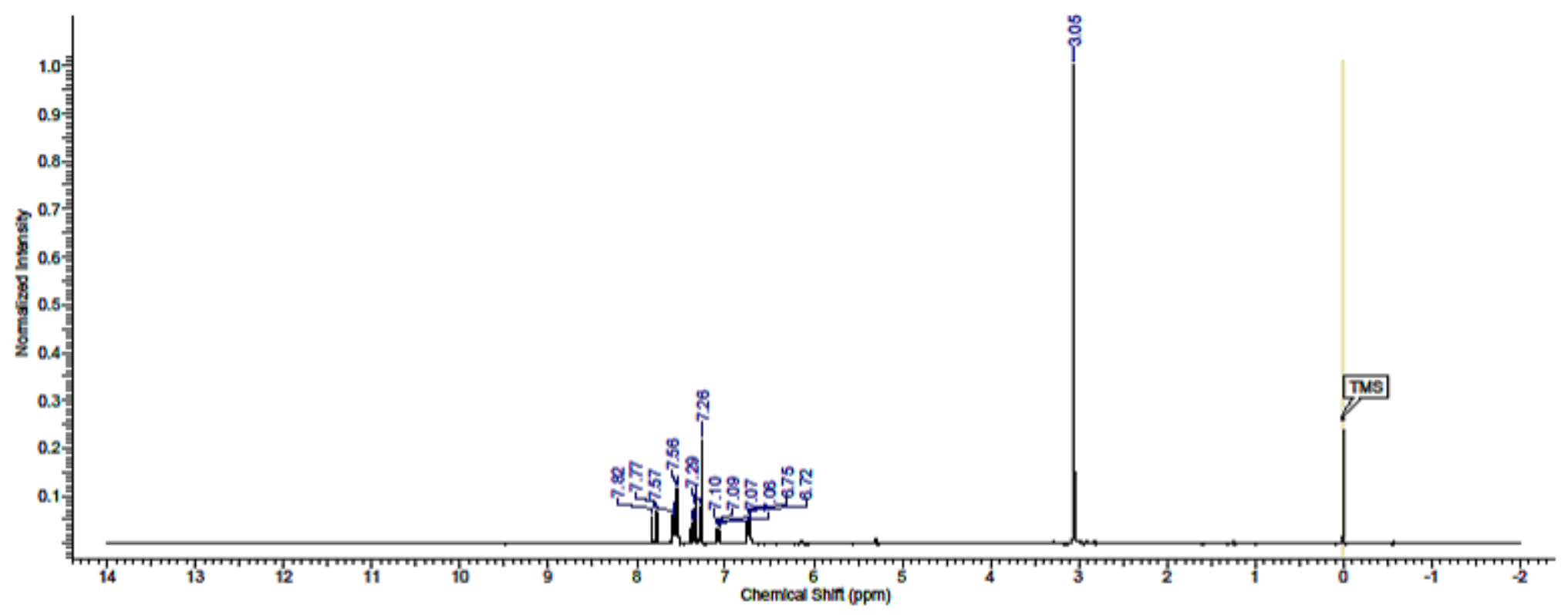

Espectro 8. Espectro de RMN ${ }^{\top} \mathrm{H}\left(300 \mathrm{MHz}, \mathrm{CDCl}_{3}\right)$ da estrutura 13. 


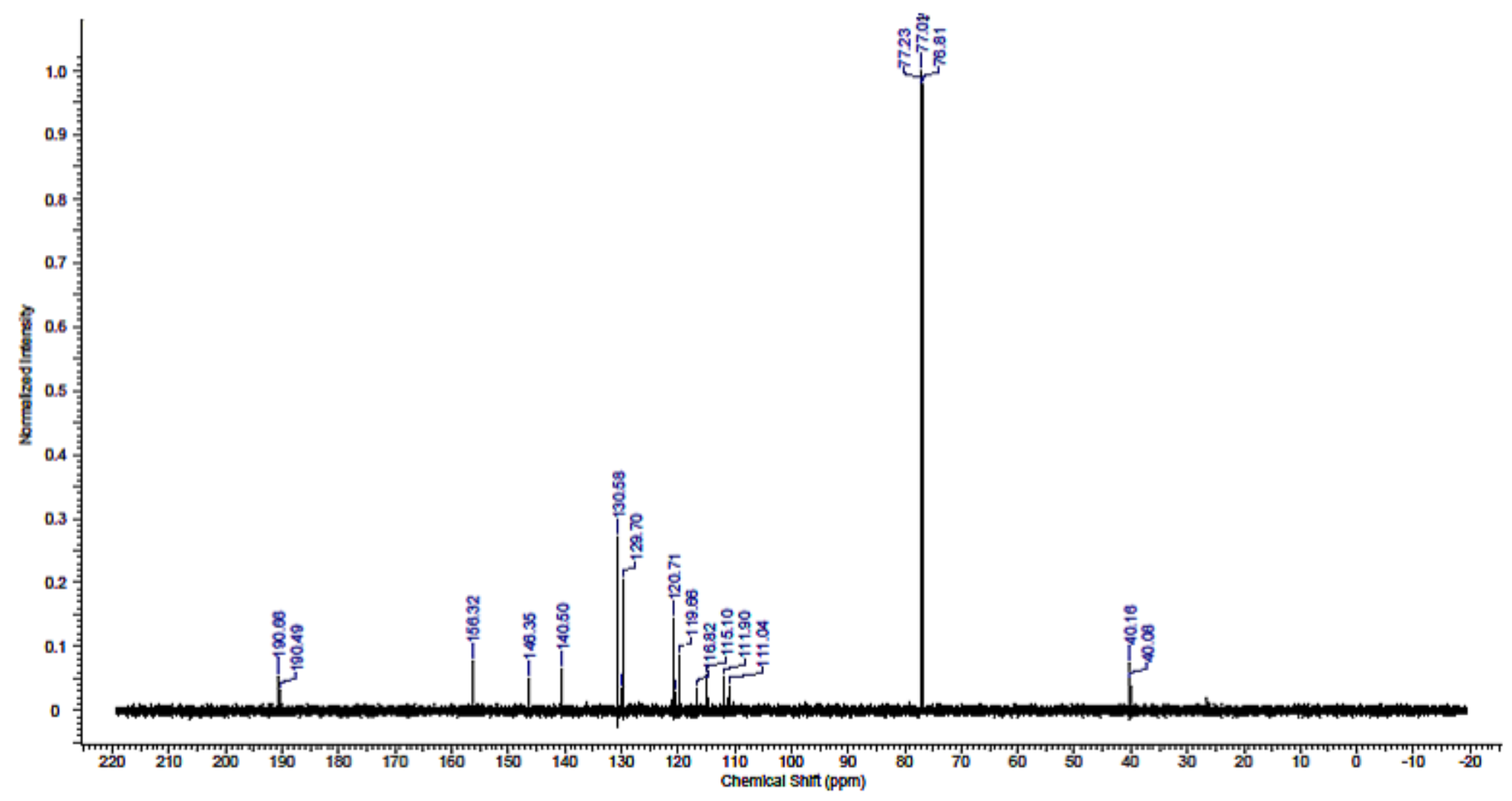

Espectro 9. Espectro de $\mathrm{RMN}{ }^{13} \mathrm{C}\left(150 \mathrm{MHz}, \mathrm{CDCl}_{3}\right)$ da estrutura 13. 


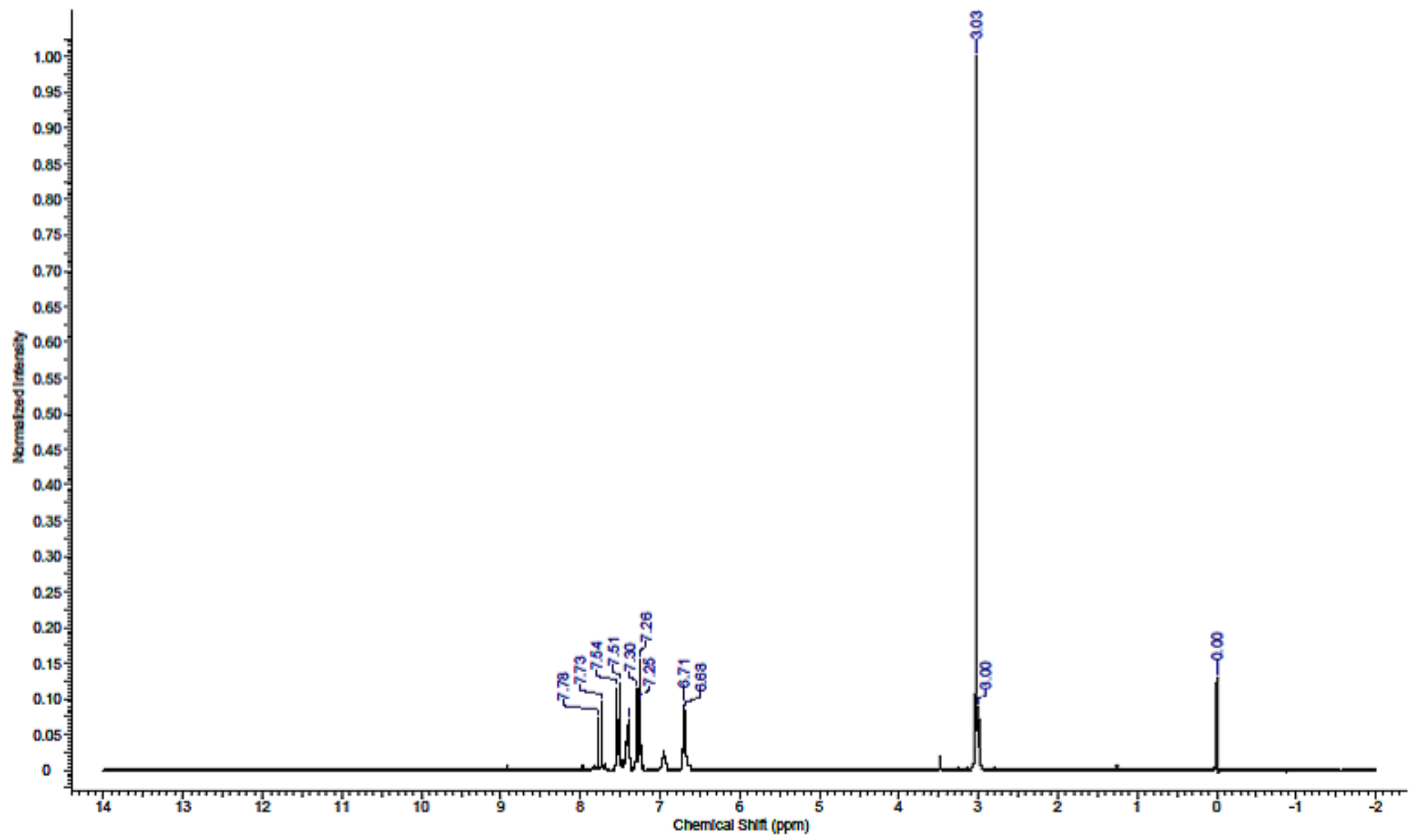

Espectro 10. Espectro de $\mathrm{RMN}{ }^{1} \mathrm{H}\left(300 \mathrm{MHz}, \mathrm{CDCl}_{3}\right)$ da estrutura 14. 


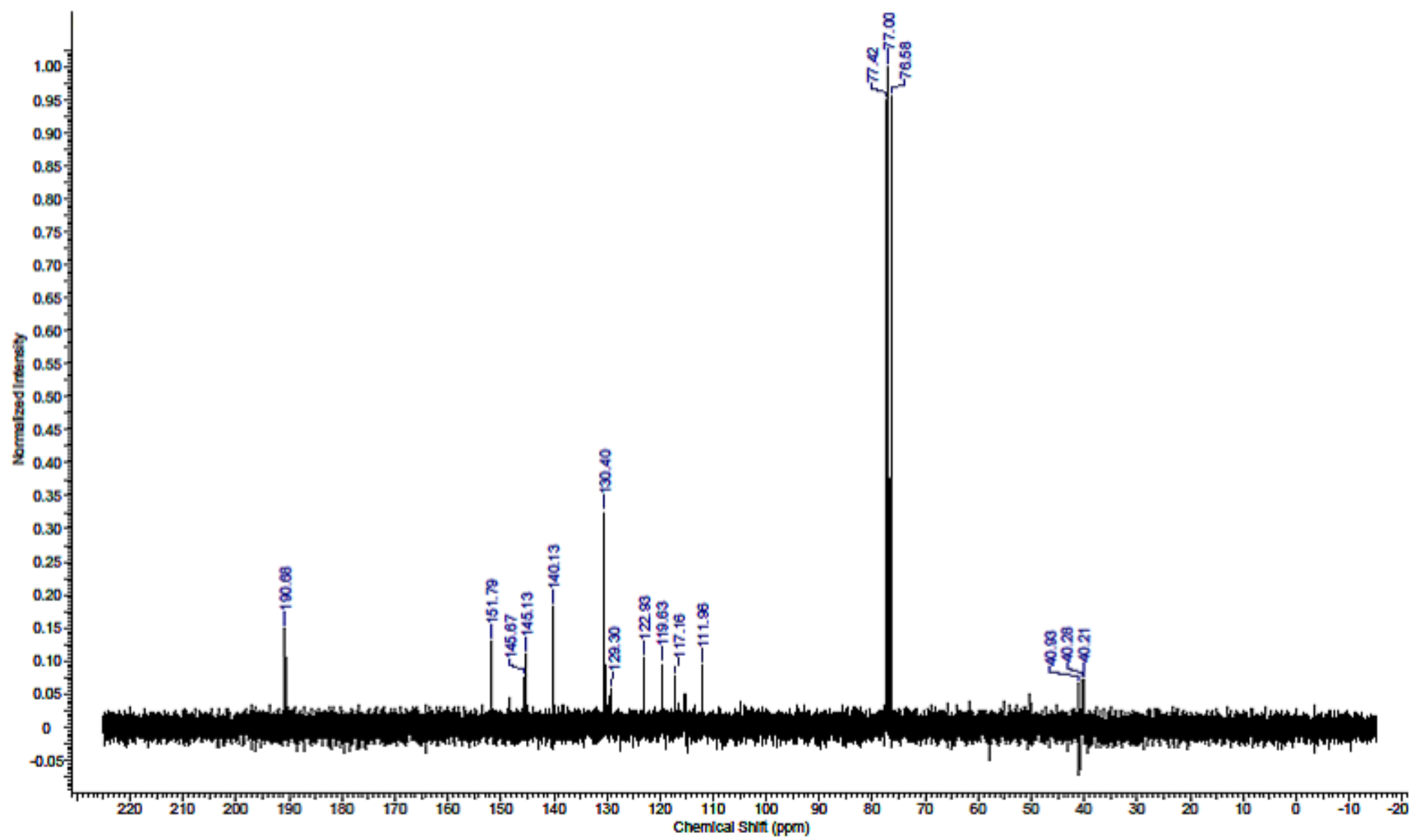

Espectro 11. Espectro de $\mathrm{RMN}{ }^{13} \mathrm{C}\left(75 \mathrm{MHz}, \mathrm{CDCl}_{3}\right)$ da estrutura 14. 


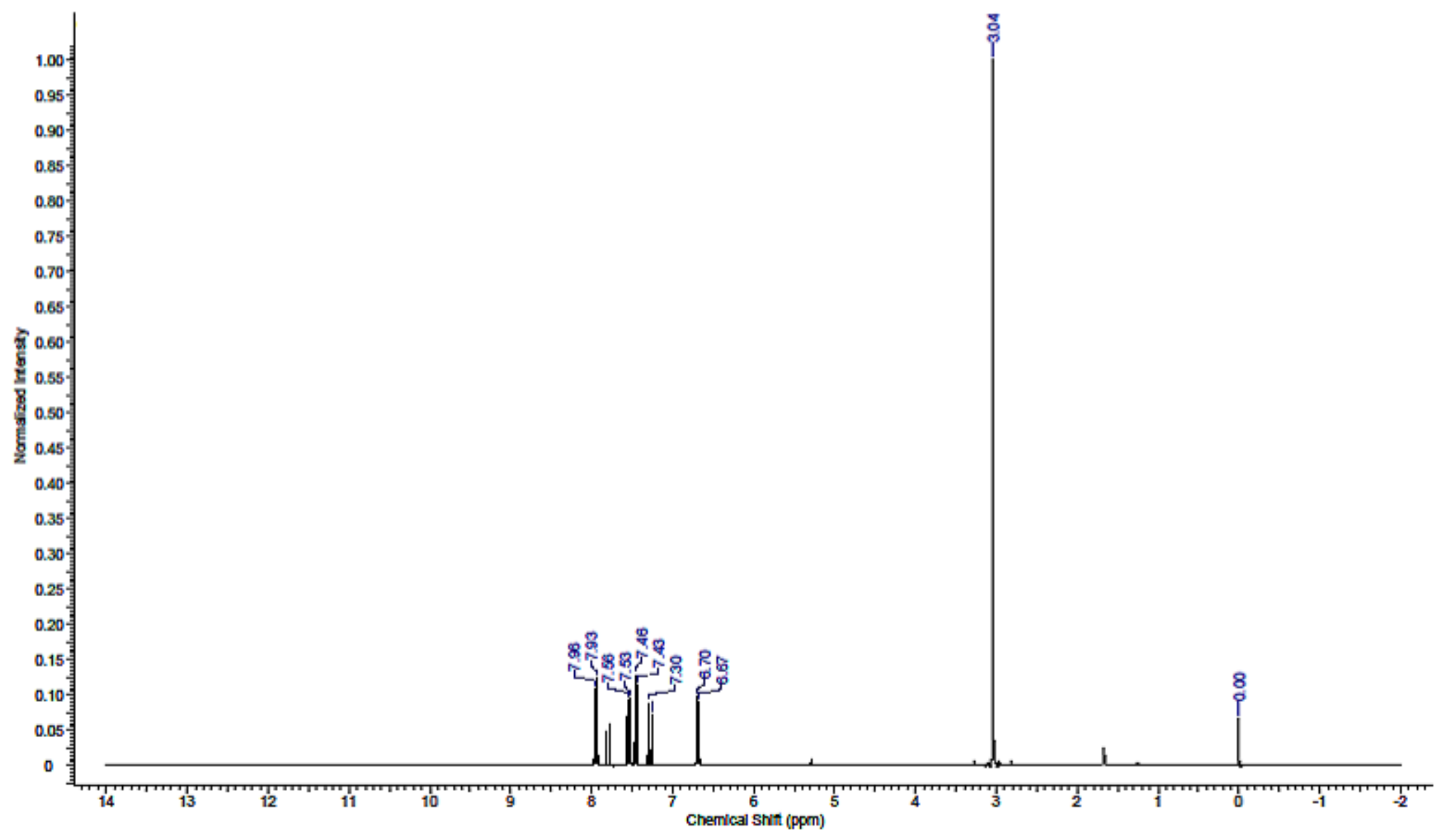

Espectro 12. Espectro de $\mathrm{RMN}^{1} \mathrm{H}\left(300 \mathrm{MHz}, \mathrm{CDCl}_{3}\right)$ da estrutura 15. 


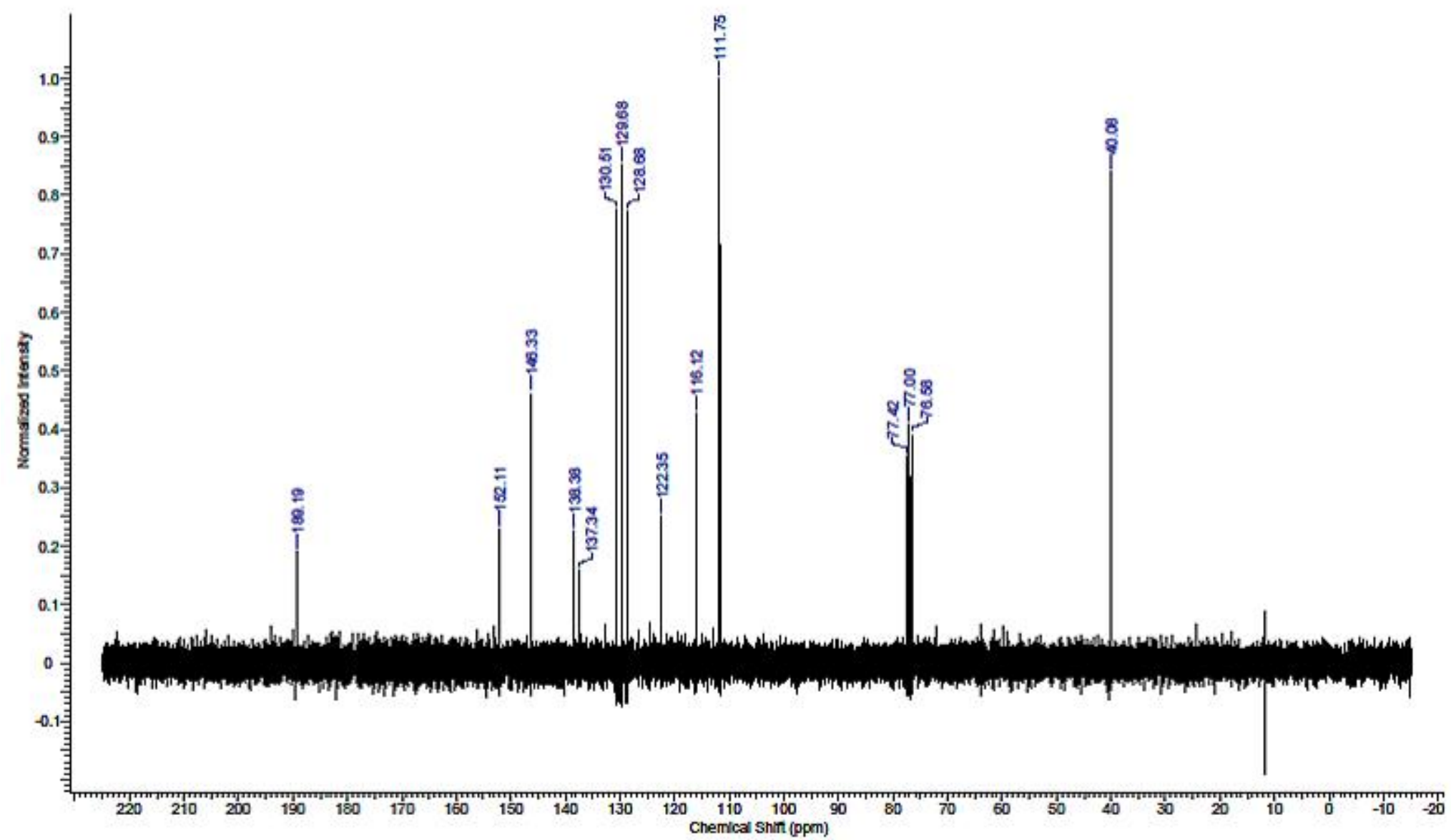

Espectro 13. Espectro de $\mathrm{RMN}^{13} \mathrm{C}\left(75 \mathrm{MHz}, \mathrm{CDCl}_{3}\right)$ da estrutura 15. 


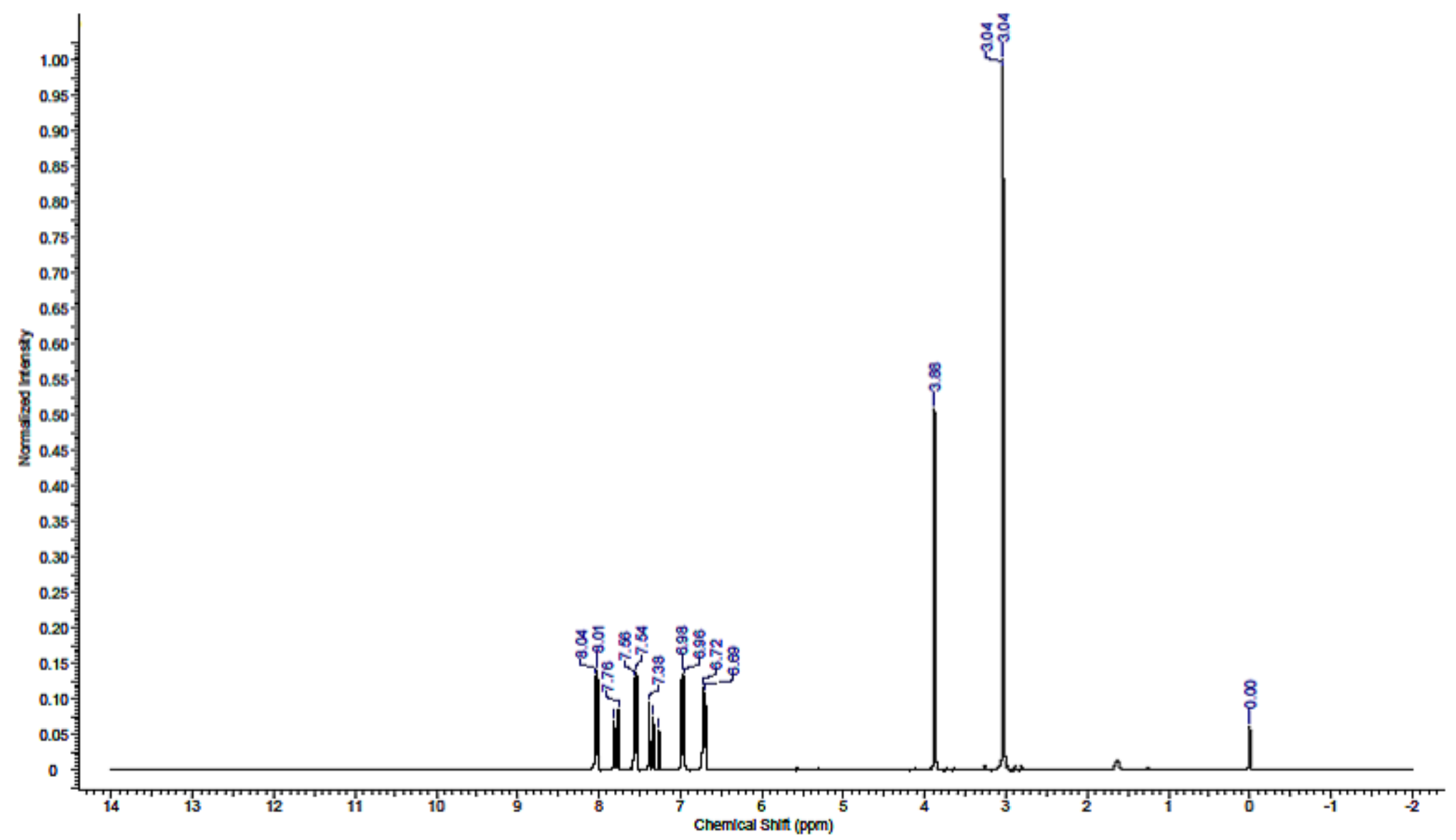

Espectro 14. Espectro de $\mathrm{RMN}^{1} \mathrm{H}\left(300 \mathrm{MHz}, \mathrm{CDCl}_{3}\right)$ da estrutura 16. 


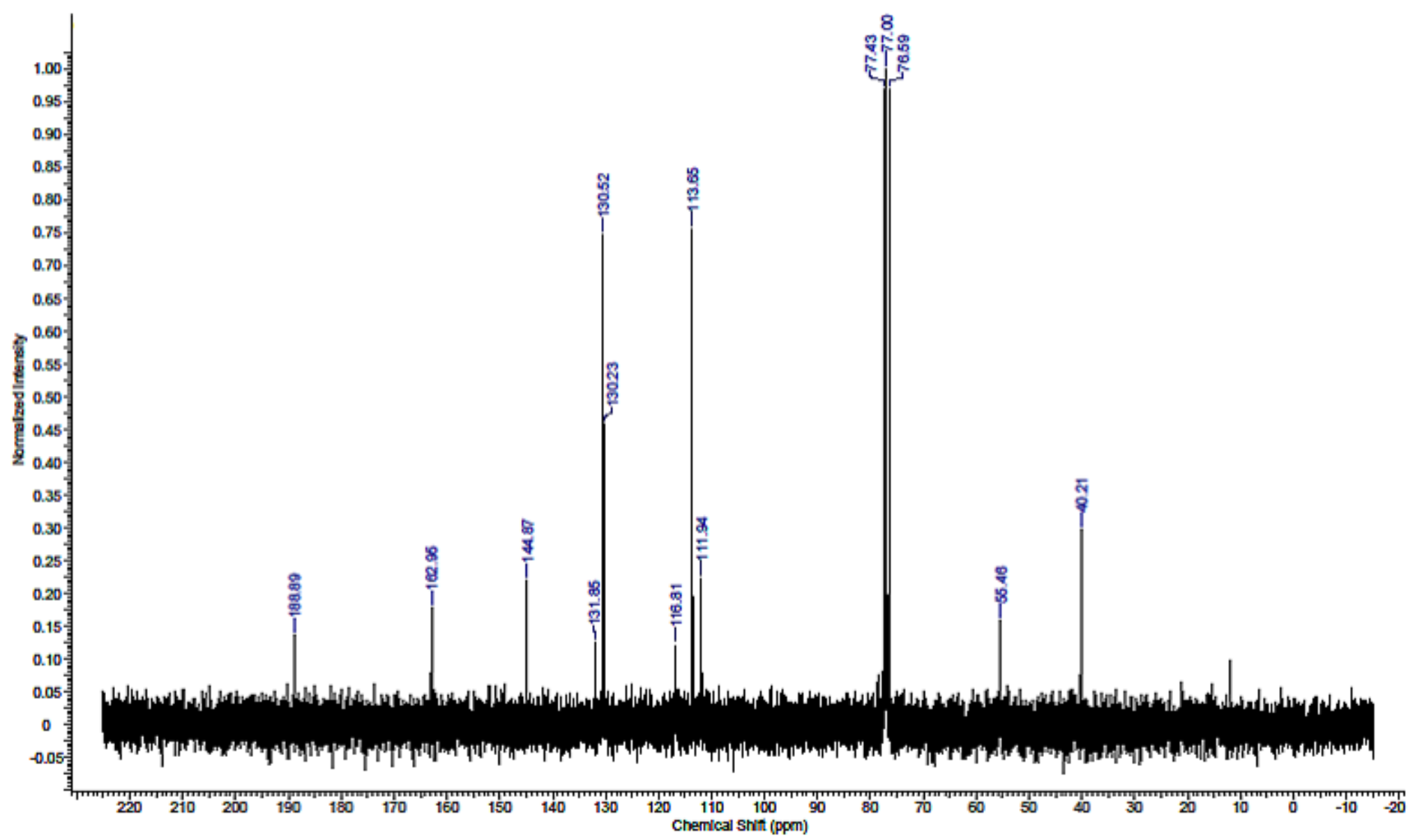

Espectro 15. Espectro de $\mathrm{RMN}{ }^{13} \mathrm{C}\left(75 \mathrm{MHz}, \mathrm{CDCl}_{3}\right)$ da estrutura 16. 


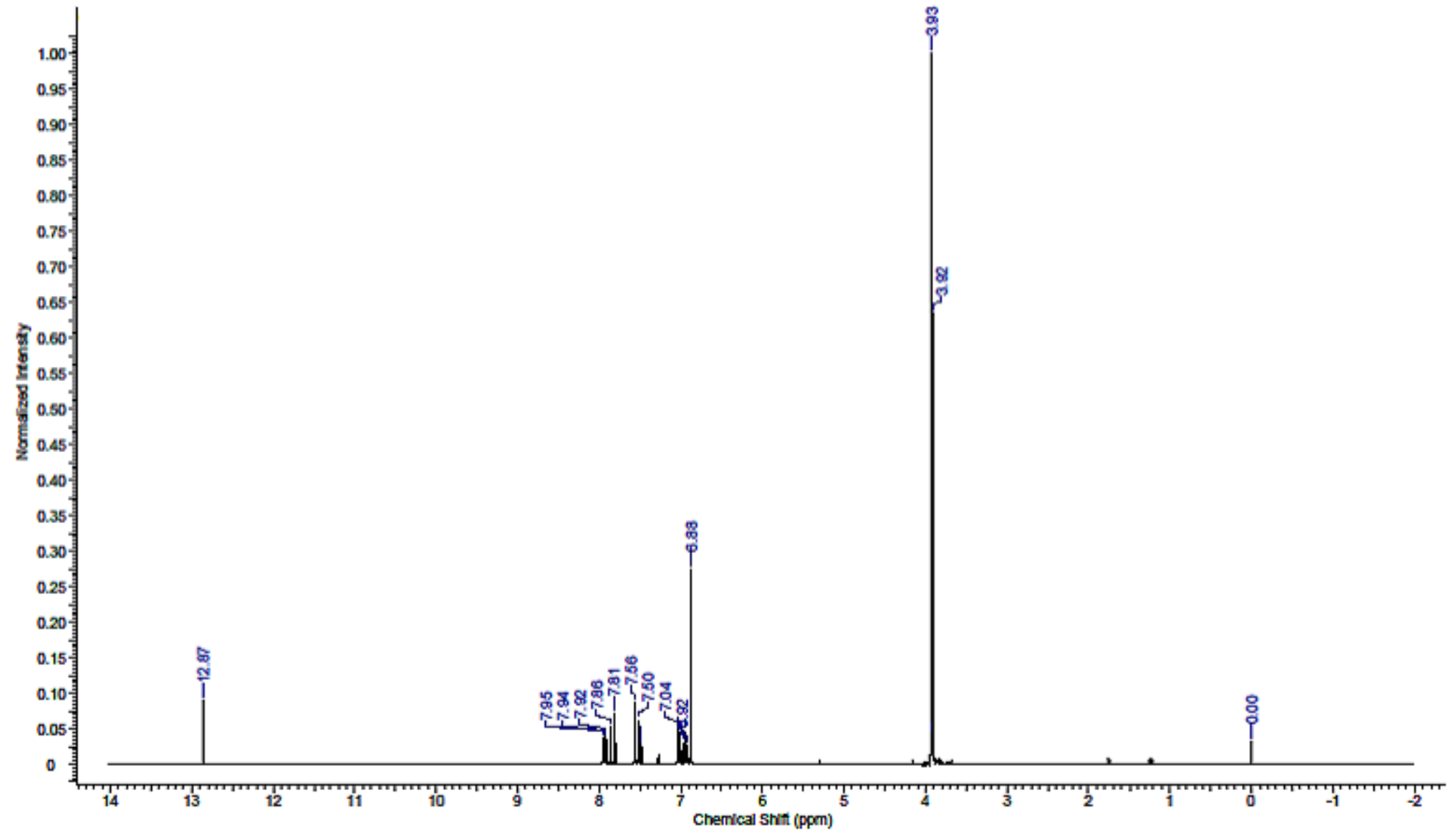

Espectro 16. Espectro de $\mathrm{RMN}{ }^{1} \mathrm{H}\left(300 \mathrm{MHz}, \mathrm{CDCl}_{3}\right)$ da estrutura 17. 


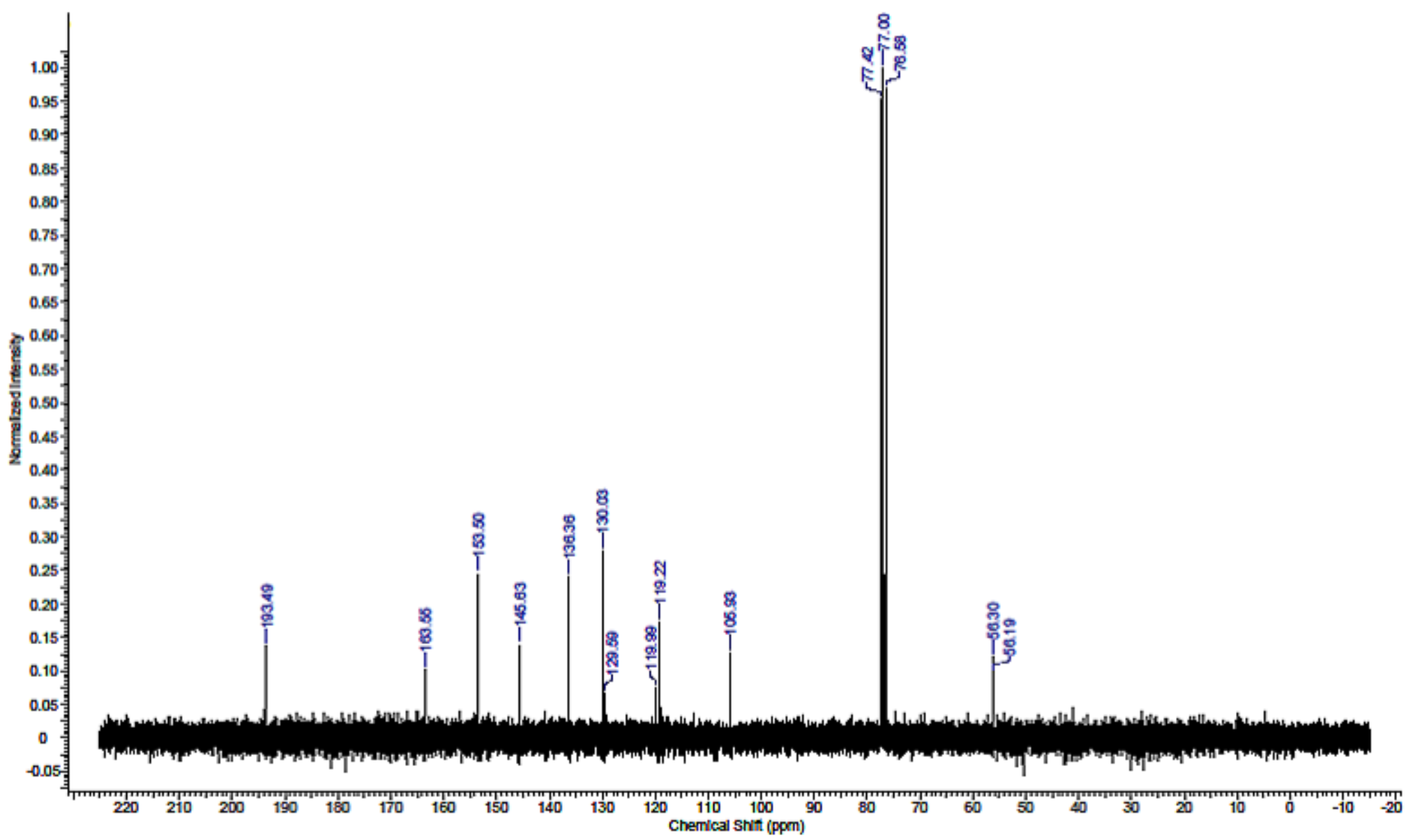

Espectro 17. Espectro de $\mathrm{RMN}{ }^{13} \mathrm{C}\left(75 \mathrm{MHz}, \mathrm{CDCl}_{3}\right)$ da estrutura 17. 


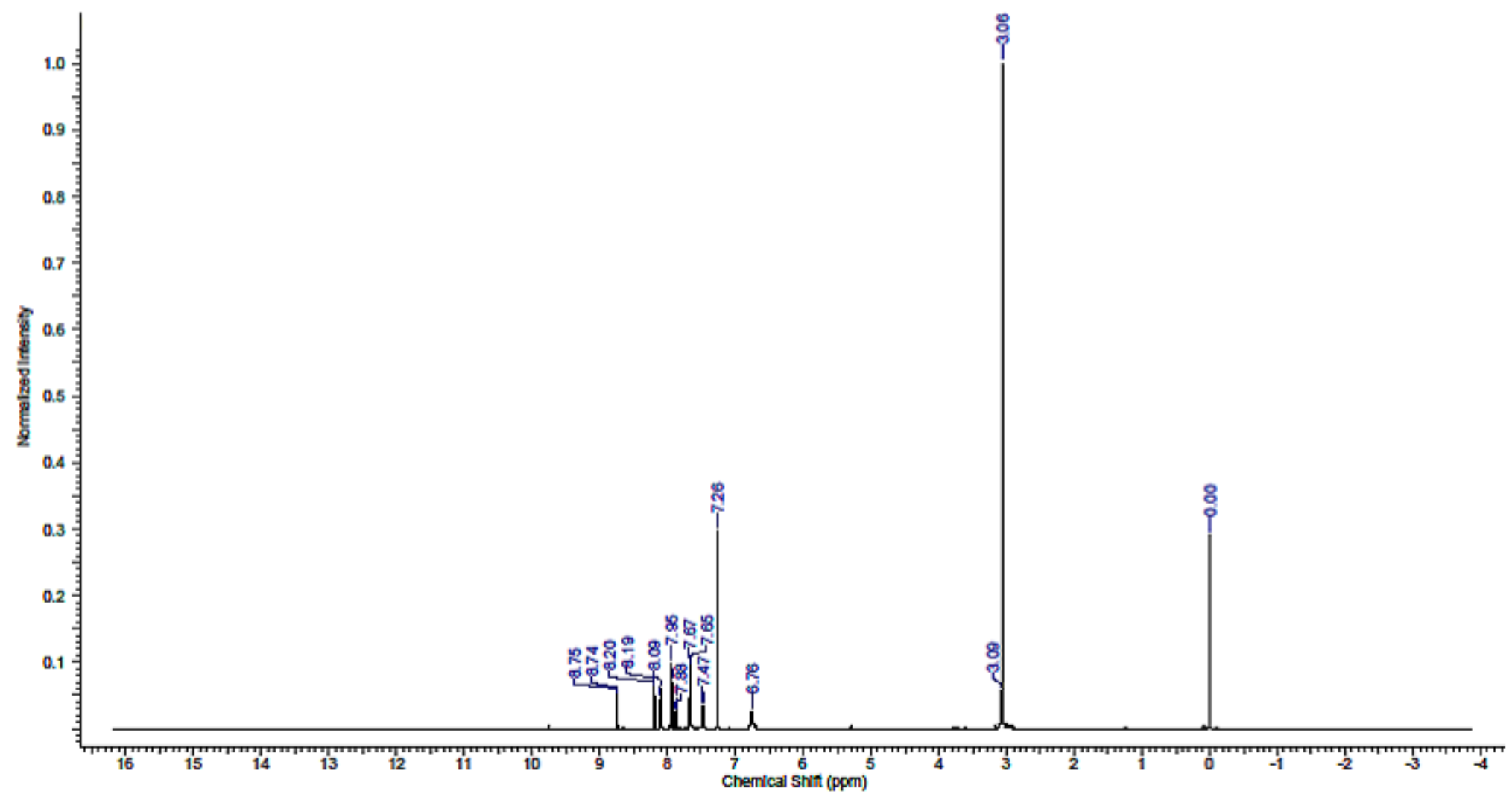

Espectro 18. Espectro de $\mathrm{RMN}^{1} \mathrm{H}\left(600 \mathrm{MHz}, \mathrm{CDCl}_{3}\right)$ da estrutura 18. 


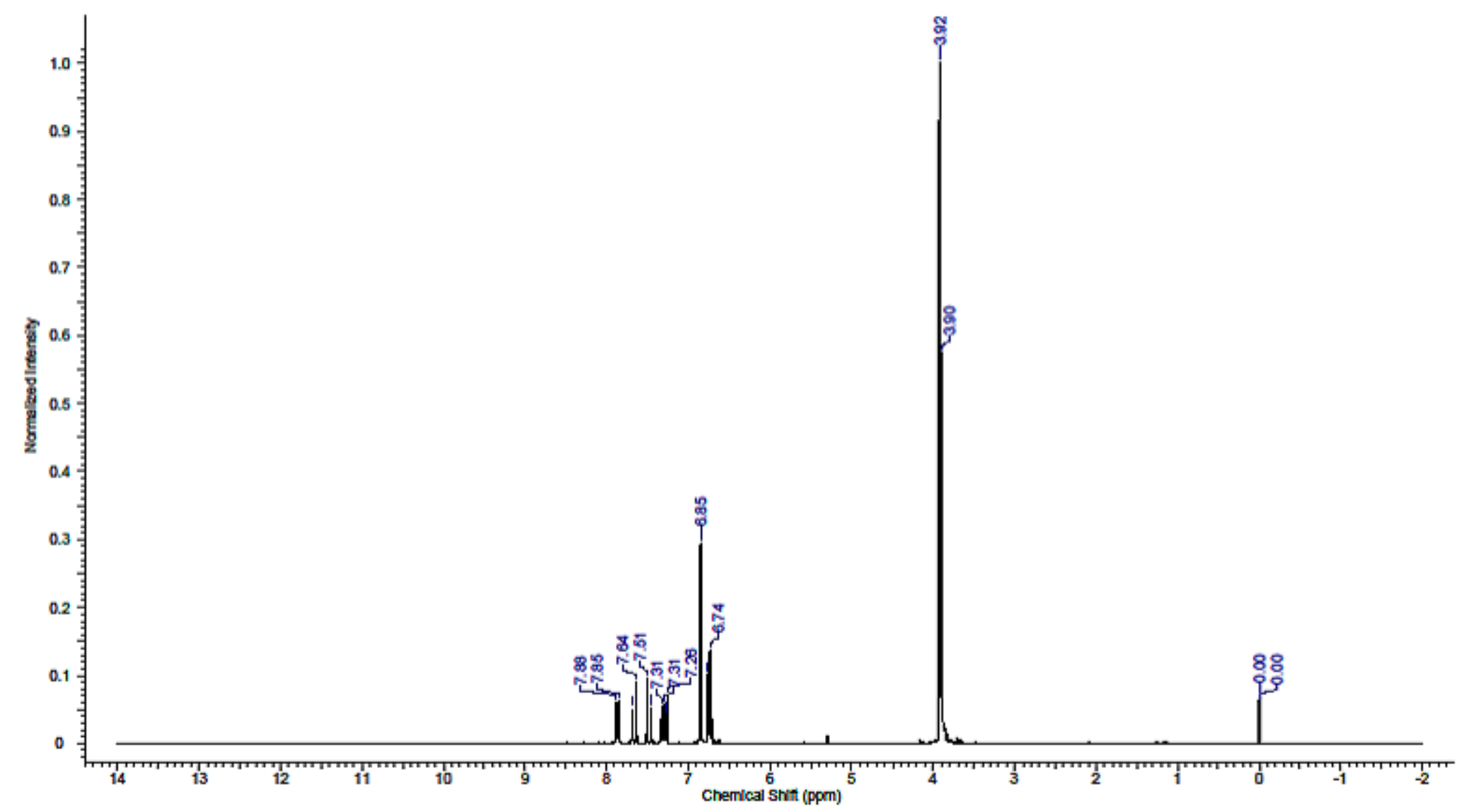

Espectro 19. Espectro de RMN ${ }^{1} \mathrm{H}\left(300 \mathrm{MHz}, \mathrm{CDCl}_{3}\right)$ da estrutura 19. 


\subsection{Absorção e Emissão}
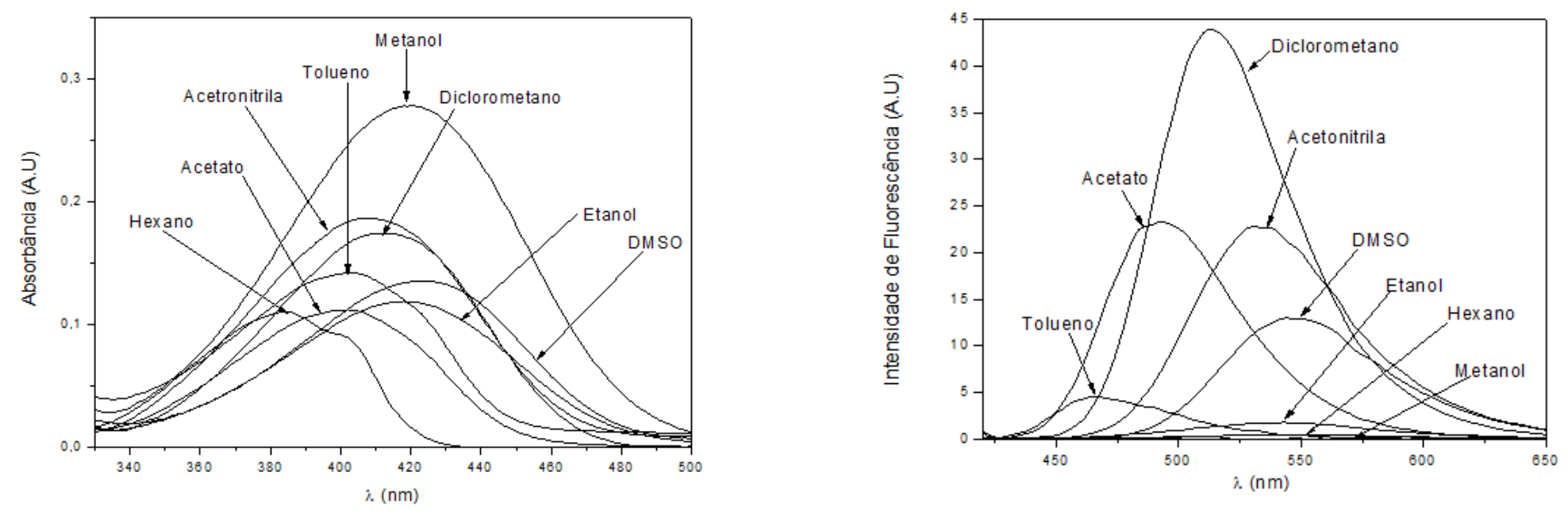

Espectro 20. Espectros de absorção (esquerda) e emissão (direita) da estrutura 9.
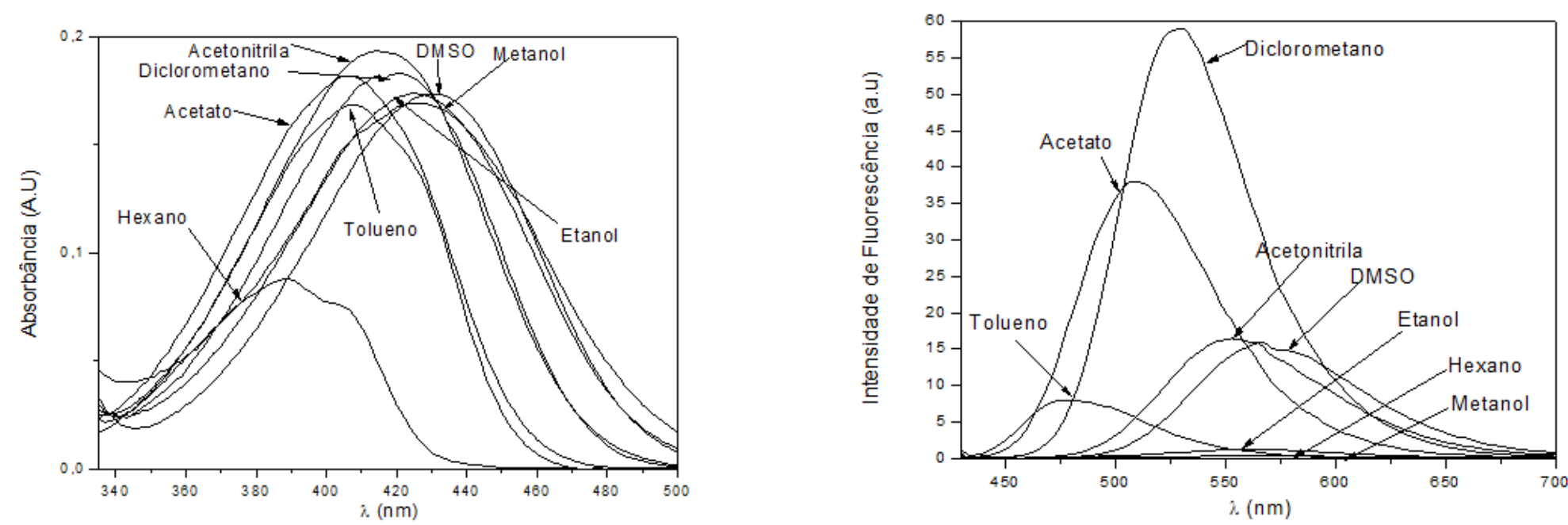
Espectro 21. Espectros de absorção (esquerda) e emissão (direita) da estrutura 10
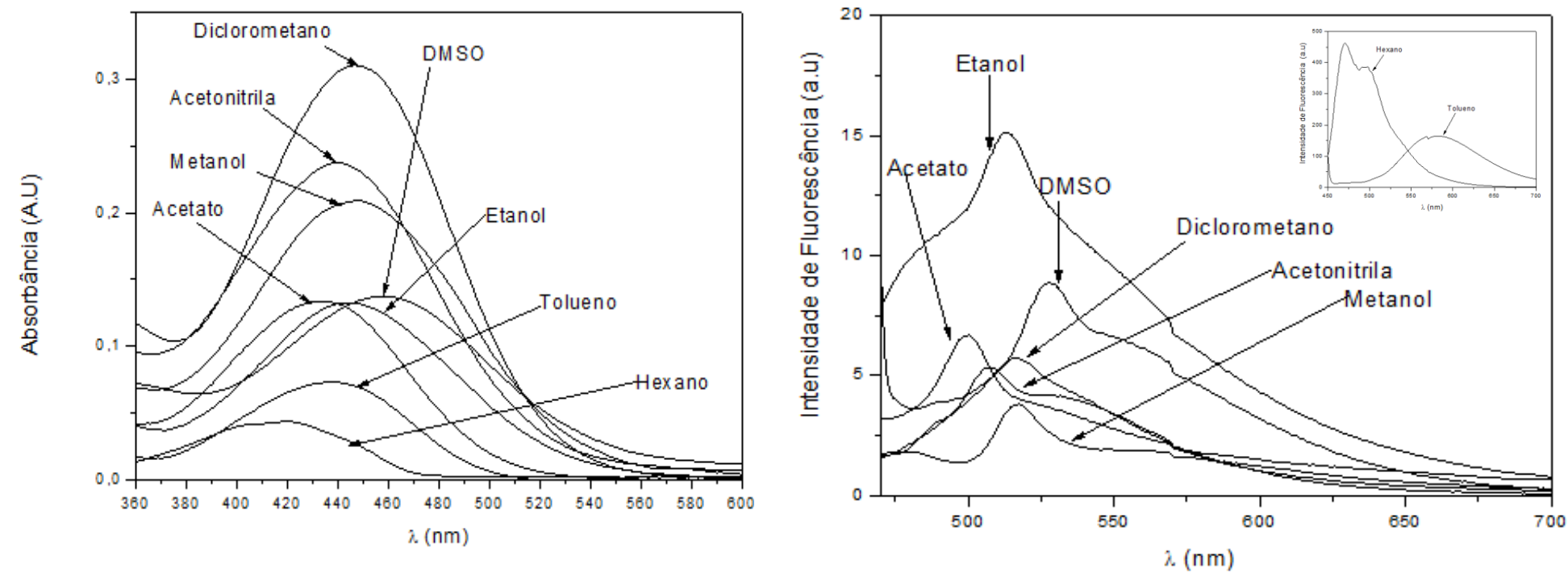

Espectro 22. Espectros de absorção (esquerda) e emissão, com input, (direita) da estrutura 11.
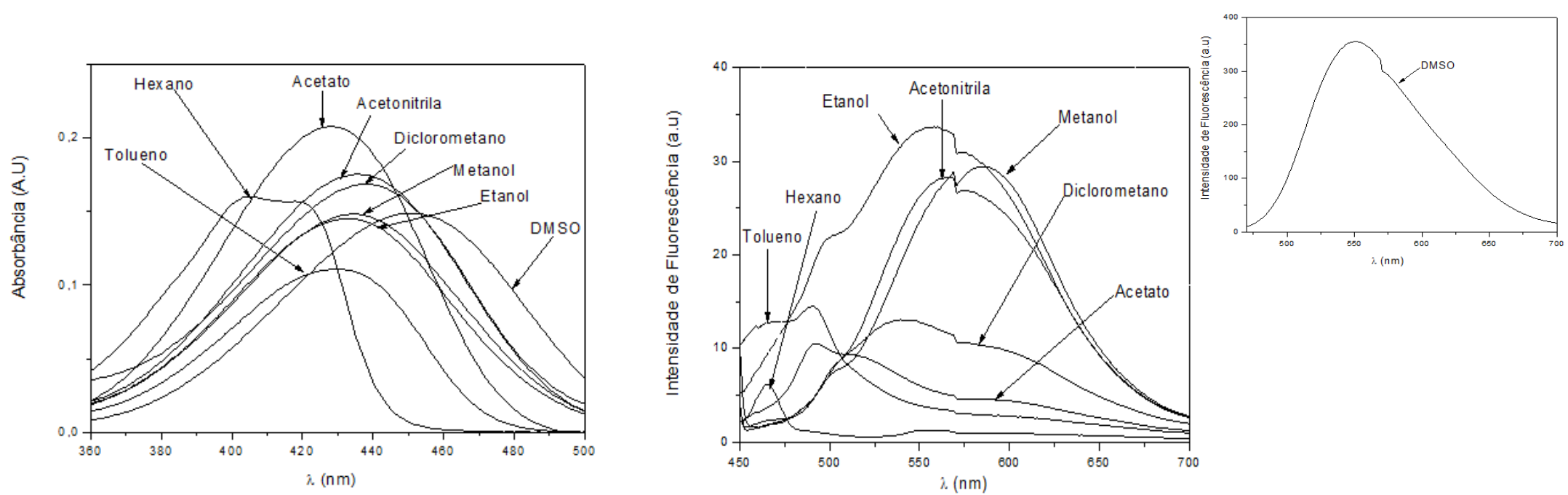
Espectro 23. Espectros de absorção (esquerda) e emissão, com input, (direita) da estrutura 12.
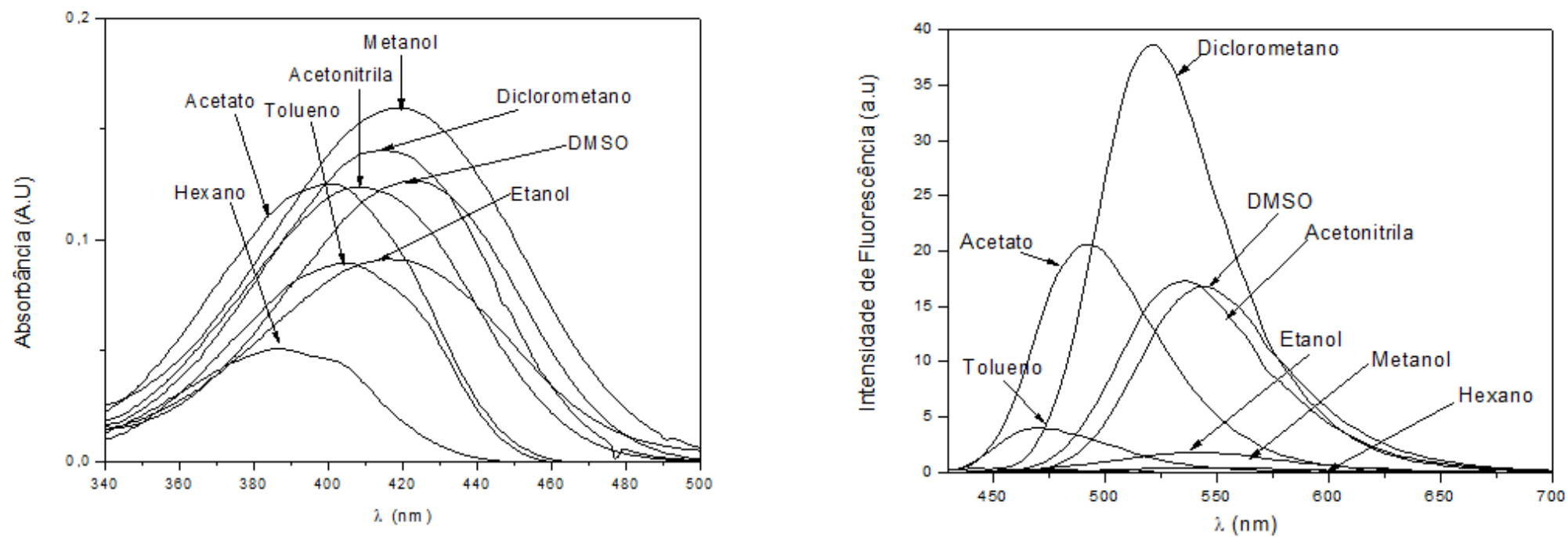

Espectro 24. Espectros de absorção (esquerda) e emissão (direita) da estrutura 13 

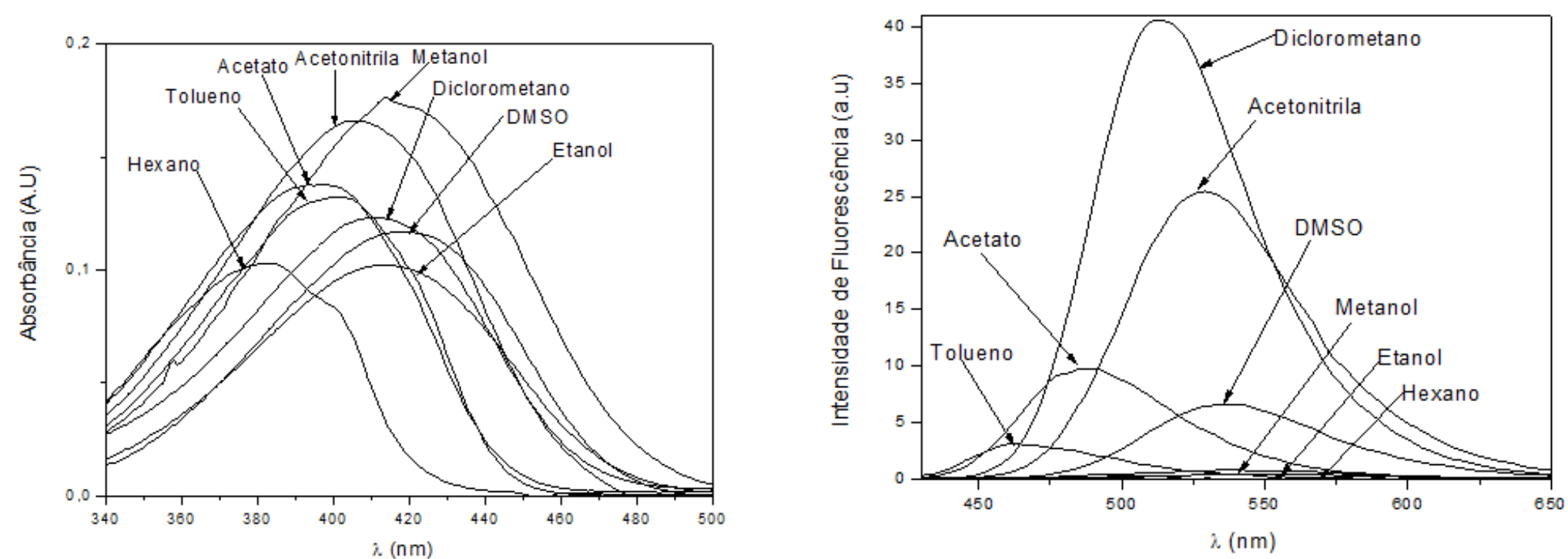

Espectro 25. Espectros de absorção (esquerda) e emissão (direita) da estrutura 14. 

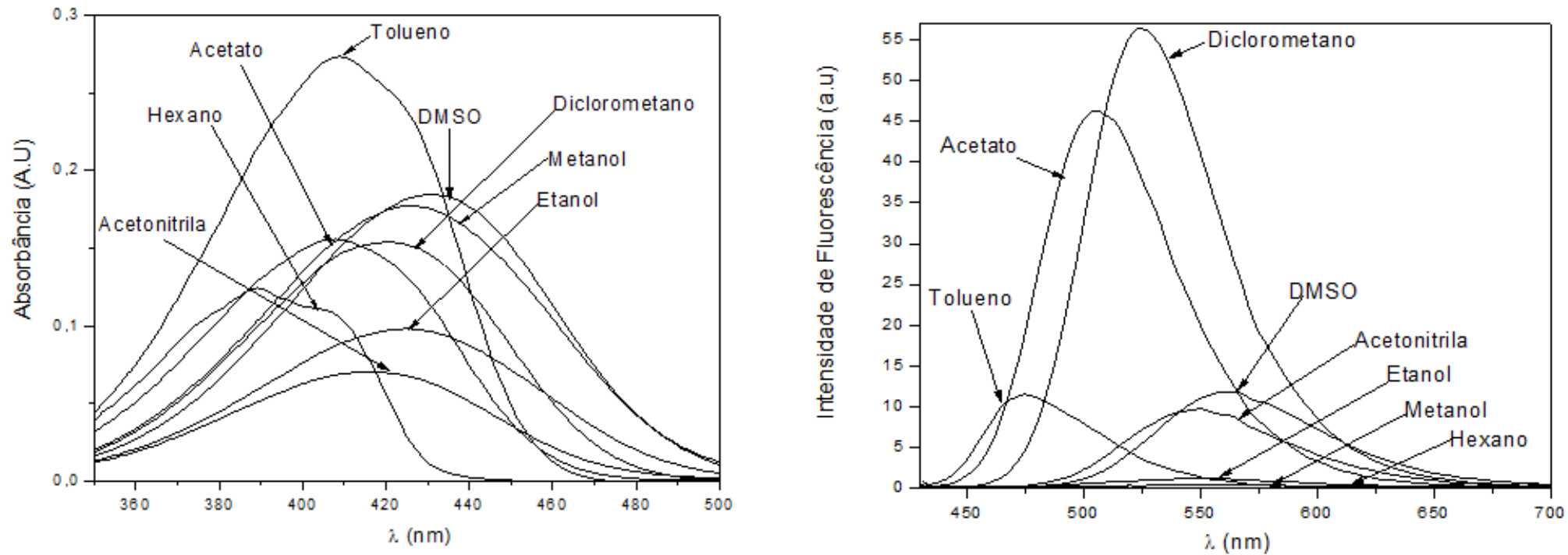

Espectro 26. Espectros de absorção (esquerda) e emissão (direita) da estrutura 15.
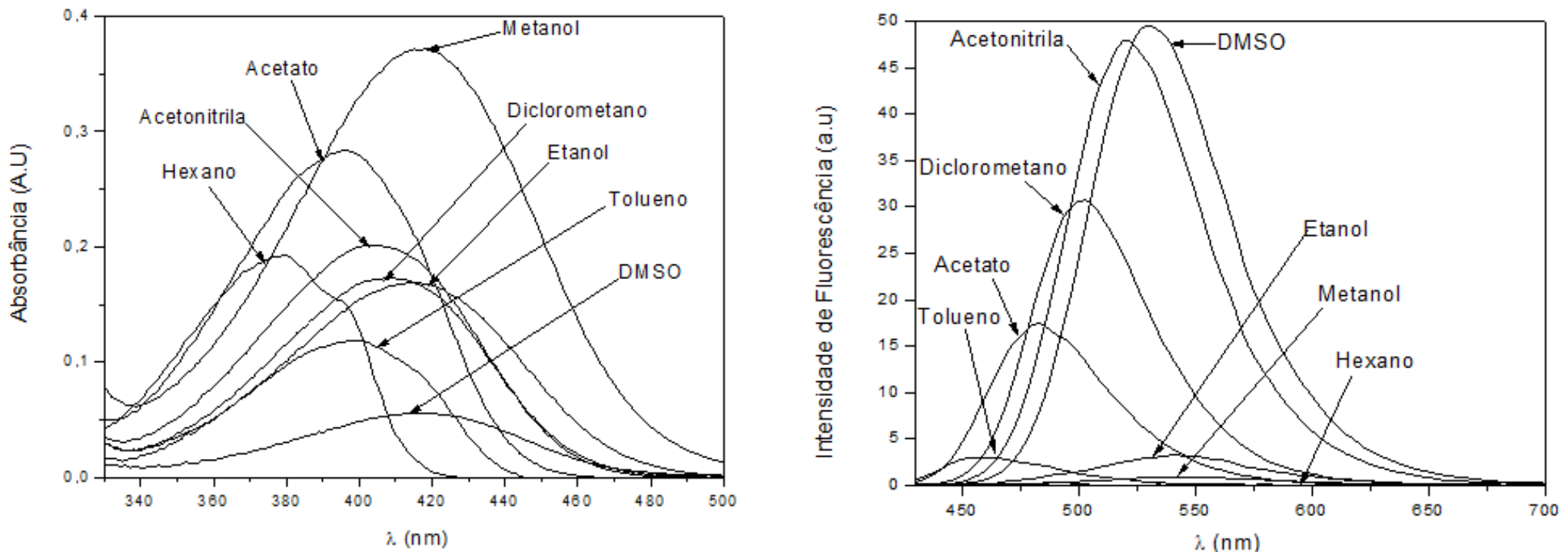
Espectro 27. Espectros de absorção (esquerda) e emissão (direita) da estrutura 16.
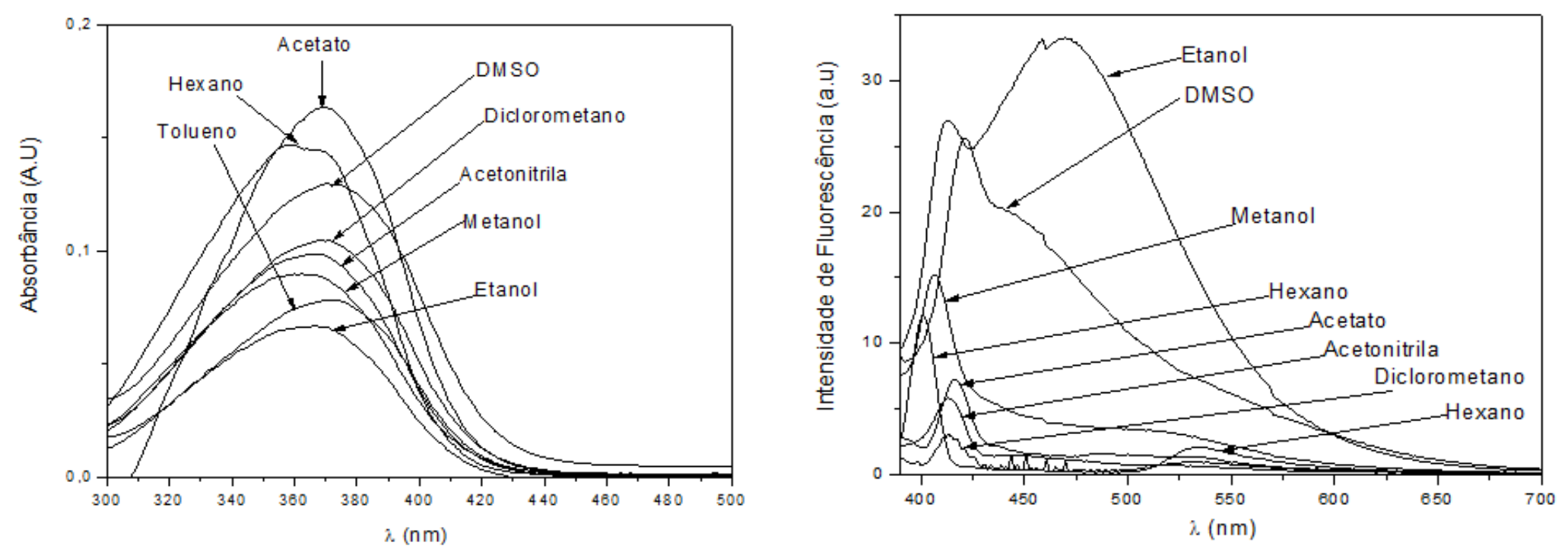

Espectro 28. Espectros de absorção (esquerda) e emissão, com input, (direita) da estrutura 17. 

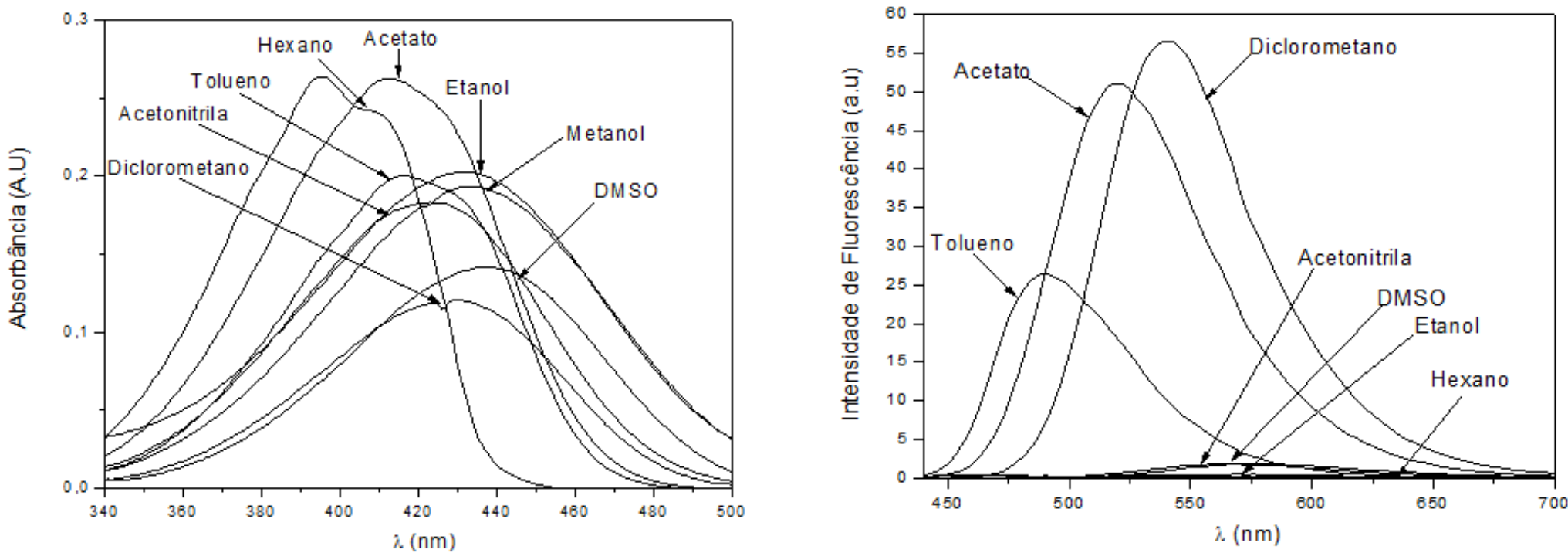

Espectro 29. Espectros de absorção (esquerda) e emissão (direita) da estrutura 18
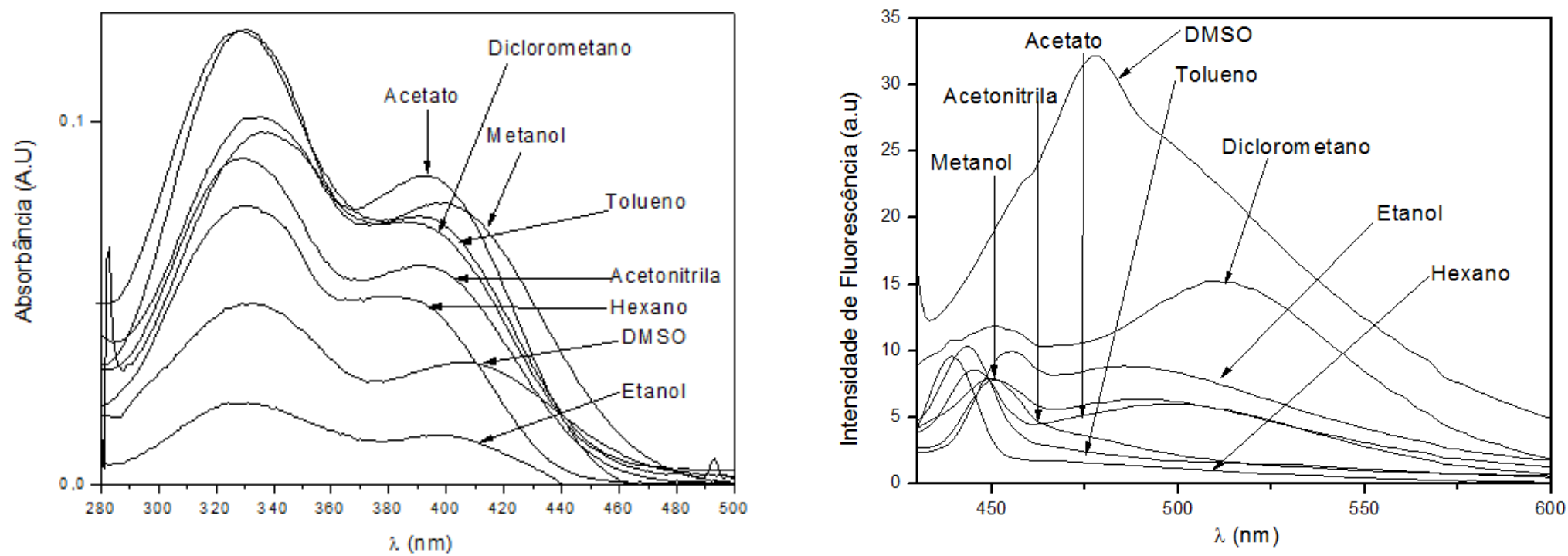

Espectro 30. Espectros de absorção (esquerda) e emissão (direita) da estrutura 19. 


\subsection{Lippert-Mataga}

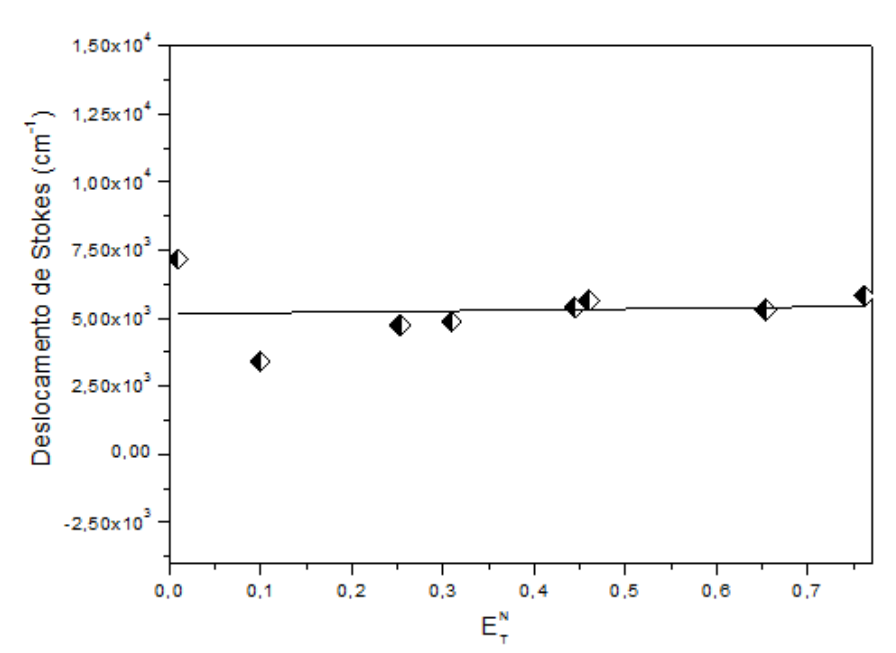

Gráfico 1. Lippert-Mataga do composto 9. 


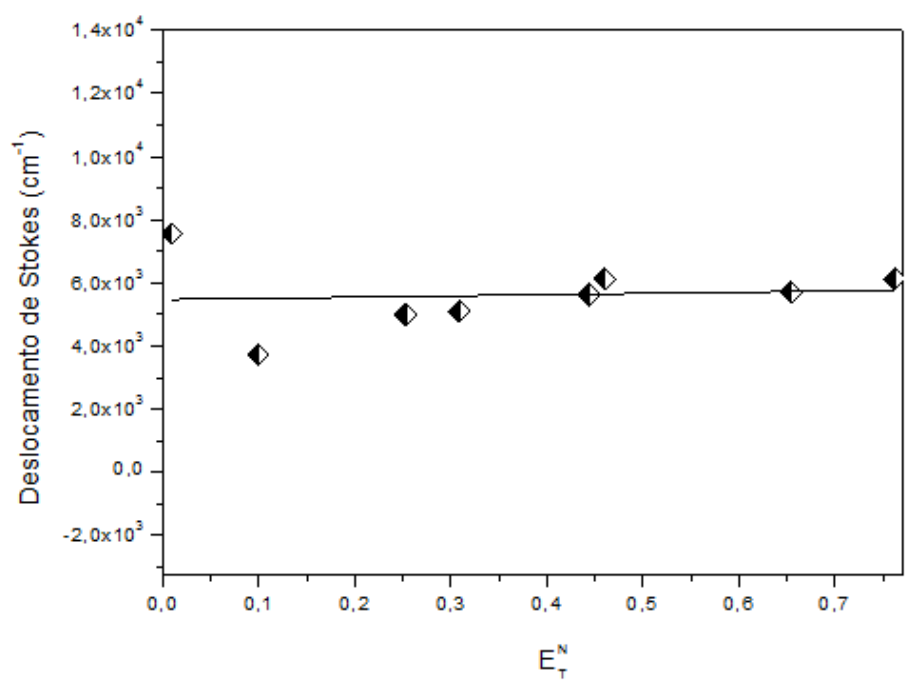

Gráfico 2. Lippert-Mataga do composto 10.

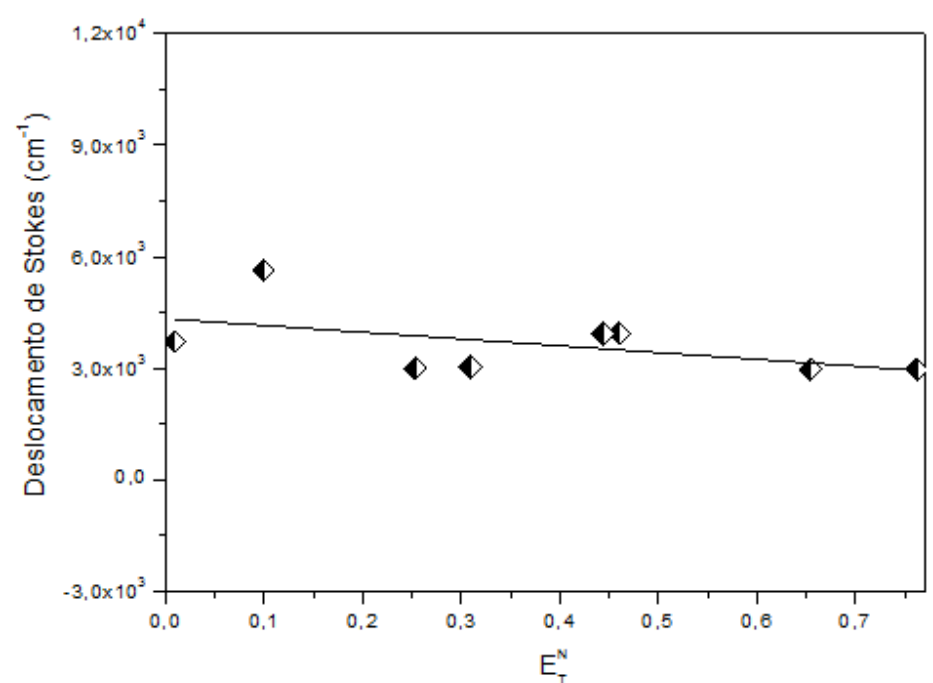




\section{Dissertação de Mestrado}

Gráfico 3. Lippert-Mataga do composto 11.

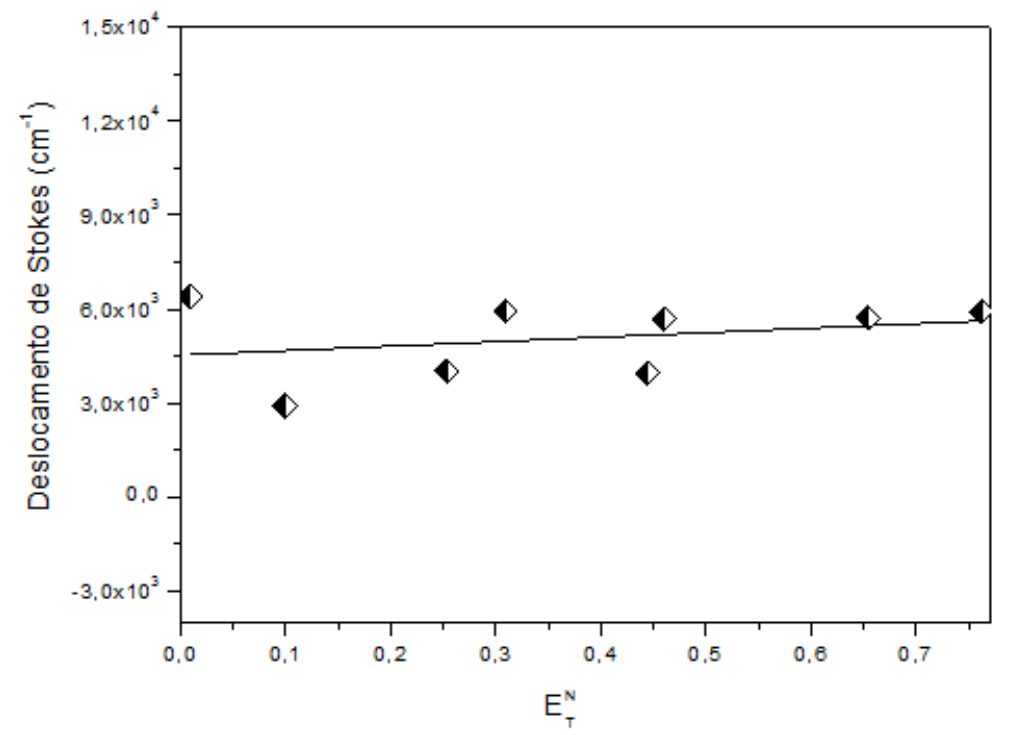

Gráfico 4. Lippert-Mataga do composto 12. 


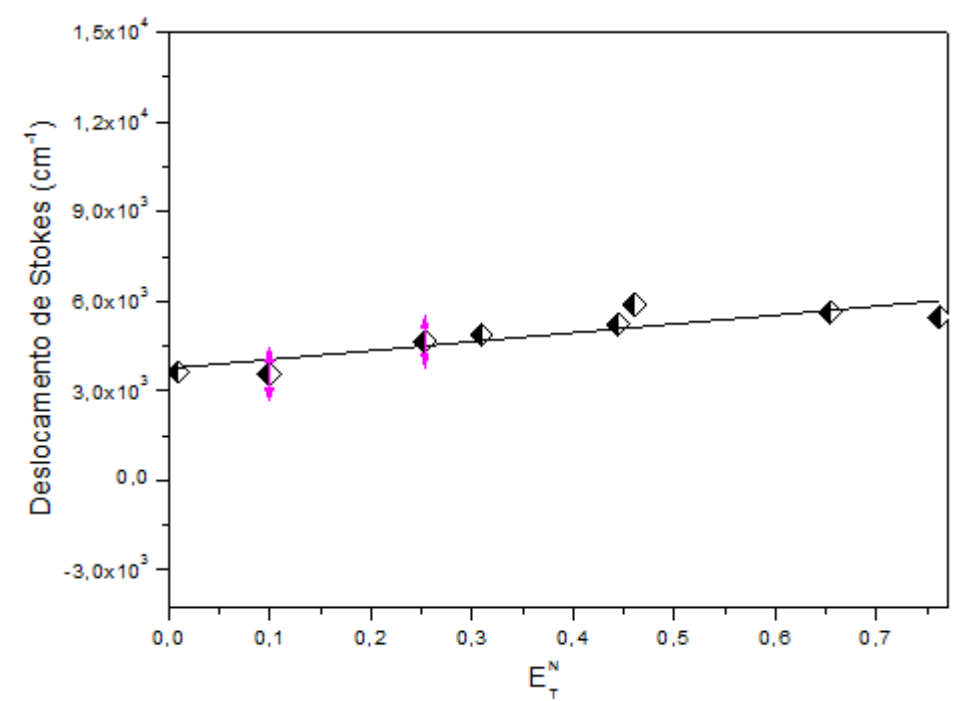

Gráfico 5. Lippert-Mataga do composto 13.

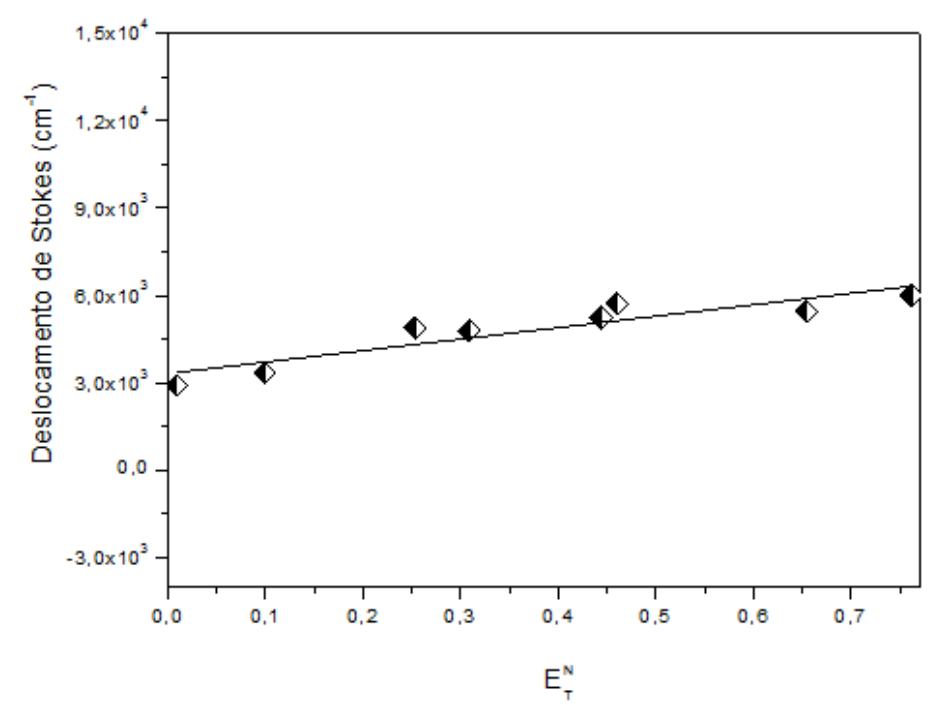


Gráfico 6. Lippert-Mataga do composto 14.

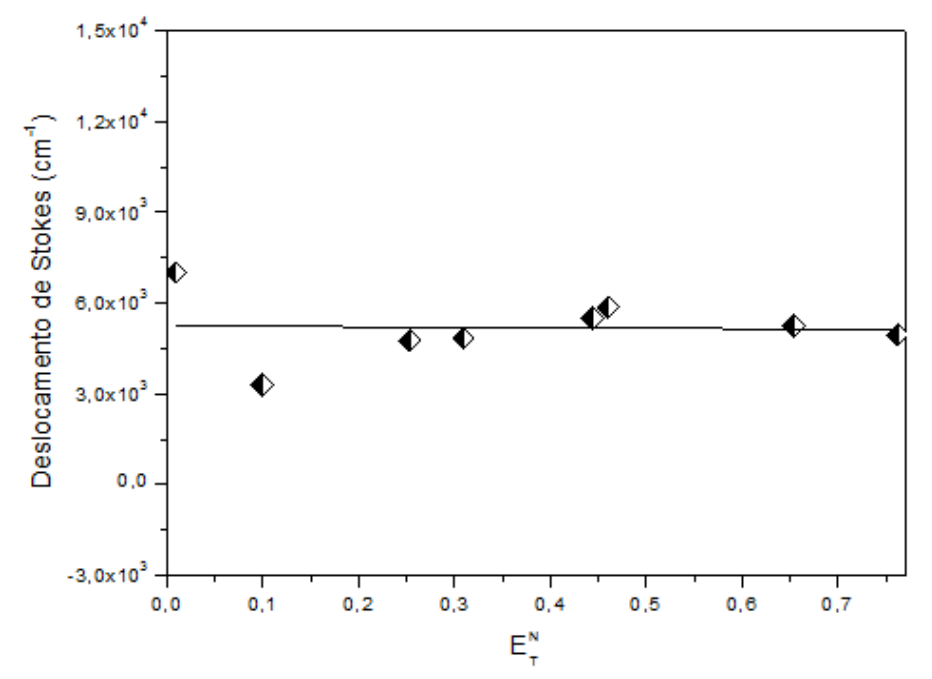

Gráfico 7. Lippert-Mataga do composto 15.

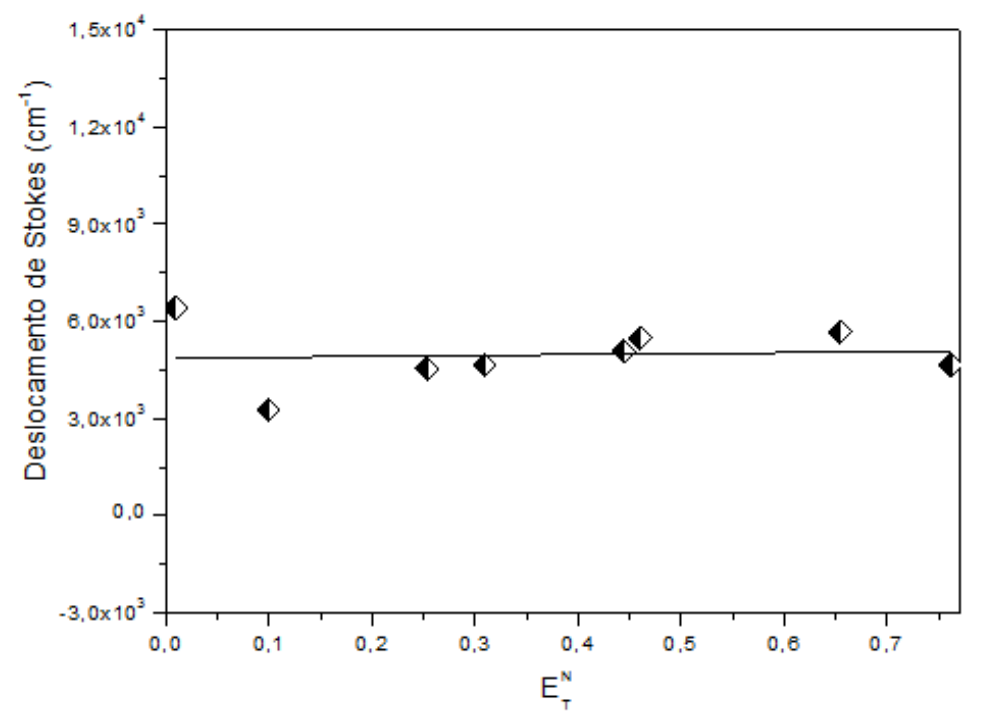


Gráfico 8. Lippert-Mataga do composto 16.

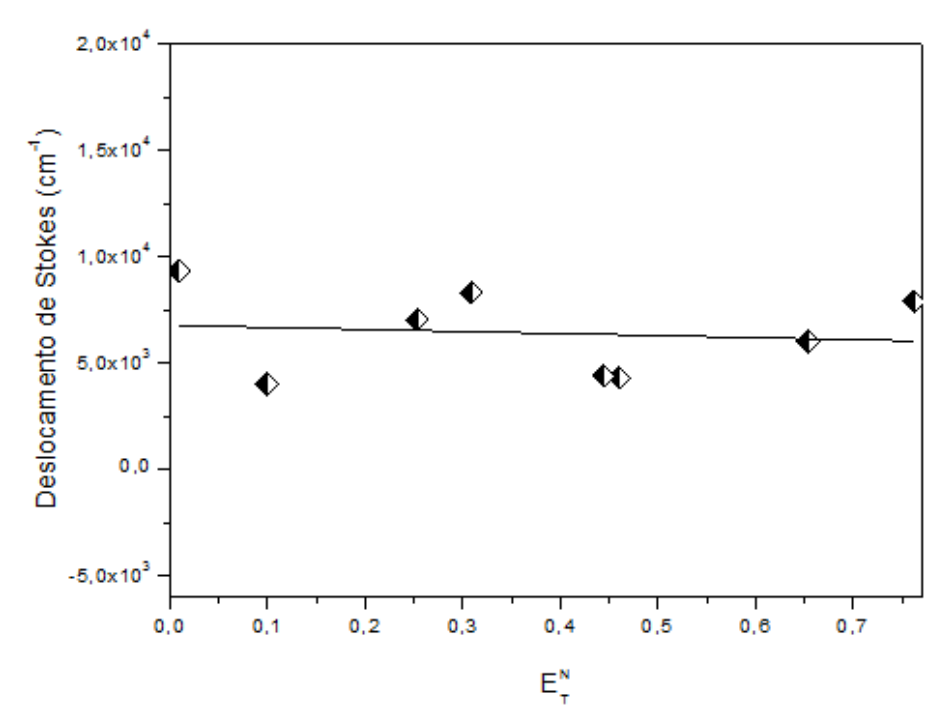

Gráfico 9. Lippert-Mataga do composto 17. 


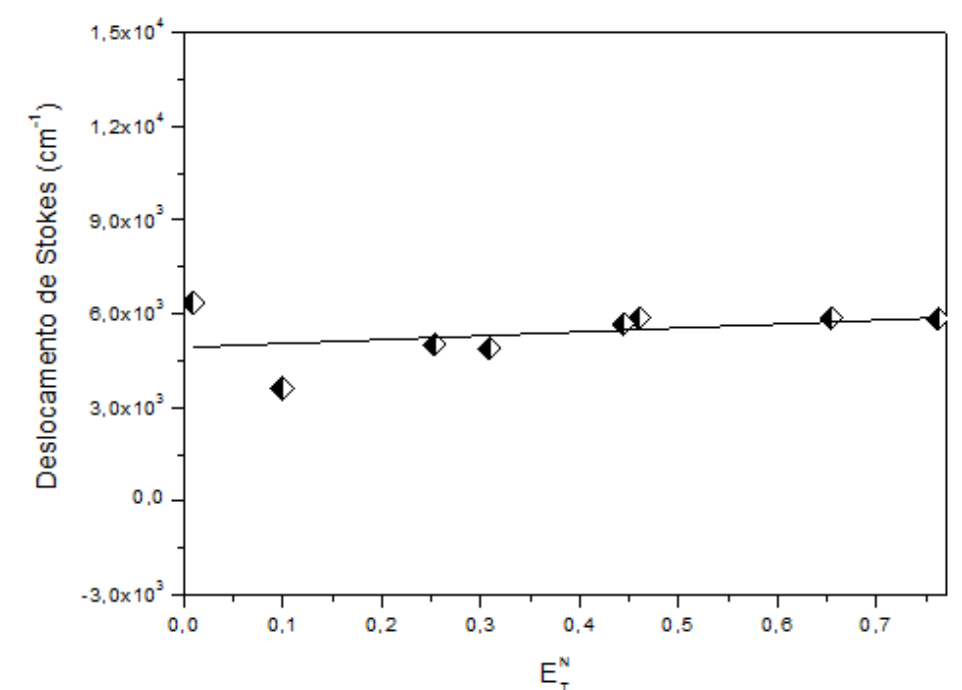

Gráfico 10. Lippert-Mataga do composto 18.

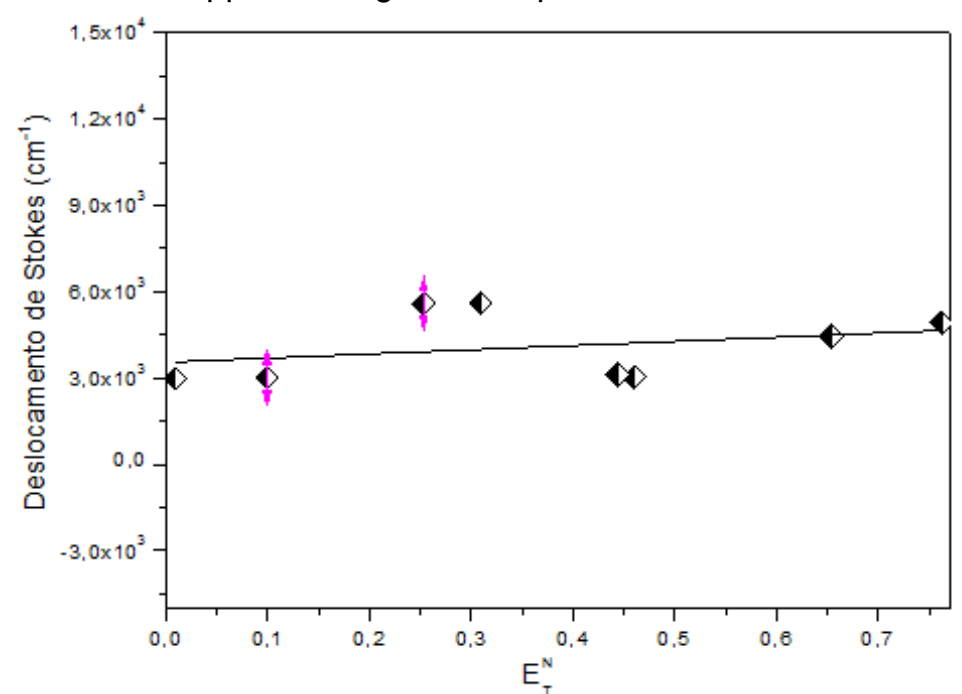

Gráfico 11. Lippert-Mataga do composto 19. 